\title{
Influencia de los estándares urbanísticos en los nuevos desarrollos residenciales ${ }^{1}$
}

\author{
Borja López RodríGuez \\ Madrid (España), 2006-2007.
}

Introducción

Estándares contenidos en la normativa urbanística

Metodología . . . . . . . . . . . . . . . . . . . . . . . . . . 111

Normativa urbanística española . . . . . . . . . . . . . . . . . . . . . . . . . . . . 114

Normativa urbanística de Aragón . . . . . . . . . . . . . . . . . . . . . . . . . . . . . 120

Normativa urbanística de Castilla-La Mancha . . . . . . . . . . . . . . . . . . . . . . . . . . 124

Normativa urbanística de Castilla y León . . . . . . . . . . . . . . . . . . . . . 125

Normativa urbanística de Cataluña . . . . . . . . . . . . . . . . . . . . . . . . . 132

Normativa urbanística de Navarra . . . . . . . . . . . . . . . . . . . . . . . . . 133

Normativa urbanística del País Vasco . . . . . . . . . . . . . . . . . . . . . 137

Normativa urbanística de la Comunidad Valenciana . . . . . . . . . . . . . . . . . . . . . . . 144

$\begin{array}{lr}\text { Estándares urbanísticos comparados } & 148\end{array}$

Densidad . . . . . . . . . . . . . . . . . . . . . . . . . . . . 148

Espacios libres públicos . . . . . . . . . . . . . . . . . . . . . . . . 151

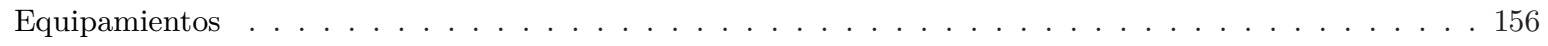

Dotaciones comparadas . . . . . . . . . . . . . . . . . . . . . . . . 160

Influencia de los estándares en los nuevos desarrollos urbanos 163

Modulación de los estándares dotacionales en función del número total de viviendas del sector . . . . . 167

Exceso de dotaciones en los sectores de baja densidad . . . . . . . . . . . . . . . . . . . 167

Exceso de ocupación de suelo en los modelos de alta densidad . . . . . . . . . . . . . . . . . . . 171

Límites de los estándares dotacionales . . . . . . . . . . . . . . . . . . . . . . . . . . 172

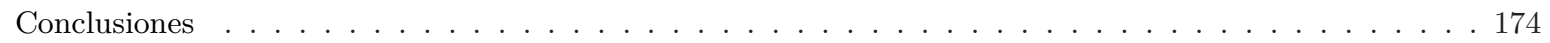

$\begin{array}{lr}\text { Fuentes y referencias bibliográficas } & 176\end{array}$

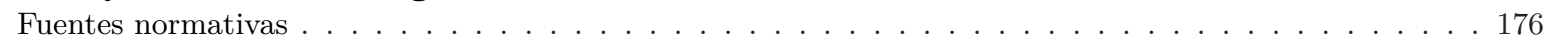

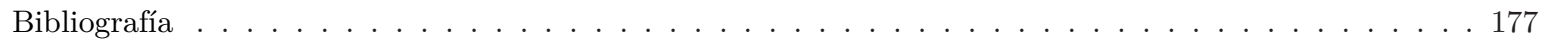

\section{Introducción}

La planificación del crecimiento de la ciudad es un principio asumido por el sistema jurídico-administrativo español, al menos desde que se aprobó la primera ley del suelo en 1956 (Ley de 12 de mayo de 1956 sobre Régimen del Suelo y Ordenación Urbana). Según este sistema, la función de ordenar la ciudad corresponde a los ayuntamientos, función que realizan a través de los planes urbanísticos, aunque deben ceñirse a unos límites fijados por normativas de ámbito estatal o autonómico. Estos límites son de dos tipos:

- Por un lado, las leyes establecen «determinaciones materiales de ordenación, que en todo caso se imponen a las de los planes» (García de Enterría y Parejo Alfonso, 1981:199). Así ocurre, por ejemplo, con la clasificación de un terreno como suelo urbano, que no depende de un plan, sino que es una determinación directamente aplicable siempre que dicho terreno cumpla ciertas condiciones establecidas en la Ley.

- Por otro lado, se fijan «criterios mínimos inderogables de ordenación, no directamente aplicables, sino dirigidos especialmente a reducir la discrecionalidad de la potestad de planeamiento» (GARCía De Enterría y Parejo Alfonso, 1981:199). Así ocurre en el caso de las dotaciones mínimas de zonas verdes, obligatorias por ley, pero que necesitan plasmarse a través de un plan. A este tipo de límites se refieren García de Enterría y Parejo Alfonso (1981:199) como «estándares urbanísticos».

\footnotetext{
${ }^{1}$ El presente trabajo es resultado de un Trabajo de Investigación Tutelada dirigido por Agustín Hernández AJA y José Manuel Naredo dentro del programa de doctorado Periferias, Sostenibilidad y Vitalidad Urbana impartido por el Departamento de Urbanística y Ordenación del Territorio de la Universidad Politécnica de Madrid durante el curso 2006-2007.
} 
Campos Venuti (1971:112) ha interpretado los estándares urbanísticos como «parámetros cuantitativos o dimensiones óptimas, variables en el tiempo y en el espacio, sobre las funciones o exigencias a satisfacer por el hombre cuando construye las ciudades y, en general, modifica o conserva el espacio natural». Esta interpretación está relacionada tanto con la mejora de la calidad de vida como con la preservación del medio ambiente, siendo ambos objetivos principales de la planificación urbana. Así, los estándares urbanísticos establecen cuantificaciones que se consideran óptimas o mínimas para alcanzar estos objetivos.

Los estándares urbanísticos han evolucionado considerablemente desde la Ley de 1956, que únicamente establecía un estándar consistente en destinar el $10 \%$ de la superficie a parques y jardines públicos; hasta la ley y el reglamento de finales de la década de los setenta (Real Decreto 1346/1976, de 9 de abril, por el que se aprueba el Texto Refundido de la Ley sobre Régimen del Suelo y Ordenación Urbana y Real Decreto 2159/1978, de 23 de junio, por el que se aprueba el Reglamento de Planeamiento para el Desarrollo y Aplicación de la Ley sobre Régimen del Suelo y Ordenación Urbana (RP-78)), que ampliaron la variedad de estándares. Esta evolución se debe, según García de Enterría Y PARejo Alfonso (1981:201), a una pérdida de confianza en la planificación elaborada por los ayuntamientos, los cuales no siempre defienden el interés público ni tienen capacidad suficiente para gestionar los planes. De ahí que aumenten las obligaciones legales impuestas por las administraciones superiores, tanto por el Estado, cuando el urbanismo se consideraba una competencia estatal; como por las comunidades autónomas, una vez que se ha descentralizado la competencia sobre urbanismo. El objetivo declarado en estas normativas es orientar la planificación urbanística municipal, condicionando el modelo urbano que puede proponer el planeamiento general o de desarrollo; estableciendo unos límites cuantificables y, por tanto, objetivos.

Actualmente, debido a la dispersión legislativa originada por la cesión competencial a las comunidades autónomas, encontramos variadas formas de estándares. Podemos encontrar un amplio abanico de conceptos, tales como:

- Densidad o intensidad de edificación: La densidad suele hacer referencia a parámetros como viviendas por hectárea o habitantes/hectárea. La intensidad de edificación suele referirse a metros cuadrados edificables/unidad de superficie. En la mayoría de los casos supone la fijación de límites máximos que no pueden superarse.

- Espacios libres públicos: Fundamentalmente el concepto de zonas verdes, que sigue manteniendo una presencia en la mayoría de las legislaciones. Suelen referirse tanto al planeamiento general como al de desarrollo.

- Equipamientos: Sobre todo de cara al planeamiento de desarrollo, establece reservas mínimas para equipamientos públicos en los crecimientos urbanos.

- Aparcamientos: El número de plazas de aparcamiento es otro de los aspectos recogidos habitualmente.

- Viviendas protegidas: Se ha generalizado la imposición de porcentajes mínimos de este tipo de viviendas sobre el total de viviendas previstas por los planes.

Sin embargo, como hemos dicho, los estándares fijados por la legislación urbanística no se aplican directamente a la realidad, sino que se materializan a través de los planes de ordenación. Por ejemplo, la legislación urbanística suele establecer un estándar mínimo de zonas verdes para los nuevos desarrollos, pero es el plan de ordenación del ámbito (habitualmente un plan parcial) el que buscará el mejor emplazamiento para los parques, e incluso, aumentará su superficie por encima del mínimo obligatorio si lo considera conveniente. Se trata, por tanto, de parámetros que cuantifican las necesidades humanas de forma general y un tanto abstracta. Este carácter general y abstracto de los estándares legales ocasiona problemas al aplicarse a ciertos modelos de crecimiento que se apartan de los parámetros habituales. Así ocurre en los sectores de muy baja densidad, en los que suele darse un exceso de dotaciones; o en sectores con elevada edificabilidad, donde el cumplimiento de los estándares obliga a destinar superficies importantes para dotaciones, como veremos en este trabajo.

El estudio de la aplicación de los estándares a diversos modelos de desarrollo urbano permitirá conocer su adecuación a la realidad, de tal forma que puedan evitarse determinadas formulaciones de estándares que no son aplicables a todos los casos; o bien para evitar ciertos modelos de desarrollo que no permiten una materialización razonable de los estándares. Por eso, el presente trabajo se centra en estudiar qué resultados produce la aplicación de los estándares urbanísticos a diferentes modelos de desarrollo urbano, con el objetivo de demostrar que los estándares urbanísticos propuestos por las normativas autonómicas no siempre mejoran la calidad de vida y pueden perjudicar el diseño racional de algunos modelos de desarrollo concretos. 
El trabajo se estructura en tres capítulos más aparte de esta Introducción. El primero de ellos (capítulo 2) se dedica recoger los estándares urbanísticos que se aplican a sectores residenciales, que están contenidos en las normativas elegidas como muestra. El siguiente capítulo (capítulo 3) se centra en una comparación de las diversas regulaciones que las normativas tratadas establecen sobre el tema de los estándares de densidad y de dotaciones. En el último capítulo (capítulo 4) se analiza la aplicación de los estándares dotacionales a sectores residenciales con distintas edificabilidades brutas y se establecen las conclusiones finales del trabajo.

\section{Estándares contenidos en la normativa urbanística}

En este capítulo se recogen y estudian los estándares que aparecen en la normativa urbanística de una serie de comunidades autónomas españolas. En general, la normativa de estas comunidades se articula a través de una ley, que contiene los conceptos y normas generales, y un reglamento, que concreta las determinaciones de dicha ley. Se establece una relación jerárquica entre ellos, de tal forma que el reglamento sólo puede desarrollar los conceptos contenidos de la ley, sin contradecirlos.

Los estándares urbanísticos se encuentran tanto en las leyes como en los reglamentos; pero es en los reglamentos donde son más numerosos y establecen disposiciones más precisas. Por este motivo, hemos escogido para este trabajo aquellas comunidades que han desarrollado reglamentariamente sus leyes, ya sea total o parcialmente, puesto que, en principio, tendrán un cuadro de estándares urbanísticos más completo que las autonomías que no han elaborado un reglamento. Al menos, así debería ser aplicando la lógica normativa, aunque como veremos en el caso de la Comunidad Autónoma de Cataluña, el reglamento no añade nuevos estándares a los definidos en su ley urbanística.

Todas las autonomías estudiadas cuentan con un reglamento que desarrolla su respectiva ley de urbanismo, salvo el País Vasco. Ésta se ha incluido porque ha aprobado recientemente una ley urbanística, en la que se recogen algunos aspectos novedosos relativos a los estándares que merece la pena incluir en este estudio.

Además de la normativa autonómica, estudiaremos la normativa española elaborada a finales de los años 70, y más concretamente, el Reglamento de Planeamiento de 1978, el cual estableció por primera vez un sistema de estándares dotacionales para los planes municipales de desarrollo. Es un texto normativo en el cual se han inspirado posteriores reglamentos autonómicos, y además sigue siendo de aplicación en algunas comunidades autónomas que aún no han desarrollado sus reglamentos o que ni siquiera tiene una ley urbanística propia. Por ello, el Reglamento de Planeamiento Urbanístico de 1978 (RP-78) es una referencia importante para nuestro trabajo.

La normativa urbanística de las siete comunidades autónomas referidas, más la legislación urbanística española de finales de los 70, son las fuentes de las que vamos a recopilar los estándar urbanísticos para su posterior análisis. En el cuadro 1 se recogen los textos normativos concretos que se usarán como base del trabajo.

\section{Metodología}

\section{Estándares recogidos}

Consideramos estándares urbanísticos a las determinaciones numéricas o cuantificables que la normativa impone al planeamiento, que es el documento en el que debe verificarse el cumplimiento de dichos estándares. El planeamiento afectado por los estándares puede ser de carácter general, cuando ordena todo el municipio, o de carácter parcial, cuando ordena un ámbito concreto. Las normativas estudiadas suelen denominar sectores de suelo urbanizable a los terrenos cuyo desarrollo próximo está previsto por el planeamiento general. Además, algunas normas suelen distinguir tres usos globales que caracterizan a estos ámbitos de desarrollo: residencial, industrial o terciario. Cuando esto ocurre, las exigencias para las zonas residenciales son mayores, ya que necesitan disponer de espacios y servicios públicos que garanticen un mínimo de calidad de vida. Sin embargo, en los espacios industriales, terciarios o de servicios, los estándares impuestos se limitan a garantizar una mínima funcionalidad (como la cantidad de aparcamiento), o a establecer algunas obligaciones ambientales (como la plantación de arbolado perimetral).

Por eso, cuando se establezca una distinción de estándares en función del uso global del sector, recogeremos sólo aquellos fijados para el uso global residencial, puesto que son los que nos interesan en este estudio para evaluar la calidad de vida y el diseño de los tejidos habitables de la ciudad. En los siguientes apartados de este capítulo se presentan los estándares recogidos de la normativa española y de cada comunidad autónoma (apartados 2.2 a 2.9 ). 
Cuadro 1: Normativa base para el trabajo

\begin{tabular}{|c|c|c|}
\hline & Ley & Reglamento \\
\hline España & $\begin{array}{l}\text { Real Decreto } 1346 / 1976 \text {, de } 9 \text { de abril, por } \\
\text { el que se aprueba el Texto Refundido de la } \\
\text { Ley sobre Régimen del Suelo y Ordenación } \\
\text { Urbana }\end{array}$ & $\begin{array}{l}\text { Real Decreto } 2159 / 1978 \text {, de } 23 \text { de junio, } \\
\text { por el que se aprueba el Reglamento de } \\
\text { Planeamiento para el Desarrollo y Aplica- } \\
\text { ción de la Ley sobre Régimen del Suelo y } \\
\text { Ordenación Urbana }\end{array}$ \\
\hline Aragón & Ley 5/1999, de 25 de marzo, Urbanística & $\begin{array}{l}\text { Decreto } 52 / 2002 \text {, de } 19 \text { de febrero, por el } \\
\text { que se aprueba el Reglamento de Desarro- } \\
\text { llo Parcial de la Ley } 5 / 1999 \text {, de } 25 \text { de mar- } \\
\text { zo, Urbanística, en materia de Organiza- } \\
\text { ción, Planeamiento Urbanístico y Régimen } \\
\text { Especial de Pequeños Municipios }\end{array}$ \\
\hline $\begin{array}{l}\text { Castilla-La } \\
\text { Mancha }\end{array}$ & $\begin{array}{l}\text { Decreto Legislativo } 1 / 2004 \text {, de } 28 \text { de di- } \\
\text { ciembre, por el que se aprueba el Texto } \\
\text { Refundido de la Ley de Ordenación del Te- } \\
\text { rritorio y de la Actividad Urbanística }\end{array}$ & $\begin{array}{l}\text { Decreto } 248 / 2004 \text {, de } 14 \text { de septiembre, por } \\
\text { el que se aprueba el Reglamento de Planea- } \\
\text { miento de la Ley } 2 / 1998 \text {, de } 4 \text { de junio, de } \\
\text { Ordenación del Territorio y de la Actividad } \\
\text { Urbanística }\end{array}$ \\
\hline $\begin{array}{ll}\text { Castilla } & \text { y } \\
\text { León } & \end{array}$ & $\begin{array}{l}\text { Ley } 5 / 1999 \text {, de } 8 \text { de abril, de Urbanismo } \\
\text { de Castilla y León }\end{array}$ & $\begin{array}{l}\text { Decreto } 22 / 2004 \text {, de } 29 \text { de enero, por el que } \\
\text { se aprueba el Reglamento de Urbanismo de } \\
\text { Castilla y León }\end{array}$ \\
\hline Cataluña & $\begin{array}{l}\text { Decreto Legislativo } 1 / 2005 \text {, de } 26 \text { de julio, } \\
\text { por el que se aprueba el Texto Refundido } \\
\text { de la Ley de Urbanismo }\end{array}$ & $\begin{array}{l}\text { Decreto } 305 / 2006 \text {, de } 18 \text { de julio, por el } \\
\text { que se aprueba el Reglamento de la Ley de } \\
\text { Urbanismo }\end{array}$ \\
\hline Navarra & $\begin{array}{l}\text { Ley foral } 10 / 1994 \text {, de } 4 \text { de julio, de Orde- } \\
\text { nación del Territorio y Urbanismo } \\
\text { Decreto Legislativo } 1 / 2005 \text {, de } 26 \text { de julio, } \\
\text { por el que se aprueba el Texto Refundido } \\
\text { de la Ley de Urbanismo }\end{array}$ & $\begin{array}{l}\text { Decreto foral } 85 / 1995, \text { de } 3 \text { de abril, por el } \\
\text { que se aprueba el Reglamento de Desarro- } \\
\text { llo de la Ley Foral 10/1994, de } 4 \text { de julio, } \\
\text { de Ordenación del Territorio y Urbanismo }\end{array}$ \\
\hline País Vasco & $\begin{array}{l}\text { Ley } 2 / 2006, \text { de } 30 \text { de junio, de Suelo y Ur- } \\
\text { banismo }\end{array}$ & \\
\hline $\begin{array}{l}\text { Comunidad } \\
\text { Valenciana }\end{array}$ & $\begin{array}{l}\text { Ley } 4 / 2004 \text {, de } 30 \text { de junio, de Ordenación } \\
\text { del Territorio y Protección del Paisaje } \\
\text { Ley } 10 / 2004 \text {, de } 9 \text { de diciembre, del Suelo } \\
\text { No Urbanizable } \\
\text { Ley } 16 / 2005 \text {, de } 30 \text { de diciembre, Urbanís- } \\
\text { tica Valenciana }\end{array}$ & $\begin{array}{l}\text { Decreto } 67 / 2006 \text {, de } 19 \text { de mayo, por el que } \\
\text { se aprueba el Reglamento de Ordenación y } \\
\text { Gestión Territorial y Urbanística }\end{array}$ \\
\hline
\end{tabular}




\section{Tratamiento y análisis de los datos}

Nos interesa analizar la influencia de los estándares sobre la calidad de vida y sobre el diseño de los nuevos barrios residenciales. Por ello, mostraremos cómo estos estándares afectan a sectores representativos de diversos modelos urbanos. No obstante, existen diferentes tipos de estándares que se aplican a los sectores, pero no todos son relevantes para nuestro estudio: nos centraremos en los estándares de densidad y en los estándares dotacionales de espacios libres y equipamientos.

El indice de edificabilidad es útil para representar los distintos modelos urbanos, por dos motivos:

- En primer lugar, porque el índice de edificabilidad (también denominado intensidad en algunas normas) es un estándar impuesto por las normativas, generalmente como un máximo que no se puede superar, aunque también aparece en algunas como un mínimo. A veces, las normativas utilizan la densidad de viviendas por hectárea en vez del índice de edificabilidad, lo que obligará a realizar las conversiones oportunas. De esta forma, se estudian los casos dentro de los límites establecidos por la propia normativa.

- En segundo lugar, porque la variación en la edificabilidad define los modelos básicos de crecimiento dentro de los tejidos residenciales: baja densidad, densidad media o alta densidad. Cada uno de ellos tiene unas características formales diferentes, e incluso representan modelos de vida distintos.

Por otro lado, aplicaremos a estos sectores los estándares que establecen las cantidades mínimas de espacios libres y equipamientos señaladas en las respectivas normativas. Los denominaremos de forma genérica estándares dotacionales y comprenderán aquellos que suponen reservas de suelo cuantificables. No incluimos estándares como el de plazas de aparcamiento, anchos de calle o arbolado, puesto que no se refieren a superficies concretas. Tampoco se tiene en cuenta el estándar de viviendas protegidas que aparece en la mayoría de las normativas, puesto que se refiere a una tipología de uso residencial que, en esencia, no varía la forma del tejido urbano ni la cantidad de dotaciones existente.

Para mostrar los resultados del análisis vamos a aplicar los estándares dotacionales a una serie de sectores tipo con distintas edificabilidades que estén dentro de los límites de densidad impuestos por cada normativa. Además, vamos a utilizar un sistema de representación gráfica de los resultados de estos sectores que ayudan a visualizar dos parámetros fundamentales para el trabajo (DE LA CAL Y PEMÁN, 1998):

- Superficie del sector ocupada por las dotaciones (espacios libres + equipamientos), medida en porcentaje sobre la superficie total.

- Cantidad de dotaciones por vivienda, medida en metros cuadrados de suelo dotacional por vivienda.

El primer parámetro permite analizar la superficie que la ordenación debe destinar a dotaciones, por lo que podremos deducir la superficie disponible para otros usos. El segundo servirá para evaluar el nivel de dotaciones por vivienda considerado mínimo para los nuevos sectores.

Además, se completa el estudio con la edificabilidad media de las parcelas privadas en las que debe materializarse el aprovechamiento de los sectores. Para este cálculo se considera la superficie disponible para parcelas privadas una vez descontadas del sector las superficies públicas: espacios libres, equipamientos y viario. Esto nos permitirá hacernos una idea respecto a la tipología edificatoria que puede darse en el sector y sobre la tipología urbana a que dará lugar.

\section{Homogeneización de los datos}

Los estándares propuestos por las diferentes normativas para el desarrollo de los sectores residenciales son bastante parecidos, probablemente debido a que los legisladores han utilizado el Reglamento de Planeamiento de 1978 como referencia. Todas las normativas estudiadas regulan los tres estándares básicos que nos sirven de base: intensidad, espacios libres y equipamientos. No obstante, existen variaciones en cuanto a las unidades de medida empleadas en cada caso. Así, por ejemplo, el Reglamento de Planeamiento de 1978 establece la obligación de ceder $15 \mathrm{~m}^{2}$ por vivienda destinados a jardines, mientras que el Reglamento de Urbanismo de Castilla y León obliga a ceder para espacios libres $20 \mathrm{~m}^{2}$ por cada $100 \mathrm{~m}^{2}$ edificables en el uso predominante. Vemos que tampoco la referencia para el cálculo de la cesión es igual: aplicando el Reglamento del Estado, la superficie de jardines será proporcional al número de viviendas, sin tener en cuenta otros usos de carácter privado, como pueden ser oficinas o comercios; en cambio, el Reglamento castellanoleonés tiene en cuenta toda la edificabilidad del sector, independientemente de su uso.

Para poder comparar los estándares de diferentes normativas, es necesario adoptar una serie de hipótesis que ayudarán a homogeneizar los datos: 
- Vamos a considerar que una vivienda equivale a $100 \mathrm{~m}^{2}$ construidos. De hecho, algunas de las normativas establecen esta equivalencia. El propio Reglamento de Planeamiento de 1978, en su artículo 45, al hablar de los módulos de reserva correspondientes a los planes parciales, los establece «por vivienda o por cada 100 metros cuadrados de edificación residencial».

- También consideraremos que toda la edificabilidad del sector se consume en uso residencial. Esta hipótesis, que sin duda es más discutible, se adopta por la necesidad de tomar un sector tipo comparable en todas las normativas, ya que algunas sólo tienen en cuenta el uso residencial para establecer estándares dotacionales o de densidad. Por ello, los sectores tipo se han construido considerando que toda la edificabilidad se consume en el uso residencial.

- La superficie de espacios libres y equipamientos viene determinada por la aplicación de los estándares legales, mientras que para establecer la superficie destinada a viario es necesario adoptar algún tipo de hipótesis: hemos supuesto una dotación de $40 \mathrm{~m}^{2}$ de viario por vivienda, que podemos considerar mínima basándonos en el estudio de Hernández AJA Y LeIva Rodríguez (2006) sobre necesidades dotacionales en distintos tejidos urbanos ${ }^{2}$.

Resumiendo, los sectores tipo que nos servirán de base para el estudio son exclusivamente residenciales (no hay otros usos lucrativos); las viviendas tienen una superficie de $100 \mathrm{~m}^{2}$ construidos; y la dotación de viario es de $40 \mathrm{~m}^{2}$ por vivienda.

En los siguientes apartados se recogen los datos correspondientes a cada normativa, acompañados de comentarios sobre las propias normas y de la presentación de los gráficos sobre ocupación dotacional del sector y dotaciones por vivienda.

\section{Normativa urbanística española}

Comenzaremos por la normativa estatal que ha servido de referencia para buena parte de las comunidades autónomas que han elaborado posteriormente su legislación urbanística. Prestaremos especial atención al Real Decreto 2159/1978, de 23 de junio, por el que se aprueba el Reglamento de Planeamiento para el Desarrollo y Aplicación de la Ley sobre Régimen del Suelo y Ordenación Urbana. Su misión fue desarrollar la Ley sobre Régimen del Suelo y Ordenación Urbana aprobada tres años antes (Texto refundido de la Ley sobre Régimen del Suelo y Ordenación Urbana, aprobado por Real Decreto 1346/1976, de 9 de abril). Esta Ley incluía algunos estándares urbanísticos básicos que se desarrollan de manera exhaustiva en el Reglamento, sobre todo en el caso de los sectores de suelo urbanizable de uso residencial. Es curioso que los estándares se establezcan con detalle en un Anexo sobre «Reservas de suelo para dotaciones en planes parciales», y no en el articulado del Reglamento, al cual incluso contradice en alguna ocasión ${ }^{3}$.

\section{Datos recogidos}

\section{Densidad}

La densidad de los sectores residenciales se limita en el artículo 75 de la Ley del Suelo de 1976, el cual establece un máximo de 75 viviendas por hectárea que, excepcional y justificadamente, puede ascender a 100 viviendas por hectárea. Vemos que no se trata de una limitación a la edificabilidad, sino a las viviendas. La vivienda será también la unidad de medida para establecer los estándares dotacionales de espacios libres, equipamientos y aparcamientos.

\section{Dotaciones}

Como hemos dicho, los estándares dotacionales se recogen en un anexo al Reglamento de Planeamiento de 1978, en el que se concretan las «Reservas de suelo para dotaciones en planes parciales».

Las dotaciones se cuantifican y se modulan en función del número de viviendas del sector a desarrollar, incrementando las cesiones obligatorias por vivienda cuando los sectores contienen mayor número de éstas, tal como vemos en el cuadro 2.

La modulación establecida en función del número de viviendas del sector hace que cuantas más viviendas incluye el ámbito, mayores son las exigencias dotacionales. Esta modulación no tiene que ver con la densidad de viviendas por hectárea, sino con el número total de unidades de vivienda incluidas en el sector. Con este sistema, un sector de más de 2.000 viviendas tiene casi el doble de dotaciones que un

\footnotetext{
${ }^{2}$ Este aspecto se explica de forma más amplia en el capítulo cuarto, donde volveremos a utilizar el trabajo de HERNÁNDEZ AJA para establecer una propuesta teórica que confrontar con los estándares establecidos por la normativa.

${ }^{3}$ Un ejemplo de ello es el caso de los espacios deportivos, que en el artículo 45 del Reglamento se considera una variedad de espacio libre, mientras que en el Anexo es considerado como un equipamiento.
} 
CuAdro 2: Estándares dotacionales para sectores residenciales. Reglamento de Planeamiento de 1978

\begin{tabular}{|c|c|c|c|c|c|}
\hline & $\begin{array}{l}\text { Hasta } \\
250 \text { viv. }\end{array}$ & $\begin{array}{l}\text { Hasta } \\
500 \text { viv. }\end{array}$ & $\begin{array}{l}\text { Hasta } \\
1.000 \text { viv. }\end{array}$ & $\begin{array}{l}1.000-2.000 \\
\text { viv. }\end{array}$ & $>2.000$ viv. \\
\hline \multicolumn{6}{|c|}{$\begin{array}{l}\text { Sistema de espacios libres de dominio y uso públicos } \\
\text { (mínimo } 10 \% \text { de la superficie del sector) }\end{array}$} \\
\hline Jardines & \multicolumn{5}{|c|}{$15 \mathrm{~m}^{2} \mathrm{~s} /$ vivienda } \\
\hline $\begin{array}{l}\text { Áreas de juego y } \\
\text { recreo de niños }\end{array}$ & \multicolumn{2}{|c|}{$3 \mathrm{~m}^{2} \mathrm{~s} /$ vivienda } & \multicolumn{3}{|c|}{$6 \mathrm{~m}^{2} \mathrm{~s} /$ vivienda } \\
\hline \multicolumn{6}{|l|}{ Centros docentes } \\
\hline $\begin{array}{l}\text { Preescolar, } \\
\text { guardería }\end{array}$ & - & \multicolumn{4}{|c|}{$2 \mathrm{~m}^{2} \mathrm{~s} /$ vivienda } \\
\hline EGB & \multicolumn{5}{|c|}{$10 \mathrm{~m}^{2} \mathrm{~s} /$ vivienda } \\
\hline $\mathrm{BUP}$ & - & - & - & - & $4 \mathrm{~m}^{2} \mathrm{~s} / \mathrm{viv}$ \\
\hline \multicolumn{6}{|c|}{ Servicios de interés público y social } \\
\hline Parque deportivo & - & \multicolumn{2}{|c|}{$6 \mathrm{~m}^{2} \mathrm{~s} /$ vivienda } & \multicolumn{2}{|c|}{$8 \mathrm{~m}^{2} \mathrm{~s} /$ vivienda } \\
\hline $\begin{array}{l}\text { Equipamiento } \\
\text { comercial }\end{array}$ & $2 \mathrm{~m}^{2} \mathrm{c} / \mathrm{viv}$ & $1 \mathrm{~m}^{2} \mathrm{c} / \mathrm{viv}$ & $2 \mathrm{~m}^{2} \mathrm{c} / \mathrm{viv}$ & $3 \mathrm{~m}^{2} \mathrm{c} / \mathrm{viv}$ & $4 \mathrm{~m}^{2} \mathrm{c} / \mathrm{viv}$ \\
\hline Equipamiento social & $2 \mathrm{~m}^{2} \mathrm{c} / \mathrm{viv}$ & $3 \mathrm{~m}^{2} \mathrm{c} / \mathrm{viv}$ & $4 \mathrm{~m}^{2} \mathrm{c} / \mathrm{viv}$ & \multicolumn{2}{|c|}{$6 \mathrm{~m}^{2} \mathrm{c} /$ vivienda } \\
\hline Totales (sólo m² m $^{2}$ & $28 \mathrm{~m}^{2} \mathrm{~s} /$ viv. & $36 \mathrm{~m}^{2} \mathrm{~s} / \mathrm{viv}$. & $39 \mathrm{~m}^{2} \mathrm{~s} / \mathrm{viv}$. & $41 \mathrm{~m}^{2} \mathrm{~s} / \mathrm{viv}$ & $46 \mathrm{~m}^{2} \mathrm{~s} / \mathrm{viv}$. \\
\hline $\begin{array}{ll}\text { Plazas } & \text { de } \\
\text { aparcamiento } & \end{array}$ & \multicolumn{5}{|c|}{1 plaza/100 $\mathrm{m}^{2}$ construidos } \\
\hline
\end{tabular}

1 vivienda $=100 \mathrm{~m}^{2}$ construidos uso residencial

$\mathrm{m}^{2} \mathrm{~s}=$ metro cuadrado de suelo

$\mathrm{m}^{2} \mathrm{c}=$ metro cuadrado construido 
sector de menos de 250 viviendas, pues pasa el ratio por vivienda pasa de $30 \mathrm{~m}^{2}$ a $56 \mathrm{~m}^{2}$ (incluyendo los metros cuadrados construidos, que enseguida explicaremos). Esta diferenciación aparece en otras normativas y será uno de los temas que se tratará en el capítulo de conclusiones.

Hay que señalar que la mayoría de los módulos se establecen en metros cuadrados de suelo $\left(\mathrm{m}^{2} \mathrm{~s}\right)$ por vivienda, salvo los equipamientos comerciales y sociales, que se establecen en metros cuadrados construidos $\left(\mathrm{m}^{2} \mathrm{c}\right)$, por lo que forman parte de edificios con otros usos (plantas bajas de edificios residenciales, por ejemplo). Además, se trata de dotaciones que pueden tener carácter privado y, por tanto, consumirán parte de la edificabilidad lucrativa asignada al sector. Por estos motivos, no se tendrán en cuenta para los sectores tipo que se evalúan a continuación.

\section{Sectores tipo}

En el cuadro 3 se indican las superficies correspondientes a la aplicación de los estándares a sectores tipo de uso residencial con distintas edificabilidades y distinto número de viviendas.

Los datos de partida son el número de viviendas del sector y la edificabilidad del mismo. A partir de ellos y de los estándares recogidos en el cuadro 3, obtenemos la superficie del sector, así como la superficie destinada a espacios libres y equipamientos. A partir de estas superficies, podemos obtener el porcentaje de suelo que la ordenación tendrá que destinar a dotaciones, así como el ratio de dotaciones por vivienda. Estos datos se representan gráficamente relacionándolos con la edificabilidad, de tal forma que podemos visualizar el incremento de la ocupación de la superficie y el descenso del ratio por vivienda conforme aumenta la edificabilidad del sector (ver figura 2.1 y figura 2.2 respectivamente).

Las edificabilidades de los sectores estudiados se sitúan entre 0,15 y $0,75 \mathrm{~m}^{2} \mathrm{t} / \mathrm{m}^{2} \mathrm{~s}$. Como ya se ha indicado, consideramos que toda la edificabilidad se consume en uso residencial, en viviendas de $100 \mathrm{~m}^{2}$ construidos, por lo que la equivalencia entre edificabilidad y densidad de viviendas es muy sencilla: 0,15 $\mathrm{m}^{2} \mathrm{t} / \mathrm{m}^{2} \mathrm{~s}$ equivalen a 15 viviendas por hectárea y $0,75 \mathrm{~m}^{2} \mathrm{t} / \mathrm{m}^{2} \mathrm{~s}$ a 75 viviendas por hectárea. Aunque no hay un límite mínimo de edificabilidad, no parece razonable plantear sectores residenciales con densidades menores de 15 viviendas por hectárea, mientras que 75 viviendas por hectárea es el límite máximo permitido por la Ley sobre Régimen del Suelo y Ordenación Urbana de 1976.

La última columna del cuadro 3 nos muestra la edificabilidad media de las parcelas lucrativas del sector. Podemos ver que los tejidos varían desde modelos de baja densidad, con edificabilidades de 0,18 $\mathrm{m}^{2} \mathrm{t} / \mathrm{m}^{2} \mathrm{~s}$ por parcela, lo que suele materializarse en viviendas unifamiliares con grandes jardines privados; hasta edificios de vivienda en altura, con edificabilidades de hasta $2,11 \mathrm{~m}^{2} \mathrm{t} / \mathrm{m}^{2} \mathrm{~s}$.

El Reglamento de Planeamiento de 1978 establece un estándar de $18 \mathrm{~m}^{2}$ por vivienda destinado a espacios libres de dominio y uso públicos, pero también indica que la superficie destinada a este uso no puede ser inferior al $10 \%$ de la superficie total del sector.

La superficie destinada a dichas reservas [espacios libres públicos] será, como mínimo, de 18 metros cuadrados por vivienda o por cada 100 metros cuadrados de edificación residencial, si no se hubiera fijado expresamente el número de viviendas que se pudieran construir. Esta reserva no podrá ser inferior al 10 por 100 de la total superficie ordenada, $[\ldots]$

RP-78, art. 45.1.c

El porcentaje mínimo del $10 \%$ es el causante de que las gráficas correspondientes a las dotaciones por vivienda (ver figura 2) no sean horizontales hasta que los sectores tienen edificabilidades superiores a $0,55 \mathrm{~m}^{2} \mathrm{t} / \mathrm{m}^{2} \mathrm{~s}$. Esto es debido a que en sectores con edificabilidades menores, la cesión resulta superior aplicando el $10 \%$ de la superficie del sector que aplicando el módulo de $18 \mathrm{~m}^{2}$ por vivienda.

En consecuencia, el límite mínimo del $10 \%$ de superficie para espacios libres, que puede resultar razonable, genera una de las paradojas del sistema planteado por el Reglamento de Planeamiento de 1978: vemos que en sectores de muy poca densidad de viviendas (edificabilidades menores a $0,25 \mathrm{~m}^{2} \mathrm{t} / \mathrm{m}^{2} \mathrm{~s}$ ), la superficie de espacios libres y equipamientos públicos por vivienda es muy alta. Nada menos de $91,67 \mathrm{~m}^{2} \mathrm{~s}$ por vivienda en el caso más desfavorable (15 viviendas por hectárea), de los cuales $66,67 \mathrm{~m}^{2}$ corresponden a espacios libres y $25 \mathrm{~m}^{2}$ a equipamientos.

Resulta así que los sectores de menor densidad, en los que las viviendas suelen disponer de amplios jardines privados, la dotación de espacios libres públicos es mucho mayor que en sectores de densidades superiores. Comentaremos con mayor detalle este aspecto en el capítulo de conclusiones.

Sin embargo, a partir de edificabilidades mayores de $0,55 \mathrm{~m}^{2} \mathrm{t} / \mathrm{m}^{2} \mathrm{~s}$, comienza a aplicarse el módulo de metros cuadrados de espacios libres por vivienda, puesto que supone cesiones mayores que el $10 \%$ de la superficie del sector. Por esta razón, la gráfica de la figura 2.2 se vuelve horizontal en el momento en que las cesiones obligatorias por vivienda se mantienen constantes. 
Cundro 3: Aplicación de estándares dotacionales a sectores tipo de uso residencial. Reglamento de Planeamiento de 1978

Sector de 250 viviendas

\begin{tabular}{|c|c|c|c|c|c|c|}
\hline Edifica- & Superf. & Espacios & Equipa- & \multicolumn{2}{|c|}{ Dotaciones } & Edificab. \\
\hline $\begin{array}{l}\text { bilidad } \\
\left(\mathrm{m}^{2} \mathrm{t} / \mathrm{m}^{2} \mathrm{~s}\right)\end{array}$ & $\begin{array}{l}\text { del sector } \\
\qquad\left(\mathrm{m}^{2}\right)\end{array}$ & $\begin{array}{l}\text { libres } \\
\left(\mathrm{m}^{2}\right)\end{array}$ & $\begin{array}{l}\text { mientos } \\
\qquad\left(\mathrm{m}^{2}\right)\end{array}$ & $\begin{array}{c}\text { Ocupación } \\
\text { de suelo } \\
\text { (\% de sup.) }\end{array}$ & $\begin{array}{c}\text { Ratio } \\
\text { por vivda. } \\
\left.\text { ( } \mathrm{m}^{2} / \text { vivda. }\right)\end{array}$ & $\begin{array}{c}\text { parcela } \\
\text { neta } \\
\left(\mathrm{m}^{2} \mathrm{t} / \mathrm{m}^{2} \mathrm{~s}\right)\end{array}$ \\
\hline 0,15 & 166.667 & 16.667 & 2.500 & 11,50 & 76,67 & 0,18 \\
\hline 0,35 & 71.429 & 7.143 & 2.500 & 13,50 & 38,57 & 0,48 \\
\hline 0,55 & 45.455 & 4.500 & 2.500 & 15,40 & 28,00 & 0,88 \\
\hline 0,75 & 33.333 & 4.500 & 2.500 & 21,00 & 28,00 & 1,53 \\
\hline
\end{tabular}

Sector de 500 viviendas

\begin{tabular}{|c|c|c|c|c|c|c|}
\hline Edifica- & Superf. & Espacios & Equipa- & Dota & iones & lificab. \\
\hline $\begin{array}{l}\text { bilidad } \\
\left(\mathrm{m}^{2} \mathrm{t} / \mathrm{m}^{2} \mathrm{~s}\right)\end{array}$ & $\begin{array}{l}\text { del sector } \\
\qquad\left(\mathrm{m}^{2}\right)\end{array}$ & $\begin{array}{l}\text { libres } \\
\left(\mathrm{m}^{2}\right)\end{array}$ & $\begin{array}{l}\text { mientos } \\
\left(\mathrm{m}^{2}\right)\end{array}$ & $\begin{array}{c}\text { Ocupación } \\
\text { de suelo } \\
\text { (\% de sup.) }\end{array}$ & $\begin{array}{c}\text { Ratio } \\
\text { por vivda. } \\
\left(\mathrm{m}^{2} / \text { vivda. }\right)\end{array}$ & $\begin{array}{c}\text { parcela } \\
\text { neta } \\
\left(\mathrm{m}^{2} \mathrm{t} / \mathrm{m}^{2} \mathrm{~s}\right)\end{array}$ \\
\hline 0,15 & $\begin{array}{l}333.333 \\
\end{array}$ & 33.333 & 9.000 & 12,70 & 84,67 & 0,18 \\
\hline 0,35 & 142.857 & 14.286 & 9.000 & 16,30 & 46,57 & 0,50 \\
\hline 0,55 & 90.909 & 9.000 & 9.000 & 19,80 & 36,00 & 0,95 \\
\hline 0,75 & 66.667 & 9.000 & 9.000 & 27,00 & 36,00 & 1,74 \\
\hline
\end{tabular}

Sector de 1.000 viviendas

\begin{tabular}{|c|c|c|c|c|c|c|}
\hline Edifica- & Superf. & Espacios & Equipa- & \multicolumn{2}{|c|}{ Dotaciones } & Edificab. \\
\hline $\begin{array}{l}\text { bilidad } \\
\left(\mathrm{m}^{2} \mathrm{t} / \mathrm{m}^{2} \mathrm{~s}\right)\end{array}$ & $\begin{array}{l}\text { del sector } \\
\qquad\left(\mathrm{m}^{2}\right)\end{array}$ & $\begin{array}{l}\text { libres } \\
\left(\mathrm{m}^{2}\right)\end{array}$ & $\begin{array}{l}\text { mientos } \\
\left(\mathrm{m}^{2}\right)\end{array}$ & $\begin{array}{c}\text { Ocupación } \\
\text { de suelo } \\
\text { (\% de sup.) }\end{array}$ & $\begin{array}{c}\text { Ratio } \\
\text { por vivda. } \\
\left(\mathrm{m}^{2} / \text { vivda. }\right)\end{array}$ & $\begin{array}{c}\text { parcela } \\
\text { neta } \\
\left(\mathrm{m}^{2} \mathrm{t} / \mathrm{m}^{2} \mathrm{~s}\right)\end{array}$ \\
\hline 0,15 & 666.667 & 66.667 & 18.000 & 12,70 & 84,67 & 0,18 \\
\hline 0,35 & 285.714 & 28.571 & 18.000 & 16,30 & 46,57 & 0,50 \\
\hline 0,55 & 181.818 & 21.000 & 18.000 & 21,45 & 39,00 & 0,97 \\
\hline 0,75 & 133.333 & 21.000 & 18.000 & 29,25 & 39,00 & 1,84 \\
\hline
\end{tabular}

Sector de 2.000 viviendas

\begin{tabular}{|c|c|c|c|c|c|c|}
\hline Edifica- & Superf. & Espacios & Equipa- & Dota & iones & Edificab. \\
\hline $\begin{array}{l}\text { bilidad } \\
\left(\mathrm{m}^{2} \mathrm{t} / \mathrm{m}^{2} \mathrm{~s}\right)\end{array}$ & $\begin{array}{l}\text { del sector } \\
\qquad\left(\mathrm{m}^{2}\right)\end{array}$ & $\begin{array}{l}\text { libres } \\
\left(\mathrm{m}^{2}\right)\end{array}$ & $\begin{array}{l}\text { mientos } \\
\left(\mathrm{m}^{2}\right)\end{array}$ & $\begin{array}{l}\text { Ocupación } \\
\text { de suelo } \\
\text { (\% de sup.) }\end{array}$ & $\begin{array}{c}\text { Ratio } \\
\text { por vivda. } \\
\left(\mathrm{m}^{2} / \text { vivda. }\right)\end{array}$ & $\begin{array}{c}\text { parcela } \\
\text { neta } \\
\left(\mathrm{m}^{2} \mathrm{t} / \mathrm{m}^{2} \mathrm{~s}\right)\end{array}$ \\
\hline 0,15 & 1.333 .333 & 133.333 & 40.000 & 13,00 & 86,67 & 0,19 \\
\hline 0,35 & 571.429 & 57.143 & 40.000 & 17,00 & 48,57 & 0,51 \\
\hline 0,55 & 363.636 & 42.000 & 40.000 & 22,55 & 41,00 & 0,99 \\
\hline 0,75 & 266.667 & 42.000 & 40.000 & 30,75 & 41,00 & 1,91 \\
\hline
\end{tabular}

Sector de 4.000 viviendas

\begin{tabular}{|c|c|c|c|c|c|c|}
\hline Edifica- & Superf. & Espacios & Equipa- & Dota & iones & Edificab. \\
\hline $\begin{array}{l}\text { bilidad } \\
\left(\mathrm{m}^{2} \mathrm{t} / \mathrm{m}^{2} \mathrm{~s}\right)\end{array}$ & $\begin{array}{l}\text { del sector } \\
\qquad\left(\mathrm{m}^{2}\right)\end{array}$ & $\begin{array}{l}\text { libres } \\
\left(\mathrm{m}^{2}\right)\end{array}$ & $\begin{array}{l}\text { mientos } \\
\left(\mathrm{m}^{2}\right)\end{array}$ & $\begin{array}{l}\text { Ocupación } \\
\text { de suelo } \\
\text { (\% de sup.) }\end{array}$ & $\begin{array}{c}\text { Ratio } \\
\text { por vivda. } \\
\left(\mathrm{m}^{2} / \text { vivda. }\right)\end{array}$ & $\begin{array}{c}\text { parcela } \\
\text { neta } \\
\left(\mathrm{m}^{2} \mathrm{t} / \mathrm{m}^{2} \mathrm{~s}\right)\end{array}$ \\
\hline 0,15 & 2.666 .666 & 266.667 & 100.000 & 13,75 & 91,67 & 0,19 \\
\hline 0,35 & 1.142 .857 & 114.286 & 100.000 & 18,75 & 53,57 & 0,52 \\
\hline 0,55 & 727.273 & 84.000 & 100.000 & 25,30 & 46,00 & 1,04 \\
\hline 0,75 & 533.333 & 84.000 & 100.000 & 34,50 & 46,00 & 2,11 \\
\hline
\end{tabular}




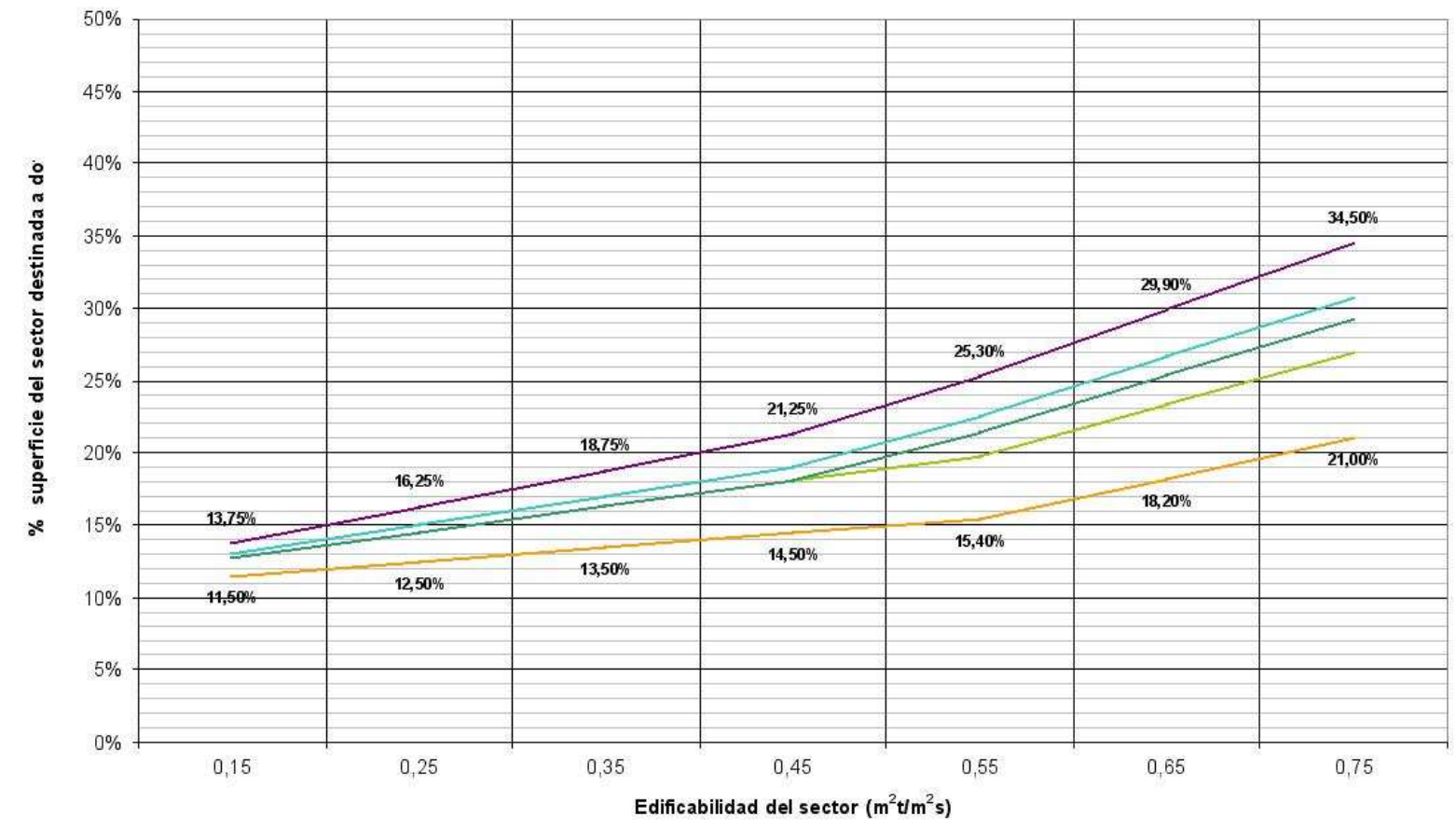

250 viviendas -500 viviendas -1000 viviendas -2000 viviendas -4000 viviendas

Figura 1: Superficie ocupada (\%) por las dotaciones en sectores tipo de uso residencial. Reglamento de Planeamiento de 1978

Elaboración propia 


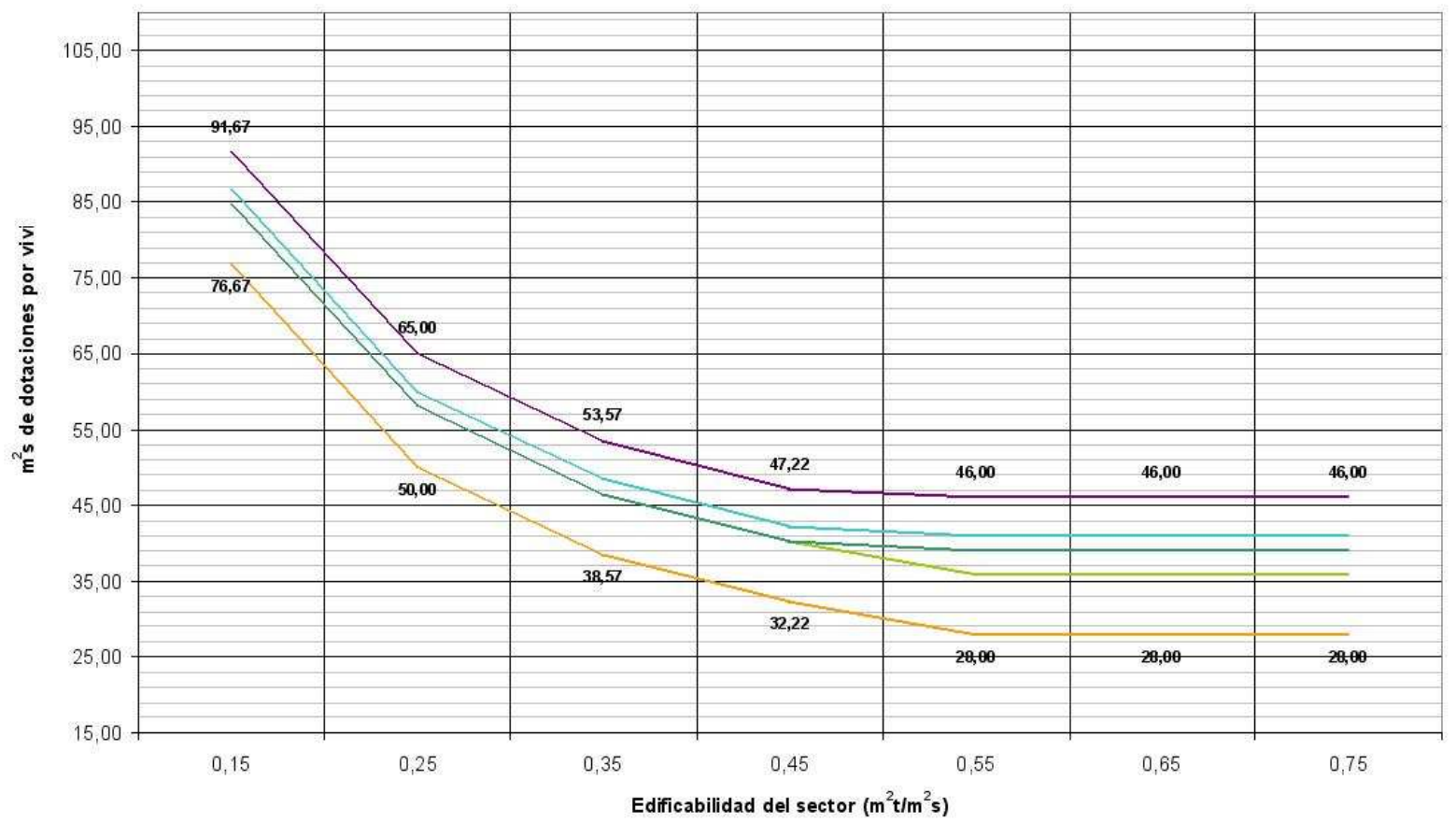

-250 viviendas -500 viviendas -1000 viviendas -2000 viviendas -+ de 2000 viviendas

Figura 2: Dotaciones por vivienda en sectores tipo de uso residencial. Reglamento de Planeamiento de 1978

Elaboración propia 


\section{Normativa urbanística de Aragón}

La Comunidad Autónoma de Aragón cuenta con legislación urbanística propia desde 1999 (Ley 5/1999, de 25 de marzo, Urbanística) y con un Reglamento (Decreto 52/2002, de 19 de febrero, por el que se aprueba el Reglamento de Desarrollo Parcial de la Ley 5/1999, de 25 de marzo, Urbanística, en materia de Organización, Planeamiento Urbanístico y Régimen Especial de Pequeños Municipios) que desarrolla parte de las determinaciones que la Ley establece. Este Reglamento sustituye por completo al Reglamento de Planeamiento de 1978 en esta comunidad autónoma aunque, como veremos, es continuador de muchas de las determinaciones introducidas por aquél sobre dotaciones, aunque incrementa las exigencias de forma general.

\section{Datos recogidos}

\section{Densidad}

La Ley Urbanística de Aragón establece un límite a la edificabilidad residencial de $8.500 \mathrm{~m}^{2} /$ hectárea en los sectores de suelo urbanizable1. Al igual que el Reglamento de Planeamiento de 1978, se limita la capacidad residencial de los sectores pero no se limita para otros usos. Aplicando la equivalencia de 100 $\mathrm{m}^{2}$ construidos por vivienda, tenemos una densidad máxima de 85 viviendas por hectárea.

\section{Dotaciones}

El Reglamento aragonés fija una serie de estándares con un alto grado de detalle para los tres usos globales que permite: residencial, industrial y terciario o de servicios. Recogeremos únicamente los referidos al uso global residencial (ver cuadro 4).

CUADRO 4: Estándares dotacionales para sectores residenciales. Normativa urbanística de Aragón

\begin{tabular}{|c|c|c|c|c|c|}
\hline & $\begin{array}{l}50-100 \\
\text { viv. }\end{array}$ & $\begin{array}{l}101-250 \\
\text { viv. }\end{array}$ & $\begin{array}{l}251-500 \\
\text { viv. }\end{array}$ & $\begin{array}{l}501-1.000 \\
\text { viv. }\end{array}$ & $\begin{array}{l}>1.000 \\
\text { viv. }\end{array}$ \\
\hline $\begin{array}{l}\text { Espacios libres } \\
\text { de uso público }\end{array}$ & \multicolumn{5}{|c|}{$\begin{array}{c}10 \% \text { de la superficie } \\
\text { ó } 18 \mathrm{~m}^{2} / \text { unidad de reserva }\end{array}$} \\
\hline \multicolumn{6}{|l|}{ Equipamiento educativo } \\
\hline Educación infantil & - & - & - & \multicolumn{2}{|c|}{$3 \mathrm{~m}^{2} / \mathrm{u}$. reserva } \\
\hline Educación primaria & - & - & \multicolumn{3}{|c|}{$6 \mathrm{~m}^{2} /$ unidad de reserva } \\
\hline $\begin{array}{l}\text { Educación secundaria } \\
\text { obligatoria }\end{array}$ & - & - & \multicolumn{3}{|c|}{$4 \mathrm{~m}^{2} /$ unidad de reserva } \\
\hline Educación secundaria (otros) & - & - & - & - & $4 \mathrm{~m}^{2} / \mathrm{u}$.res. \\
\hline \multicolumn{6}{|l|}{ Otros equipamientos } \\
\hline Equipamiento deportivo & - & - & $3 \mathrm{~m}^{2} /$ viv. & $6 \mathrm{~m}^{2} /$ viv. & $9 \mathrm{~m}^{2} /$ viv. \\
\hline Equipamiento social & - & - & $4 \mathrm{~m}^{2} /$ viv. & $6 \mathrm{~m}^{2} /$ viv. & $10 \mathrm{~m}^{2} /$ viv. \\
\hline Equipamiento polivalente & $10 \mathrm{~m}^{2} /$ viv. & $12 \mathrm{~m}^{2} /$ viv. & - & - & - \\
\hline Totales $(*)$ & $28 \mathrm{~m}^{2} /$ viv. & $30 \mathrm{~m}^{2} /$ viv. & $35 \mathrm{~m}^{2} /$ viv. & $43 \mathrm{~m}^{2} /$ viv. & $54 \mathrm{~m}^{2} / \mathrm{viv}$ \\
\hline
\end{tabular}

(*) Suponiendo 1 vivienda $=1$ unidad de reserva $=85 \mathrm{~m}^{2}$ construidos.

Vemos que se produce un cambio en la unidad de medida utilizada para referenciar las dotaciones: pasa de hablar de $\mathrm{m}^{2}$ por unidad de reserva a $\mathrm{m}^{2}$ por vivienda. La unidad de reserva equivale, según indica el propio Reglamento, a $85 \mathrm{~m}^{2}$ construidos de uso residencial. En cuanto a las viviendas, desconocemos si equivalen a las unidades de reserva o se refieren al número de viviendas del sector, sea cual sea su superficie construida, pero parece razonable pensar que los redactores de la normativa quisieran mantener constante la unidad de medida. Por ello, consideraremos que los módulos se refieren a viviendas de 85 $\mathrm{m}^{2}$ construidos.

\section{Sectores tipo}

Sin embargo, para poder comparar los datos obtenidos de ocupación de suelo y dotaciones por vivienda con el resto de normativas, deberemos utilizar el mismo criterio respecto al tamaño de la vivienda. De 
esta forma, los datos del cuadro 4 debemos modificarlos para que se adapten a viviendas de $100 \mathrm{~m}^{2}$ construidos. Por ejemplo, la reserva de espacios libres de $18 \mathrm{~m}^{2}$ por unidad de reserva, equivale a 21,18 $\mathrm{m}^{2}$ por $« 100 \mathrm{~m}^{2}$ construidos de uso residencial». También es necesario adaptar los tramos de número de viviendas, tal como muestra el cuadro 5, en la que se recogen los sectores tipo.

Las cesiones por vivienda son superiores en los sectores que incluyen un mayor número de viviendas. Por ejemplo, en el caso de dos sectores con una misma edificabilidad de $0,75 \mathrm{~m}^{2} \mathrm{t} / \mathrm{m}^{2} \mathrm{~s}$, el ratio de dotaciones por vivienda es de $32,94 \mathrm{~m}^{2}$ si tiene 85 viviendas, mientras que alcanza $63,53 \mathrm{~m}^{2}$ cuando tiene 1700 viviendas. Prácticamente el doble de dotaciones, aunque la edificabilidad es la misma.

El porcentaje de superficie ocupada por las cesiones dotacionales en el caso de Aragón (ver figura 3) supera los parámetros que hemos visto para el Reglamento de Planeamiento de 1978. El caso extremo se ha señalado en negrita en el cuadro 5, y se produce cuando el sector alcanza el límite de densidad señalado por la normativa. En este sector las dotaciones de espacios libres y equipamientos ocupan más de la mitad de la superficie y obliga a que la edificabilidad media por parcela sea de $7,09 \mathrm{~m}^{2} \mathrm{t} / \mathrm{m}^{2} \mathrm{~s}$, edificabilidad que recuerda a los modelos urbanos propuestos por los Congresos Internacionales de Arquitectura Moderna (CIAM): altas torres residenciales dispersas entre viales, parques y equipamientos de baja altura.

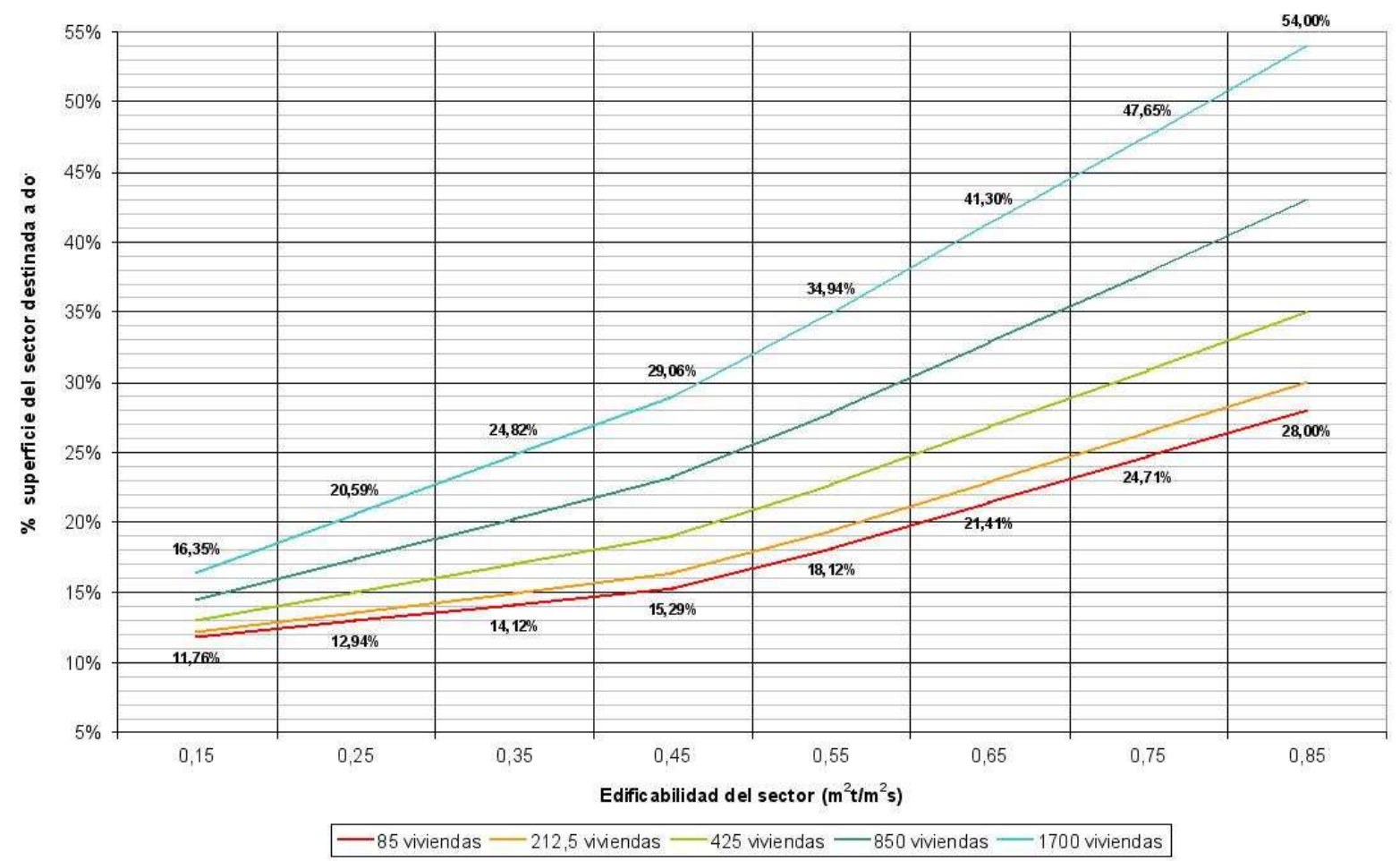

Figura 3: Superficie ocupada (\%) por las dotaciones en sectores tipo de uso residencial. Normativa urbanística de Aragón

Elaboración propia

Respecto al ratio de dotaciones por vivienda, también encontramos en la normativa aragonesa un incremento de algunos aspectos regulados por el Reglamento de Planeamiento de 1978 (ver figura 4). El ratio de dotaciones por vivienda se eleva cuando la edificabilidad se reduce, llegando a haber $109 \mathrm{~m}^{2}$ por vivienda en el caso más desfavorable: el de un sector de más de 1.000 viviendas y una edificabilidad de $0,15 \mathrm{~m}^{2} \mathrm{t} / \mathrm{m}^{2} \mathrm{~s}$.

En cuanto al cambio de curvatura de las gráficas, se produce también la estabilización de la cesión por vivienda cuando deja de aplicarse el porcentaje mínimo de superficie del sector destinada a espacios libres que, en el caso de Aragón, también es el $10 \%$. Para un sector con una edificabilidad de $0,55 \mathrm{~m}^{2} \mathrm{t} / \mathrm{m}^{2} \mathrm{~s}$ deja de aplicarse el porcentaje y sólo se aplican los módulos por vivienda. 
Cundro 5: Aplicación de estándares dotacionales a sectores tipo de uso residencial. Normativa urbanística de Aragón

Sector de 85 viviendas

\begin{tabular}{|c|c|c|c|c|c|c|}
\hline Edifica- & Superf. & Espacios & Equipa- & \multicolumn{2}{|c|}{ Dotaciones } & Edificab. \\
\hline $\begin{array}{c}\text { bilidad } \\
\left(\mathrm{m}^{2} \mathrm{t} / \mathrm{m}^{2} \mathrm{~s}\right)\end{array}$ & $\begin{array}{l}\text { del sector } \\
\qquad\left(\mathrm{m}^{2}\right)\end{array}$ & $\begin{array}{l}\text { libres } \\
\left(\mathrm{m}^{2}\right)\end{array}$ & $\begin{array}{l}\text { mientos } \\
\qquad\left(\mathrm{m}^{2}\right)\end{array}$ & $\begin{array}{c}\text { Ocupación } \\
\text { de suelo } \\
\text { (\% de sup.) }\end{array}$ & $\begin{array}{c}\text { Ratio } \\
\text { por vivda. } \\
\left(\mathrm{m}^{2} / \text { vivda. }\right)\end{array}$ & $\begin{array}{c}\text { parcela } \\
\text { neta } \\
\left(\mathrm{m}^{2} \mathrm{t} / \mathrm{m}^{2} \mathrm{~s}\right)\end{array}$ \\
\hline 0,15 & 56.667 & 5.667 & 1.000 & 11,76 & 78,43 & 0,18 \\
\hline 0,35 & 24.286 & 2.429 & 1.000 & 14,12 & 40,34 & 0,49 \\
\hline 0,55 & 15.455 & 1.800 & 1.000 & 18,12 & 32,94 & 0,92 \\
\hline 0,75 & 11.333 & 1.800 & 1.000 & 24,71 & 32,94 & 1,66 \\
\hline
\end{tabular}

Sector de 212,5 viviendas

\begin{tabular}{|c|c|c|c|c|c|c|}
\hline \multirow{2}{*}{$\begin{array}{l}\text { Edifica- } \\
\text { bilidad } \\
\left(\mathrm{m}^{2} \mathrm{t} / \mathrm{m}^{2} \mathrm{~s}\right)\end{array}$} & \multirow{2}{*}{$\begin{array}{c}\text { Superf. } \\
\text { del sector } \\
\left(\mathrm{m}^{2}\right)\end{array}$} & \multirow{2}{*}{$\begin{array}{c}\text { Espacios } \\
\text { libres } \\
\left(\mathrm{m}^{2}\right)\end{array}$} & \multirow{2}{*}{$\begin{array}{l}\text { Equipa- } \\
\text { mientos } \\
\left(\mathrm{m}^{2}\right)\end{array}$} & \multicolumn{2}{|c|}{ Dotaciones } & \multirow{2}{*}{$\begin{array}{c}\text { Edificab. } \\
\text { parcela } \\
\text { neta } \\
\left(\mathrm{m}^{2} \mathrm{t} / \mathrm{m}^{2} \mathrm{~s}\right)\end{array}$} \\
\hline & & & & $\begin{array}{c}\text { Ocupación } \\
\text { de suelo } \\
\text { (\% de sup.) }\end{array}$ & $\begin{array}{c}\text { Ratio } \\
\text { por vivda. } \\
\left(\mathrm{m}^{2} / \text { vivda. }\right)\end{array}$ & \\
\hline 0,15 & 141.667 & 14.167 & 3.000 & 12,12 & 80,78 & 0,18 \\
\hline 0,35 & 60.714 & 6.071 & 3.000 & 14,94 & 42,69 & 0,49 \\
\hline 0,55 & 38.636 & 4.501 & 3.000 & 19,41 & 35,30 & 0,94 \\
\hline 0,75 & 28.333 & 4.501 & 3.000 & 26,47 & 35,30 & 1,72 \\
\hline
\end{tabular}

Sector de 425 viviendas

\begin{tabular}{|c|c|c|c|c|c|c|}
\hline \multirow{2}{*}{$\begin{array}{l}\text { Edifica- } \\
\text { bilidad } \\
\left(\mathrm{m}^{2} \mathrm{t} / \mathrm{m}^{2} \mathrm{~s}\right)\end{array}$} & \multirow{2}{*}{$\begin{array}{c}\text { Superf. } \\
\text { del sector } \\
\left(\mathrm{m}^{2}\right)\end{array}$} & \multirow{2}{*}{$\begin{array}{c}\text { Espacios } \\
\text { libres } \\
\left(\mathrm{m}^{2}\right)\end{array}$} & \multirow{2}{*}{$\begin{array}{l}\text { Equipa- } \\
\text { mientos } \\
\left(\mathrm{m}^{2}\right)\end{array}$} & \multicolumn{2}{|c|}{ Dotaciones } & \multirow{2}{*}{$\begin{array}{c}\text { Edificab. } \\
\text { parcela } \\
\text { neta } \\
\left(\mathrm{m}^{2} \mathrm{t} / \mathrm{m}^{2} \mathrm{~s}\right)\end{array}$} \\
\hline & & & & $\begin{array}{c}\text { Ocupación } \\
\text { de suelo } \\
\text { (\% de sup.) }\end{array}$ & $\begin{array}{c}\text { Ratio } \\
\text { por vivda. } \\
\left(\mathrm{m}^{2} / \text { vivda. }\right)\end{array}$ & \\
\hline 0,15 & 283.333 & 28.333 & 8.500 & 13,00 & 86,67 & 0,19 \\
\hline 0,35 & 121.429 & 12.143 & 8.500 & 17,00 & 48,57 & 0,51 \\
\hline 0,55 & 77.273 & 9.002 & 8.500 & 22,65 & 41,18 & 0,99 \\
\hline 0,75 & 56.667 & 9.002 & 8.500 & 30,89 & 41,18 & 1,92 \\
\hline
\end{tabular}

Sector de 850 viviendas

\begin{tabular}{|c|c|c|c|c|c|c|}
\hline \multirow{2}{*}{$\begin{array}{l}\text { Edifica- } \\
\text { bilidad } \\
\left(\mathrm{m}^{2} \mathrm{t} / \mathrm{m}^{2} \mathrm{~s}\right)\end{array}$} & \multirow{2}{*}{$\begin{array}{c}\text { Superf. } \\
\text { del sector } \\
\left(\mathrm{m}^{2}\right)\end{array}$} & \multirow{2}{*}{$\begin{array}{c}\text { Espacios } \\
\text { libres } \\
\left(\mathrm{m}^{2}\right)\end{array}$} & \multirow{2}{*}{$\begin{array}{l}\text { Equipa- } \\
\text { mientos } \\
\left(\mathrm{m}^{2}\right)\end{array}$} & \multicolumn{2}{|c|}{ Dotaciones } & \multirow{2}{*}{$\begin{array}{c}\text { Edificab. } \\
\text { parcela } \\
\text { neta } \\
\left(\mathrm{m}^{2} \mathrm{t} / \mathrm{m}^{2} \mathrm{~s}\right)\end{array}$} \\
\hline & & & & $\begin{array}{c}\text { Ocupación } \\
\text { de suelo } \\
\text { (\% de sup.) }\end{array}$ & $\begin{array}{c}\text { Ratio } \\
\text { por vivda. } \\
\left(\mathrm{m}^{2} / \text { vivda. }\right)\end{array}$ & \\
\hline 0,15 & 566.667 & 56.667 & 25.000 & 14,41 & 96,08 & 0,19 \\
\hline 0,35 & 242.857 & 24.286 & 25.000 & 20,29 & 57,98 & 0,53 \\
\hline 0,55 & 154.545 & 18.003 & 25.000 & 27,83 & 50,59 & 1,10 \\
\hline 0,75 & 113.333 & 18.003 & 25.000 & 37,94 & 50,59 & 2,34 \\
\hline
\end{tabular}

Sector de 1.700 viviendas

\begin{tabular}{|c|c|c|c|c|c|c|}
\hline \multirow{2}{*}{$\begin{array}{l}\text { Edifica- } \\
\text { bilidad } \\
\left(\mathrm{m}^{2} \mathrm{t} / \mathrm{m}^{2} \mathrm{~s}\right)\end{array}$} & \multirow{2}{*}{$\begin{array}{c}\text { Superf. } \\
\text { del sector } \\
\left(\mathrm{m}^{2}\right)\end{array}$} & \multirow{2}{*}{$\begin{array}{c}\text { Espacios } \\
\text { libres } \\
\left(\mathrm{m}^{2}\right)\end{array}$} & \multirow{2}{*}{$\begin{array}{l}\text { Equipa- } \\
\text { mientos } \\
\left(\mathrm{m}^{2}\right)\end{array}$} & \multicolumn{2}{|c|}{ Dotaciones } & \multirow{2}{*}{$\begin{array}{c}\text { Edificab. } \\
\text { parcela } \\
\text { neta } \\
\left(\mathrm{m}^{2} \mathrm{t} / \mathrm{m}^{2} \mathrm{~s}\right)\end{array}$} \\
\hline & & & & $\begin{array}{c}\text { Ocupación } \\
\text { de suelo } \\
\text { (\% de sup.) }\end{array}$ & $\begin{array}{c}\text { Ratio } \\
\text { por vivda. } \\
\left(\mathrm{m}^{2} / \text { vivda. }\right)\end{array}$ & \\
\hline 0,15 & 1.133 .333 & 113.333 & 72.000 & 16,35 & 109,02 & 0,19 \\
\hline 0,35 & 485.714 & 48.571 & 72.000 & 24,82 & 70,92 & $\overline{0,57}$ \\
\hline 0,55 & 309.091 & 36.006 & 72.000 & 34,94 & 63,53 & 1,28 \\
\hline 0,75 & 226.667 & 36.006 & 72.000 & 47,65 & 63,53 & 3,36 \\
\hline$\overline{0,85}$ & 200.000 & 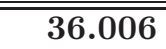 & $\overline{72.000}$ & $\overline{\overline{54,00}}$ & 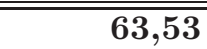 & $\overline{\overline{7,09}}$ \\
\hline
\end{tabular}




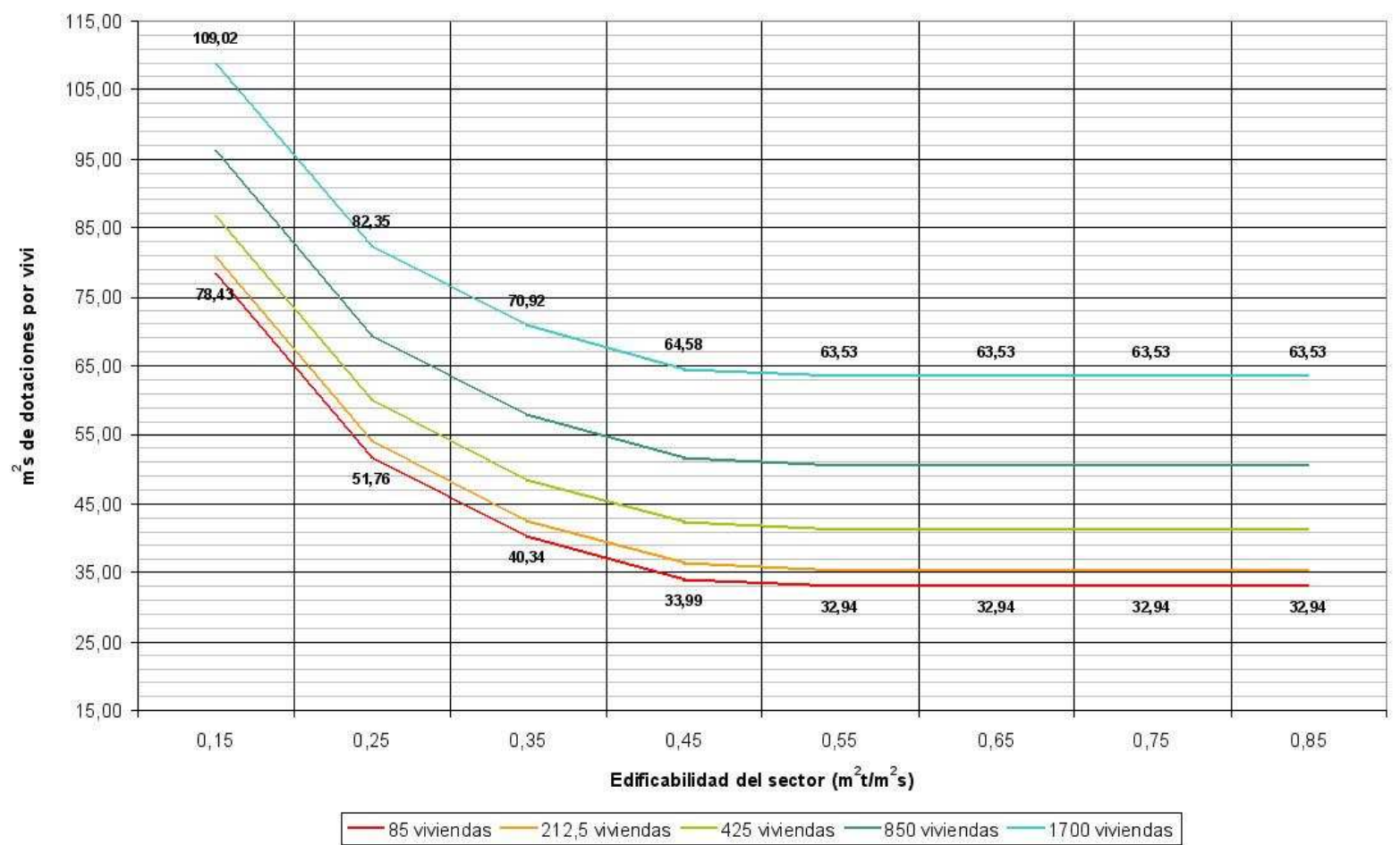

Figura 4: Dotaciones por vivienda en sectores tipo de uso residencial. Normativa urbanística de Aragón

Elaboración propia 


\section{Normativa urbanística de Castilla-La Mancha}

La Comunidad Autónoma de Castilla-La Mancha cuenta con un Reglamento de Planeamiento (Decreto 248/2004, de 14 de septiembre, que aprueba el Reglamento de Planeamiento de la Ley 2/1998, de 4 de junio, de Ordenación del Territorio y de la Actividad Urbanística (D248-04)) que desarrolla su legislación propia sobre urbanismo (Decreto Legislativo 1/2004, de 28 de diciembre, por el que se aprueba el Texto Refundido de la Ley de Ordenación del Territorio y de la Actividad Urbanística ${ }^{4}$ ). Al contrario que los casos estudiados anteriormente, el Reglamento castellanomanchego simplifica considerablemente los estándares para los sectores residenciales, en primer lugar, porque no hace diferenciación alguna por el número de viviendas que tenga el sector.

\section{Datos recogidos}

No obstante, sí incluye alguna determinación novedosa, como es la regulación de estándares dotacionales también en suelo urbano no consolidado, algo que no es habitual en el resto de normativas estudiadas. El cuadro 6 muestra estos estándares.

CuAdro 6: Estándares dotacionales en suelo urbano no consolidado. Normativa urbanística de Castilla-La Mancha

\begin{tabular}{|l|l|}
\hline Densidad máxima & $10.000 \mathrm{~m}^{2}$ de edificación residencial/hectárea \\
\hline Zonas verdes públicas & $10 \%$ de la superficie si la edificabilidad lucrativa es menor o igual \\
& a $6.000 \mathrm{~m}^{2}$ construibles/hectárea \\
& $\begin{array}{l}18 \mathrm{~m}^{2} \mathrm{~s} / 100 \mathrm{~m}^{2} \text { de edificabilidad lucrativa si es mayor de } 6.000 \\
\mathrm{~m}^{2} \text { construibles/hectárea }\end{array}$ \\
\hline Equipamientos públicos & $20 \mathrm{~m}^{2} \mathrm{~s} / 100 \mathrm{~m}^{2}$ de edificabilidad lucrativa \\
\hline
\end{tabular}

Para establecer los sectores tipo de nuestro trabajo, emplearemos los estándares recogidos en el artículo 22 del Reglamento de Planeamiento de Castilla-La Mancha, correspondientes al suelo urbanizable. Dicho artículo los denomina «estándares de calidad» e incluye entre ellos la densidad máxima permitida (ver cuadro 7).

El límite de densidad se establece para la edificabilidad residencial, por lo que pueden añadirse otros usos de carácter privado al sector. Sin embargo, los estándares correspondientes a zonas verdes y equipamientos públicos se calculan en función de la edificabilidad lucrativa, por lo que todos los usos del sector (siempre que no sean públicos) se tienen en cuenta a la hora de establecer las reservas.

CuADro 7: Estándares dotacionales en suelo urbanizable de uso residencial. Normativa urbanística de Castilla-La Mancha

\begin{tabular}{|l|l|}
\hline Densidad máxima & $10.000 \mathrm{~m}^{2}$ de edificación residencial/hectárea \\
\hline Zonas verdes públicas & $10 \%$ de la superficie si la edificabilidad lucrativa es menor o igual \\
& a $6.000 \mathrm{~m}^{2}$ construibles/hectárea \\
& $18 \mathrm{~m}^{2} \mathrm{~s} / 100 \mathrm{~m}^{2}$ de edificabilidad lucrativa si es mayor de 6.000 \\
& $\mathrm{~m}^{2}$ construibles/hectárea \\
\hline Equipamientos públicos & $20 \mathrm{~m}^{2} \mathrm{~s} / 100 \mathrm{~m}^{2}$ de edificabilidad lucrativa \\
\hline
\end{tabular}

Vemos que el Reglamento castellanomanchego establece la edificabilidad a partir de la cual deja de aplicarse la cesión obligatoria del $10 \%$ de la superficie del sector y comienza a utilizarse el módulo de 18 $\mathrm{m}^{2}$ por vivienda: a partir de $6.000 \mathrm{~m}^{2}$ por hectárea o, lo que es lo mismo, a partir de una edificabilidad de $0,6 \mathrm{~m}^{2} \mathrm{t} / \mathrm{m}^{2} \mathrm{~s}$.

\section{Sectores tipo}

Para establecer los sectores tipo utilizaremos los criterios que ya hemos comentado:

\footnotetext{
${ }^{4}$ Nótese que la fecha de aprobación de esta Ley es posterior a la aprobación del Reglamento. Esto se debe a que se trata de un texto refundido que recoge una serie de modificaciones sobre la ley original, aprobada en el año 1998.
} 
- Consideramos que 1 vivienda equivale a $100 \mathrm{~m}^{2}$ edificables.

- Consideramos que toda la edificabilidad lucrativa del sector se destina a uso residencial.

Además, extenderemos los casos de densidad/edificabilidad hasta $1,00 \mathrm{~m}^{2} \mathrm{t} / \mathrm{m}^{2} \mathrm{~s}$, puesto que la normativa de Castilla-La Mancha permite alcanzar densidades máximas de hasta $10.000 \mathrm{~m}^{2}$ de edificación residencial por hectárea. El cuadro 8 muestra los datos obtenidos para sectores de 500 viviendas con distintas edificabilidades. En este caso no importa la cantidad de viviendas, puesto que los estándares dotacionales no dependen del número total de viviendas del sector.

Cuadro 8: Aplicación de estándares dotacionales a sectores tipo de uso residencial. Normativa urbanística de Castilla-La Mancha

\section{Sector de 500 viviendas}

\begin{tabular}{|c|c|c|c|c|c|c|}
\hline \multirow{2}{*}{$\begin{array}{l}\text { Edifica- } \\
\text { bilidad } \\
\left(\mathrm{m}^{2} \mathrm{t} / \mathrm{m}^{2} \mathrm{~s}\right)\end{array}$} & \multirow{2}{*}{$\begin{array}{c}\text { Superf. } \\
\text { del sector } \\
\left(\mathrm{m}^{2}\right)\end{array}$} & \multirow{2}{*}{$\begin{array}{c}\text { Espacios } \\
\text { libres } \\
\left(\mathrm{m}^{2}\right)\end{array}$} & \multirow{2}{*}{$\begin{array}{l}\text { Equipa- } \\
\text { mientos } \\
\left(\mathrm{m}^{2}\right)\end{array}$} & \multicolumn{2}{|c|}{ Dotaciones } & \multirow{2}{*}{$\begin{array}{c}\text { Edificab. } \\
\text { parcela } \\
\text { neta } \\
\left(\mathrm{m}^{2} \mathrm{t} / \mathrm{m}^{2} \mathrm{~s}\right)\end{array}$} \\
\hline & & & & $\begin{array}{c}\text { Ocupación } \\
\text { de suelo } \\
\text { (\% de sup.) }\end{array}$ & $\begin{array}{c}\text { Ratio } \\
\text { por vivda. } \\
\left(\mathrm{m}^{2} / \text { vivda. }\right)\end{array}$ & \\
\hline 0,15 & 333.333 & 33.333 & 10.000 & 13,00 & 86,67 & 0,19 \\
\hline 0,35 & 142.857 & 14.286 & 10.000 & 17,00 & 48,57 & 0,51 \\
\hline 0,55 & 90.909 & 9.091 & 10.000 & 21,00 & 38,18 & 0,96 \\
\hline 0,75 & 66.667 & 9.000 & 10.000 & 28,50 & 38,00 & 1,81 \\
\hline 0,85 & 58.824 & 9.000 & 10.000 & 32,30 & 38,00 & 2,52 \\
\hline 1,00 & 50.000 & 9.000 & 10.000 & 38,00 & 38,00 & 4,55 \\
\hline
\end{tabular}

Los datos sobre dotaciones obtenidos para Castilla-La Mancha son similares a los de sectores de hasta 500 viviendas que obtuvimos al tratar la normativa de Aragón (apartado 2.3). Así, los porcentajes de ocupación de la superficie del sector no son excesivos a pesar de que la edificabilidad máxima permitida es superior a los casos de Aragón y del Reglamento de Planeamiento de 1978 ya analizados. En el sector con mayor densidad de viviendas, las dotaciones no ocupan más del $38 \%$ de la superficie total ordenada. En este caso, las parcelas privadas deberán tener una edificabilidad media de al menos $4,55 \mathrm{~m}^{2} \mathrm{t} / \mathrm{m}^{2} \mathrm{~s}$, elevada pero materializable sin recurrir a edificaciones de gran altura.

Lógicamente, las gráficas sobre el porcentaje de ocupación de superficie del sector que ha de destinarse a espacios libres y equipamientos se simplifican igualmente, tal como muestran las figuras 5 y 6 .

\section{Normativa urbanística de Castilla y León}

Castilla y León fue la primera Comunidad Autónoma que desarrolló su legislación urbanística (Ley 5/1999, de 8 de abril, de Urbanismo de Castilla y León) a través de un Reglamento (Decreto 22/2004, de 29 enero, por el que se aprueba el Reglamento de Urbanismo de Castilla y León). Además, dentro de las normativas estudiadas, es una de las que presenta más novedades en relación con los estándares urbanísticos. Así, veremos que introduce límites mínimos de densidad; establece índices de variedad para los nuevos desarrollos, y distingue el nivel de equipamientos en función de la población del municipio, y no de las viviendas del sector, como hemos visto en casos anteriores.

\section{Datos recogidos}

En primer lugar, el Reglamento se preocupa de definir los conceptos empleados, estableciendo de paso una estructura clara relativa a las dotaciones urbanísticas, definidas éstas en la Disposición Adicional Única Conceptos del Decreto 22/2004, de 29 enero, por el que se aprueba el Reglamento de Urbanismo de Castilla y León como el «conjunto de los sistemas y elementos que se caracterizan por estar destinados al servicio de la población», que pueden ser de cuatro tipos distintos: vías públicas, servicios urbanos, espacios libres públicos y equipamientos.

Otra novedad de la normativa castellanoleonesa es que a los ya clásicos $5 \mathrm{~m}^{2}$ de sistema general de zonas verdes por habitante que establecía la Ley de 1976, se añaden $5 \mathrm{~m}^{2}$ más destinados a equipamientos, también con la consideración de sistemas generales. Entre las normativas estudiadas, ésta es la única que establece un estándar mínimo de sistema general para equipamientos. 


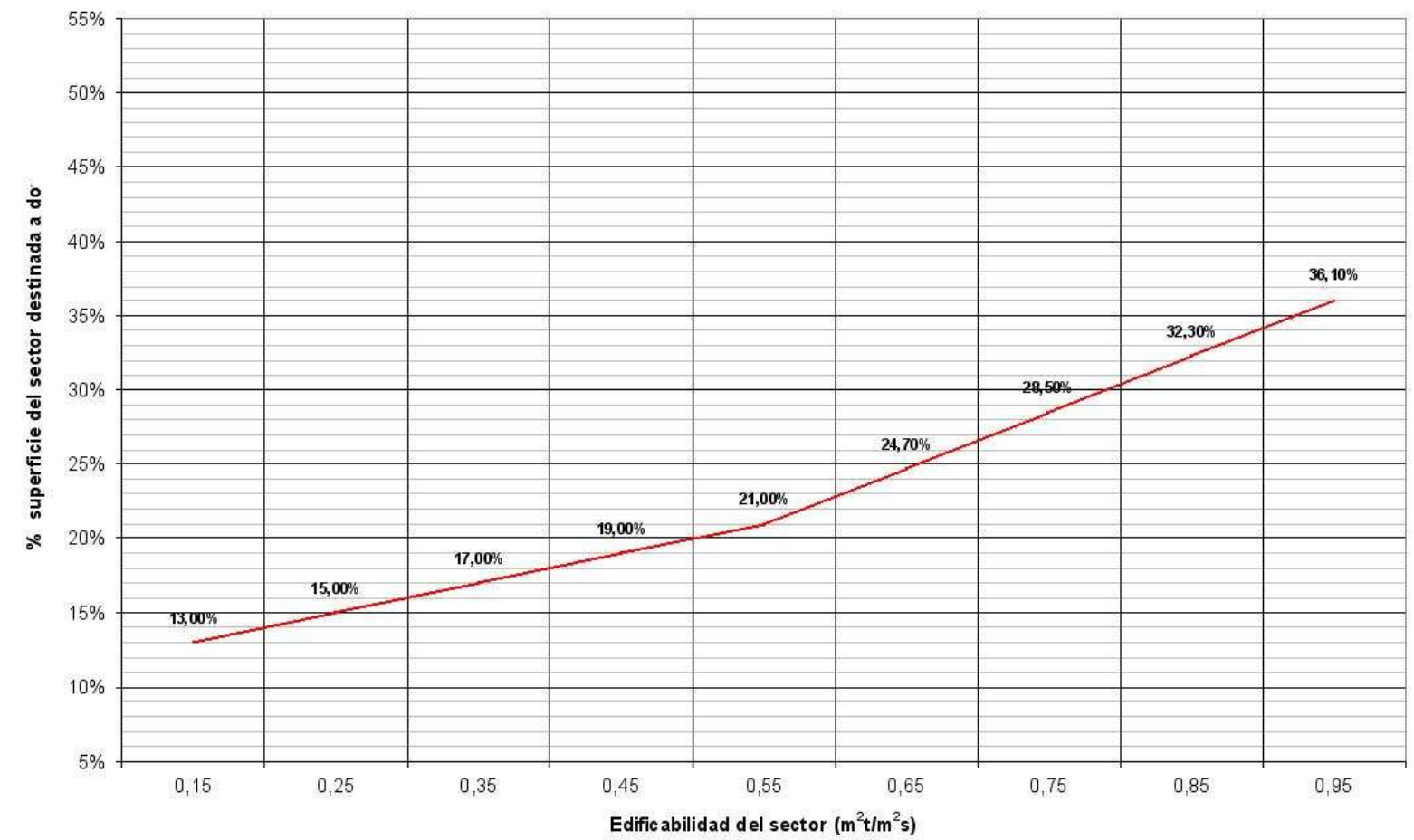

Figura 5: Superficie ocupada (\%) por las dotaciones en sectores tipo de uso residencial. Normativa urbanística de Castilla-La Mancha

Elaboración propia 


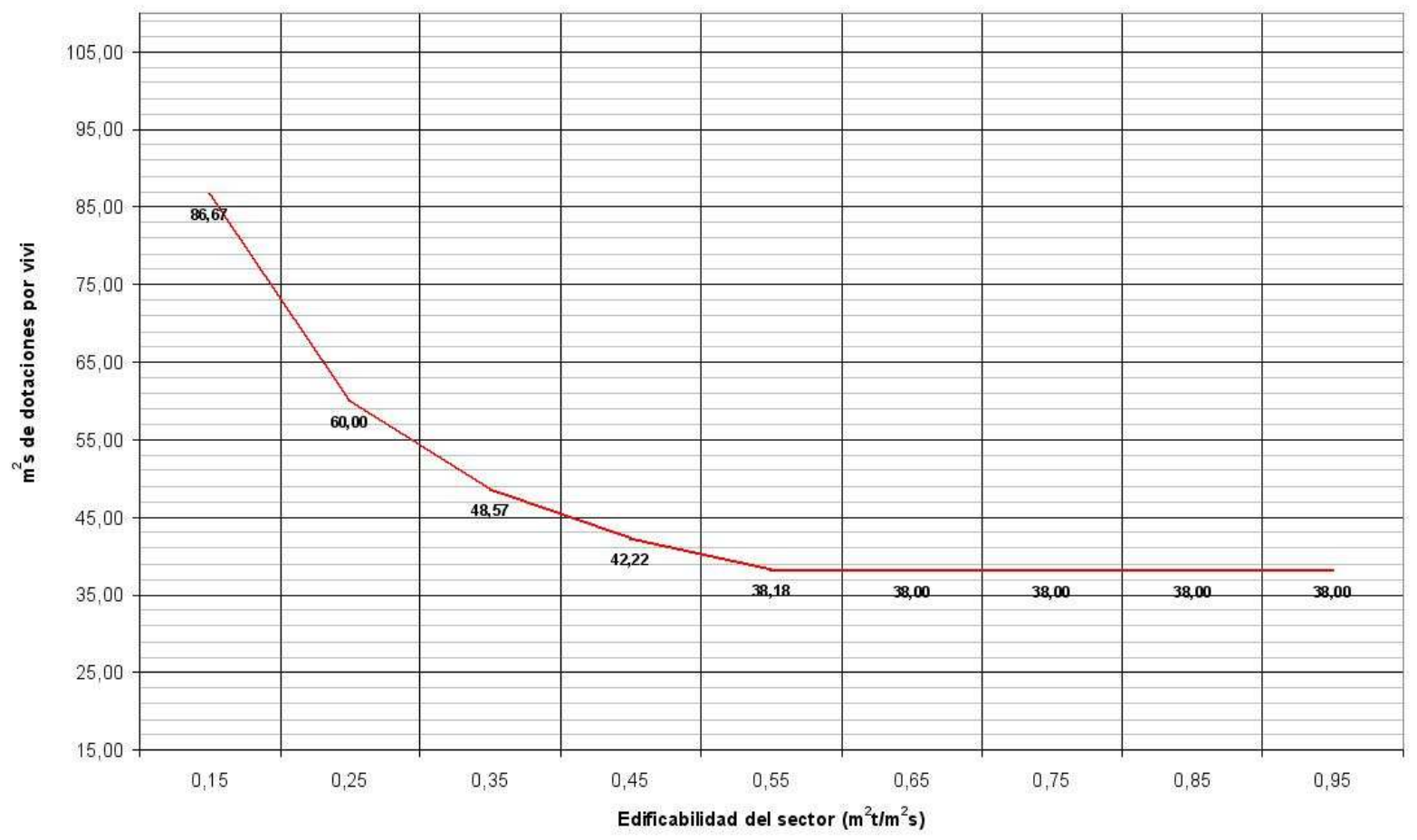

Figura 6: Dotaciones por vivienda en sectores tipo de uso residencial. Normativa urbanística de Castilla-La Mancha

Elaboración propia 


\section{Densidad}

El Reglamento de Castilla y León establece límites máximos y mínimos para la edificabilidad y la $\operatorname{densidad}^{5}$, que se modulan dependiendo de los siguientes factores:

- Del instrumento de planeamiento utilizado por el municipio para establecer la ordenación urbanística. Puede tratarse de un plan general de ordenación urbana (PGOU), obligatorio para todos los municipios con más de 20.000 habitantes, aunque también pueden elaborarlo municipios de menor tamaño (en estos casos es potestativo); o puede tratarse de normas urbanísticas municipales (NUM), instrumento de ordenación obligatorio para el resto de municipios.

- De la población del municipio en el caso de que tenga un PGOU como instrumento de ordenación: se permiten mayores densidades para los municipios de población superior a 20.000 habitantes.

El cuadro 9 recoge los valores asignados por la normativa a cada uno de estos casos.

\section{CuADro 9: Intensidades reguladas por la normativa urbanística de Castilla y León}

\begin{tabular}{|l|r|r|r|}
\hline & \multicolumn{2}{|c|}{ PGOU } & \multicolumn{1}{c|}{ NUM } \\
\hline \hline $\begin{array}{l}\text { Edificabilidad máxima } \\
\text { de usos privados }\end{array}$ & $>20.000$ habitantes & $10.000 \mathrm{~m}^{2} / \mathrm{ha}$ & $5.000 \mathrm{~m}^{2} / \mathrm{ha}$ \\
\hline & $<20.000$ habitantes & $7.500 \mathrm{~m}^{2} / \mathrm{ha}$ & $5.000 \mathrm{~m}^{2} / \mathrm{ha}$ \\
\hline \hline $\begin{array}{l}\text { Densidad máxima de } \\
\text { viviendas }\end{array}$ & $>20.000$ habitantes & $70 \mathrm{viv} / \mathrm{ha}$ & $30 \mathrm{viv} / \mathrm{ha}$ \\
\hline & $<20.000$ habitantes & $50 \mathrm{viv} / \mathrm{ha}$ & $30 \mathrm{viv} \cdot / \mathrm{ha}$ \\
\hline \hline $\begin{array}{l}\text { Densidad mínima de } \\
\text { viviendas }\end{array}$ & $>20.000$ habitantes & $40 \mathrm{viv} / \mathrm{ha}$ & $20 \mathrm{viv} / \mathrm{ha}$ \\
\hline & $<20.000$ habitantes & $20 \mathrm{viv} \cdot / \mathrm{ha}$ & $20 \mathrm{viv} \cdot / \mathrm{ha}$ \\
\hline
\end{tabular}

Estos límites se establecen tanto para suelo urbanizable como para suelo urbano no consolidado, ya que la normativa de Castilla y León considera que también puede haber zonas de suelo urbano susceptibles de plantear nuevos desarrollos, zonas a las que también aplica los estándares de densidad (también los dotacionales, como veremos más adelante).

La normativa castellanoleonesa ha sido la primera en introducir densidades y edificabilidades mínimas, además de las máximas. De esta forma, restringe considerablemente el tamaño de los nuevos desarrollos, como muestra la figura 7. Se aprecia cómo las zonas de baja densidad (menos de 30 viviendas por hectárea) están prohibidas en las ciudades (poblaciones de más de 20.000 habitantes), mientras que las densidades altas están restringidas para las poblaciones menores. Sorprende la escasa flexibilidad dada a los sectores en municipios con NUM, que sólo pueden establecer densidades entre 20 y 30 viviendas por hectárea.

\section{Índices de variedad e integración}

Antes de abordar los estándares dotacionales, merece la pena comentar los nuevos estándares sobre variedad introducidos por el Reglamento de Castilla y León. El cuadro 10 resume las determinaciones relativas a estos estándares. Como vemos, sólo se aplican en los municipios cuya ordenación se establece a través de un PGOU, es decir, a los de mayor tamaño.

Los tres índices se definen en el artículo 86 del Reglamento de Urbanismo de Castilla y León de la siguiente manera:

Índice de variedad de uso, que expresa el porcentaje de aprovechamiento del sector que debe destinarse a usos compatibles con el predominante, entre los cuales puede incluirse la edificación de viviendas con protección pública.

Índice de variedad tipológica, que expresa el porcentaje de aprovechamiento del sector que debe destinarse a tipologías edificatorias diferentes de la predominante.

Índice de integración social, que expresa el porcentaje de aprovechamiento de cada sector con uso predominante residencial que debe destinarse a la construcción de viviendas con protección pública.

\footnotetext{
${ }^{5}$ Las determinaciones relativas a la densidad han variado ligeramente debido a la modificación del Reglamento de Urbanismo en octubre de 2006 (Decreto 68/2006, de 5 de octubre, por el que se modifica el Decreto 22/2004, de 29 de enero, por el que se aprueba el Reglamento de Urbanismo de Castilla y León). Esta modificación rebaja la densidad mínima en los municipios con NUM de 20 a 15 viviendas por hectárea. Debido a que al inicio del trabajo no estaba aprobada esta modificación, no se ha recogido este cambio.
} 


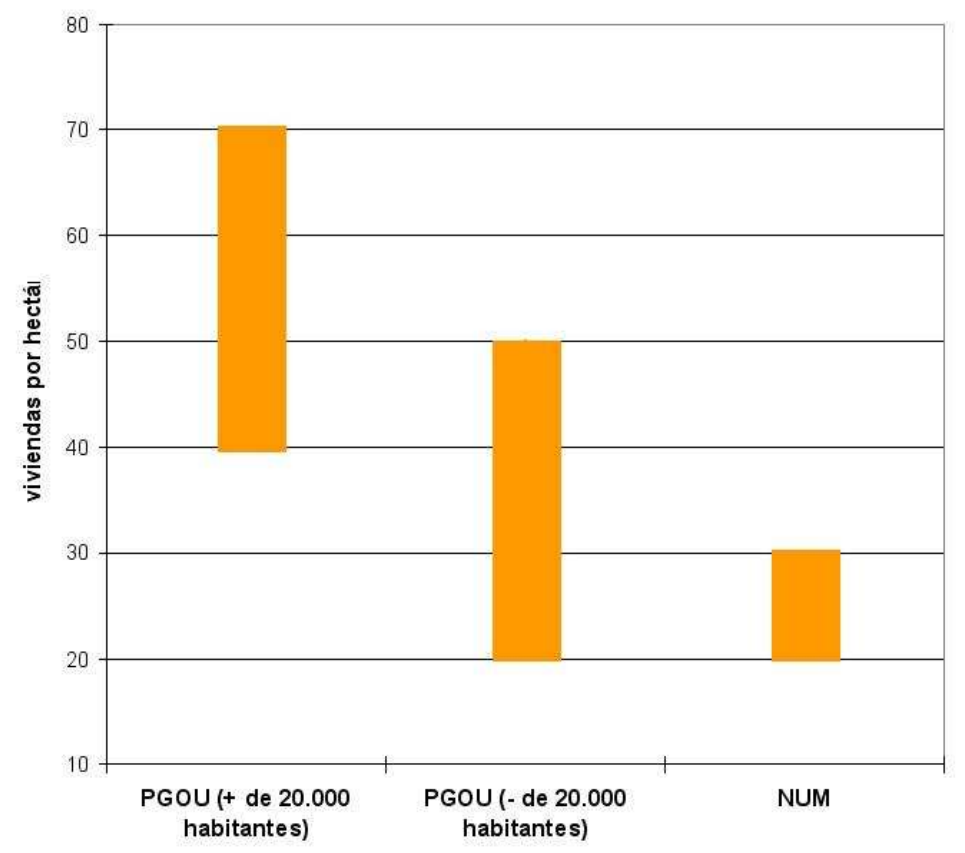

Figura 7: Densidad de viviendas permitida en sectores residenciales. Normativa urbanística de Castilla y León

Elaboración propia

CuADro 10: Índices de variedad e integración. Normativa urbanística de Castilla y León

\begin{tabular}{|l|c|c|c|}
\hline & \multicolumn{2}{|c|}{ PGOU } & NUM \\
\hline & $\begin{array}{l}\text { Suelo urbano no } \\
\text { consolidado }\end{array}$ & $\begin{array}{l}\text { Suelo urbaniza- } \\
\text { ble delimitado }\end{array}$ & \\
\hline \hline $\begin{array}{l}\text { Índice de variedad } \\
\text { de uso }\end{array}$ & $10 \%$ & $20 \%$ & - \\
\hline $\begin{array}{l}\text { Indice de variedad } \\
\text { tipológica }\end{array}$ & - & $20 \%$ & - \\
\hline $\begin{array}{l}\text { Indice de integra- } \\
\text { ción social }\end{array}$ & - & $10 \%$ & - \\
\hline
\end{tabular}


El objetivo del Reglamento en este caso es que los nuevos desarrollos residenciales contengan una cierta diversidad de usos, tipologías y grupos sociales; con mayor exigencia para el suelo urbanizable que para el suelo urbano no consolidado. Se trata de una cuestión novedosa e interesante, que abre un camino para la recuperación de la diversidad urbana y trata de reducir la separación de funciones en la ciudad.

\section{Dotaciones}

Las cesiones para espacios libres y equipamientos que deben realizar los sectores (tanto en suelo urbano no consolidado como en suelo urbanizable delimitado) se resumen en el cuadro 11. Vemos que las dotaciones varían dependiendo del instrumento de planeamiento utilizado para la ordenación general del municipio: se reducen las obligaciones para los municipios de menor tamaño, que son los que habitualmente disponen de NUM.

CUADRO 11: Estándares dotacionales en sectores de uso residencial. Normativa urbanística de Castilla y León

\begin{tabular}{|c|c|c|c|c|}
\hline & \multicolumn{2}{|c|}{ PGOU } & \multicolumn{2}{|c|}{ PGOU } \\
\hline $\begin{array}{l}\text { Espacios } \\
\text { libres } \\
\text { públicos }\end{array}$ & $\begin{array}{l}\text { Suelo urbano } \\
\text { no consolidado } \\
\text { Suelo urbanizable } \\
\text { delimitado }\end{array}$ & $\begin{array}{l}15 \mathrm{~m}^{2} / 100 \mathrm{~m}^{2} \mathrm{e}\left(^{*}\right) \\
20 \mathrm{~m}^{2} / 100 \mathrm{~m}^{2} \mathrm{e}\left(^{*}\right) \\
\text { Mínimo } 10 \% \text { sup. }\end{array}$ & $\begin{array}{l}\text { Suelo urbano } \\
\text { no consolidado } \\
\text { Suelo urbanizable } \\
\text { delimitado }\end{array}$ & $\begin{array}{l}10 \mathrm{~m}^{2} / 100 \mathrm{~m}^{2} \mathrm{e}\left(^{*}\right) \\
20 \mathrm{~m}^{2} / 100 \mathrm{~m}^{2} \mathrm{e}\left(^{*}\right) \\
\text { Mínimo } 5 \% \text { sup. }\end{array}$ \\
\hline $\begin{array}{l}\text { Equipa- } \\
\text { mientos }\end{array}$ & $\begin{array}{l}\text { Suelo urbano } \\
\text { no consolidado } \\
\text { Suelo urbanizable } \\
\text { delimitado }\end{array}$ & $\begin{array}{l}15 \mathrm{~m}^{2} / 100 \mathrm{~m}^{2} \mathrm{e}\left(^{*}\right) \\
20 \mathrm{~m}^{2} / 100 \mathrm{~m}^{2} \mathrm{e}\left(^{*}\right) \\
\text { Mínimo } 5 \% \text { sup. }\end{array}$ & $\begin{array}{l}\text { Suelo urbano } \\
\text { no consolidado } \\
\text { Suelo urbanizable } \\
\text { delimitado }\end{array}$ & $\begin{array}{l}10 \mathrm{~m}^{2} / 100 \mathrm{~m}^{2} \mathrm{e}\left(^{*}\right) \\
20 \mathrm{~m}^{2} / 100 \mathrm{~m}^{2} \mathrm{e}\left(^{*}\right) \\
\text { Mínimo } 5 \% \text { sup. }\end{array}$ \\
\hline
\end{tabular}

$\left(^{*}\right) \mathrm{m}^{2} \mathrm{e}=$ metros cuadrados edificables en el uso predominante

Podemos ver que se han simplificado los estándares dotacionales, reduciéndolos a espacios libres públicos y equipamientos. En el caso de los equipamientos, el Reglamento permite que sean privados y, aún así, cuenten para cumplir el estándar mínimo. No obstante, limita esta posibilidad al $50 \%$ del total de la superficie de dichos equipamientos.

También es significativo que se establezcan porcentajes mínimos sobre la superficie del sector para el caso de los equipamientos, de tal forma que se asegure una mínima cantidad, como ya se hace para los espacios libres en la mayoría de las normativas que estamos analizando.

\section{Sectores tipo}

Este Reglamento establece la edificabilidad «en el uso predominante» como referencia para el cálculo de las cesiones dotacionales, por lo que, en principio, puede hacer referencia a usos distintos del residencial. En la hipótesis que venimos adoptando para homogeneizar los datos de las diferentes normativas, el uso predominante es el residencial, y consideramos que toda la edificabilidad del sector se distribuye en viviendas tipo de $100 \mathrm{~m}^{2}$ construidos. El cuadro 12 recoge los datos obtenidos para los sectores tipo que, en este caso, se diferencian por el instrumento de planeamiento general (PGOU o NUM) del municipio. Sólo se estudia el suelo urbanizable, dejando el suelo urbano no consolidado, puesto que no es objeto de este trabajo.

Tampoco hemos tenido en cuenta el índice de variedad de uso, que en nuestra hipótesis obligaría a que se destinase el $20 \%$ del aprovechamiento a usos distintos del residencial (en el caso de sectores en un municipio con PGOU). El resto de índices (variedad tipológica e integración social) pueden cumplirse sin apartarse del uso residencial, por lo que no afecta a la hipótesis adoptada.

Los límites de edificabilidad privada que también establece la normativa castellano-leonesa no afectan a los cálculos hechos, pues estos límites son superiores en todos los casos a los límites de densidad de viviendas. Tampoco hay variación de los estándares dispuestos en función del número de viviendas del sector, por lo que en este caso se ha adoptado una cantidad de viviendas cualquiera.

Con los datos de los sectores tipo se pueden establecer las gráficas de porcentaje de superficie del sector ocupada. Se han tenido en cuenta las densidades de vivienda permitidas para limitar los sectores tipo de 
CuAdro 12: Aplicación de estándares dotacionales a sectores tipo de uso residencial. Normativa urbanística de Castilla y León

Sector de 1.000 viviendas en un municipio con PGOU

\begin{tabular}{|c|c|c|c|c|c|c|}
\hline Edifica- & Superf. & Espacios & Equipa- & Dota & iones & lificab. \\
\hline $\begin{array}{l}\text { bilidad } \\
\left(\mathrm{m}^{2} \mathrm{t} / \mathrm{m}^{2} \mathrm{~s}\right)\end{array}$ & $\begin{array}{l}\text { del sector } \\
\qquad\left(\mathrm{m}^{2}\right)\end{array}$ & $\begin{array}{l}\text { libres } \\
\left(\mathrm{m}^{2}\right)\end{array}$ & $\begin{array}{l}\text { mientos } \\
\left(\mathrm{m}^{2}\right)\end{array}$ & $\begin{array}{c}\text { Ocupación } \\
\text { de suelo } \\
\text { (\% de sup.) }\end{array}$ & $\begin{array}{c}\text { Ratio } \\
\text { por vivda. } \\
\left(\mathrm{m}^{2} / \text { vivda. }\right)\end{array}$ & $\begin{array}{c}\text { parcela } \\
\text { neta } \\
\left(\mathrm{m}^{2} \mathrm{t} / \mathrm{m}^{2} \mathrm{~s}\right)\end{array}$ \\
\hline 0,20 & 500.000 & 50.000 & 25.000 & 15,00 & 75,00 & 0,26 \\
\hline 0,30 & 333.333 & 33.333 & 20.000 & 16,00 & 53,33 & 0,42 \\
\hline 0,45 & 222.222 & 22.222 & 20.000 & 19,00 & 42,22 & 0,71 \\
\hline 0,55 & 181.818 & 20.000 & 20.000 & 22,00 & 40,00 & 0,98 \\
\hline 0,70 & 142.857 & 20.000 & 20.000 & 28,00 & 40,00 & 1,59 \\
\hline
\end{tabular}

Sector de 1.000 viviendas en un municipio con NUM

\begin{tabular}{|c|c|c|c|c|c|c|}
\hline Ed & iperf. & Espacios & Equipa- & Dota & iones & cab. \\
\hline $\begin{array}{l}\text { bilidad } \\
\left(\mathrm{m}^{2} \mathrm{t} / \mathrm{m}^{2} \mathrm{~s}\right)\end{array}$ & $\begin{array}{c}\text { del sector } \\
\qquad\left(\mathrm{m}^{2}\right)\end{array}$ & $\begin{array}{l}\text { libres } \\
\left(\mathrm{m}^{2}\right)\end{array}$ & $\begin{array}{c}\text { mientos } \\
\left(\mathrm{m}^{2}\right)\end{array}$ & $\begin{array}{c}\text { Ocupación } \\
\text { de suelo } \\
\text { (\% de sup.) }\end{array}$ & $\begin{array}{c}\text { Ratio } \\
\text { por vivda. } \\
\left.\text { ( } \mathrm{m}^{2} / \text { vivda. }\right)\end{array}$ & $\begin{array}{c}\text { parcela } \\
\text { neta } \\
\left(\mathrm{m}^{2} \mathrm{t} / \mathrm{m}^{2} \mathrm{~s}\right)\end{array}$ \\
\hline 0,20 & 500.000 & 25.000 & 25.000 & 10,00 & 50,00 & 0,24 \\
\hline 0,25 & 400.000 & 20.000 & 20.000 & 10,00 & 40,00 & 0,31 \\
\hline 0,30 & 333.333 & 16.667 & 20.000 & 11,00 & 36,67 & 0,39 \\
\hline
\end{tabular}

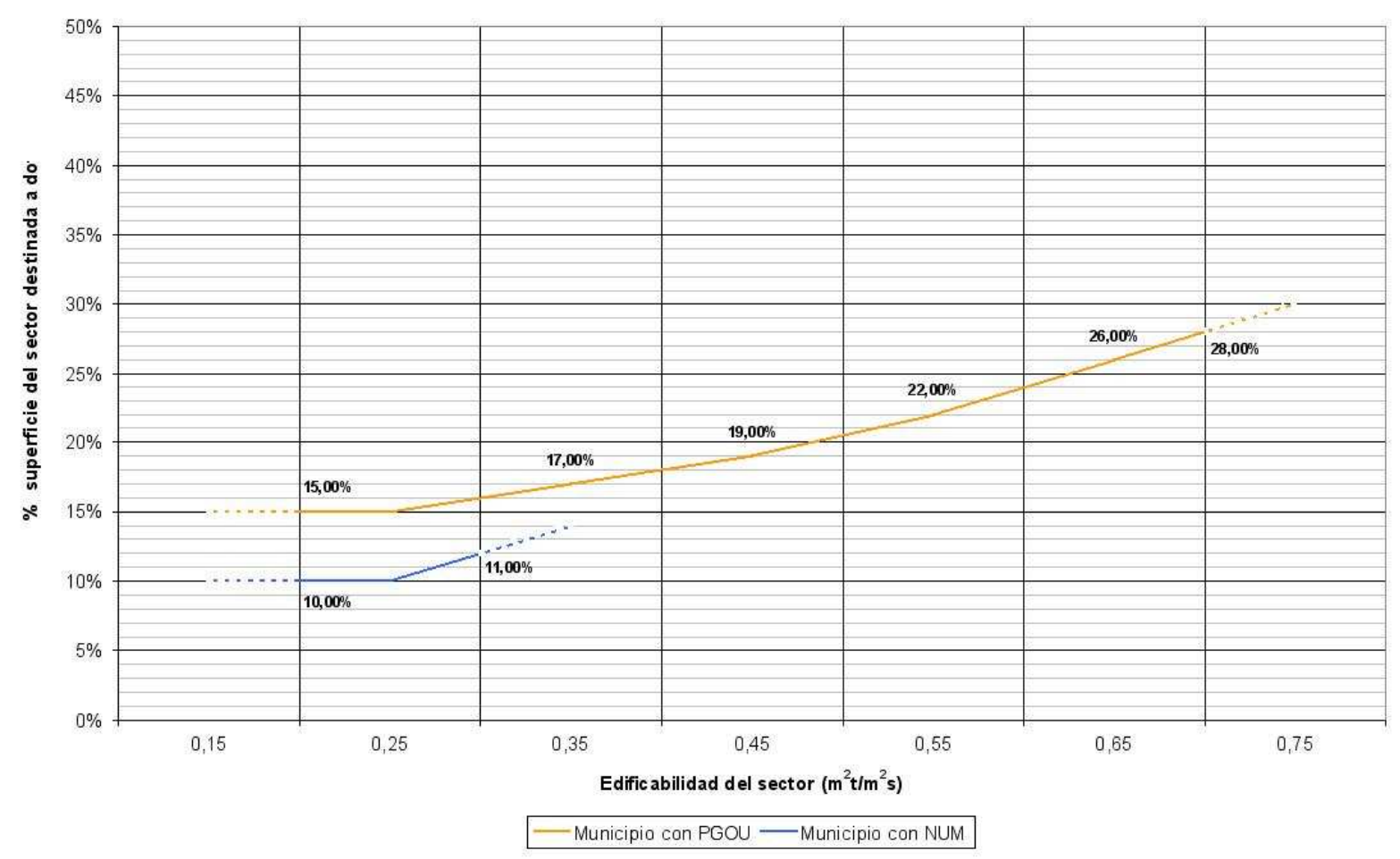

FIGURA 8: Superficie ocupada (\%) por las dotaciones en sectores tipo de uso residencial. Normativa urbanística de Castilla y León 
cada caso, si bien, se ha ampliado el rango de edificabilidades en 0,5 $\mathrm{m}^{2} \mathrm{t} / \mathrm{m}^{2} \mathrm{~s}$ para poder comparar los datos resultantes con las otras normativas, en las que estamos empleando valores múltiplos de cinco. Así se recoge en las figuras 8 y 9 .

Los porcentajes de ocupación del suelo resultan moderados en los dos casos, pues no exceden del $30 \%$ (con las densidades permitidas) y tampoco bajan del 10\%, lo que se debe probablemente a que la densidad máxima está muy limitada, sobre todo para los municipios con NUM. Por este motivo, la edificabilidad media sobre parcela privada no resulta en ningún caso excesiva, tal como vemos en el cuadro 12.

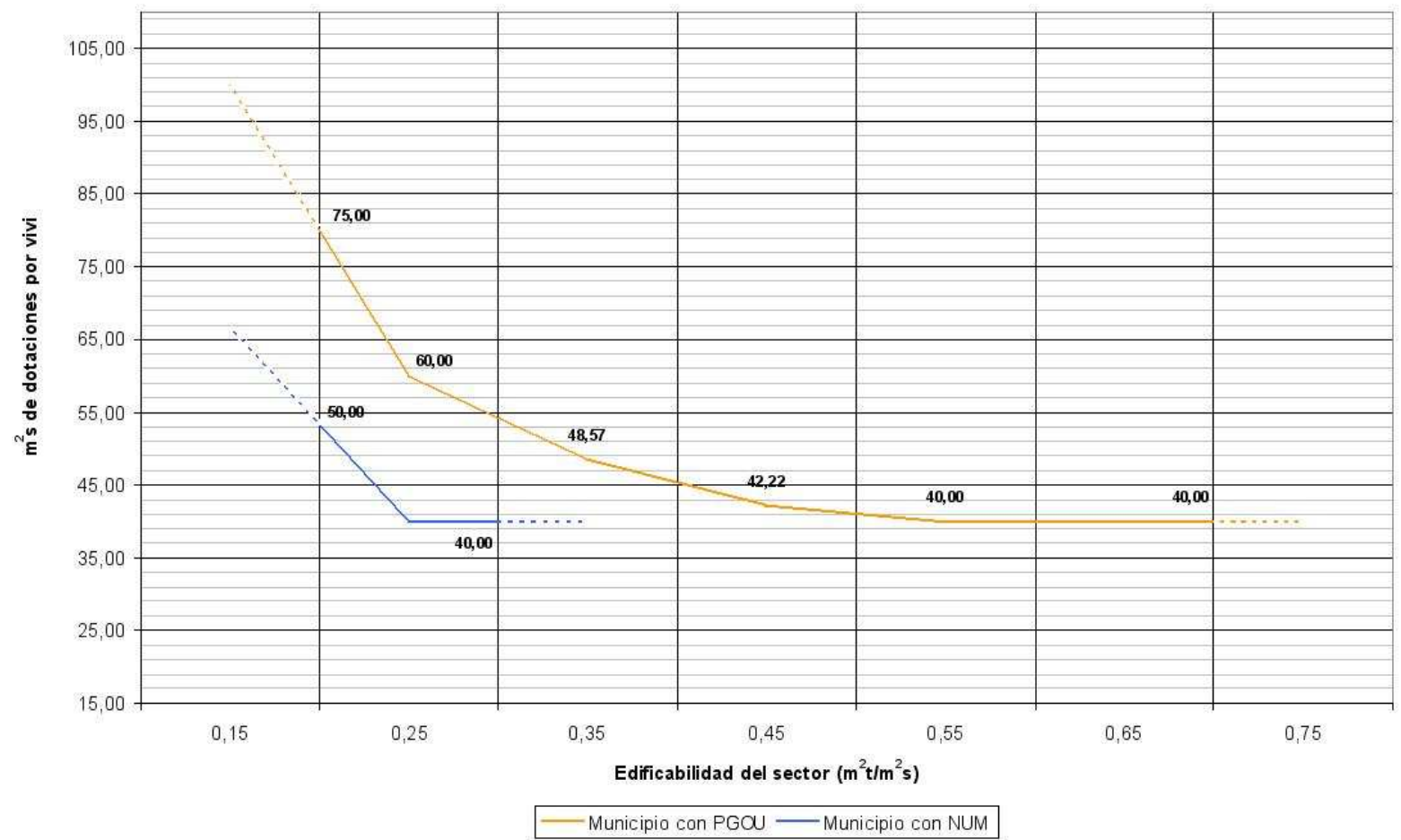

FIgura 9: Dotaciones por vivienda en sectores tipo de uso residencial. Normativa urbanística de Castilla y León

Elaboración propia

\section{Normativa urbanística de Cataluña}

La Comunidad Autónoma de Cataluña ha aprobado recientemente un reglamento (Decreto 305/2006, de 18 de julio, por el que se aprueba el Reglamento de la Ley de Urbanismo) que desarrolla la ley de urbanismo (Decreto Legislativo 1/2005, de 26 de julio, por el que se aprueba el Texto Refundido de la Ley de Urbanismo) vigente, que también fue reformada poco antes. Se ha incluido Cataluña en el presente estudio por contar con desarrollo reglamentario de las determinaciones de la Ley. Sin embargo, una vez analizado, vemos que el Reglamento no aporta nada nuevo al tema de los estándares, sino que se remite a los señalados en la Ley, ya de por sí escasos. No obstante, utilizaremos los datos hallados para el presente trabajo, aunque este apartado será necesariamente breve.

\section{Datos recogidos}

\section{Densidad}

La Ley fija una densidad máxima de 100 viviendas por hectárea en suelo urbanizable, utilizando la misma unidad de medida que empleaba la legislación estatal de 1976, las viviendas por hectárea, aunque el tope máximo ha aumentado. 
En suelo urbanizable delimitado, los planes de ordenación urbanística municipal concretan la delimitación de los sectores, que pueden ser físicamente discontinuos, y, para cada uno de éstos, [.. . l la densidad máxima, que no puede superar en ningún caso las cien viviendas por hectárea; [...].

Reglamento de la Ley de Urbanismo de Cataluña, art. 58.7

\section{Dotaciones}

Como hemos dicho, la Ley es bastante escueta en la regulación de estándares dotacionales. En el cuadro 13 se resumen las dotaciones mínimas de los sectores residenciales en suelo urbanizable, a partir de las determinaciones del artículo 65.3 de la ley catalana de urbanismo.

CUADRO 13: Estándares dotacionales en sectores de uso residencial. Normativa urbanística de Cataluña

\begin{tabular}{|l|l|}
\hline $\begin{array}{l}\text { Zonas verdes y espacios libres } \\
\text { públicos }\end{array}$ & $\begin{array}{l}\text { Mínimo } 10 \% \text { de la superficie } \\
\text { ó } 20 \mathrm{~m}^{2} \mathrm{~s} / 100 \mathrm{~m}^{2} \text { de techo edificable }\end{array}$ \\
\hline Equipamientos comunitarios & Mínimo $5 \%$ de la superficie \\
& ó $20 \mathrm{~m}^{2} \mathrm{~s} / 100 \mathrm{~m}^{2}$ de techo edificable \\
\hline
\end{tabular}

En este caso, las dotaciones dependen de toda la edificabilidad, independientemente de si tiene uso residencial o no. También es importante señalar que la Ley permite que los equipamientos comunitarios se destinen a uso de viviendas públicas, por lo que puede darse el caso de que el espacio destinado a equipamientos al servicio de la población se convierta en la práctica en más viviendas. No obstante, no tendremos en cuenta esta posibilidad para calcular los sectores tipo.

[... ] El planeamiento urbanístico general, en el caso de que prevea el sistema urbanístico de viviendas dotacionales públicas, puede determinar que esta reserva de $20 \mathrm{~m}^{2}$ por cada $100 \mathrm{~m}^{2}$ de techo edificable para equipamientos de titularidad pública se destine, en determinados sectores, totalmente o parcialmente al sistema urbanístico de viviendas dotacionales públicas $[\ldots]$

Reglamento de la Ley de Urbanismo de Cataluña, art. 65.3

\section{Sectores tipo}

A partir de las dotaciones establecidas por la normativa, podemos extraer los sectores tipo (cuadro 14). Debido a que la densidad residencial permitida se eleva hasta 100 viviendas por hectárea, las edificabilidades de los sectores tipo se amplían hasta $1,00 \mathrm{~m}^{2} \mathrm{t} / \mathrm{m}^{2} \mathrm{~s}$. En este caso, se han calculado los sectores considerando que albergan 500 viviendas, si bien este dato no influye en los datos de ocupación de suelo por parte de las dotaciones, ni en el ratio de dotaciones por vivienda.

Con estas mínimas determinaciones y adoptando criterios iguales a los de las normativas ya estudiadas, las gráficas de ocupación de suelo y de cesiones por viviendas resultan considerablemente simples (ver figuras 10 y 11).

Los porcentajes de ocupación de la superficie del sector por parte de las dotaciones no parecen suponer demasiados problemas para la ordenación, salvo en los casos de edificabilidades más elevadas. Un sector con una edificabilidad de $1,00 \mathrm{~m}^{2} \mathrm{t} / \mathrm{m}^{2} \mathrm{~s}$, destinado a uso residencial, obligaría a que la edificabilidad media de las parcelas privadas alcance $5,00 \mathrm{~m}^{2} \mathrm{t} / \mathrm{m}^{2} \mathrm{~s}$.

Respecto a las dotaciones por vivienda, se produce el ya habitual desequilibrio en los sectores de baja densidad. La figura 11 muestra que para un sector con una edificabilidad de $0,15 \mathrm{~m}^{2} \mathrm{t} / \mathrm{m}^{2} \mathrm{~s}$, habrá hasta $100 \mathrm{~m}^{2}$ de dotaciones por vivienda. Resultan cifras superiores debido a que la normativa de Cataluña establece un porcentaje mínimo también para los equipamientos.

\section{Normativa urbanística de Navarra}

Navarra fue una de las primeras comunidades autónomas que elaboraron legislación propia para sustituir a la estatal, en el año 1994. La legislación urbanística de Navarra ha sido renovada recientemente con la aprobación de una nueva ley de urbanismo (Ley foral 35/2002, de 20 de diciembre, de Ordenación del Territorio y Urbanismo) que ha sustituido a la legislación anterior (Ley foral 10/1994, de 4 de julio, 
Cuadro 14: Aplicación de estándares dotacionales a sectores tipo de uso residencial. Normativa urbanística de Cataluña

Sector de 500 viviendas

\begin{tabular}{|c|c|c|c|c|c|c|}
\hline \multirow{2}{*}{$\begin{array}{l}\text { Edifica- } \\
\text { bilidad } \\
\left(\mathrm{m}^{2} \mathrm{t} / \mathrm{m}^{2} \mathrm{~s}\right)\end{array}$} & \multirow{2}{*}{$\begin{array}{c}\text { Superf. } \\
\text { del sector } \\
\left(\mathrm{m}^{2}\right)\end{array}$} & \multirow{2}{*}{$\begin{array}{c}\text { Espacios } \\
\text { libres } \\
\left(\mathrm{m}^{2}\right)\end{array}$} & \multirow{2}{*}{$\begin{array}{l}\text { Equipa- } \\
\text { mientos } \\
\left(\mathrm{m}^{2}\right)\end{array}$} & \multicolumn{2}{|c|}{ Dotaciones } & \multirow{2}{*}{$\begin{array}{c}\text { Edificab. } \\
\text { parcela } \\
\text { neta } \\
\left(\mathrm{m}^{2} \mathrm{t} / \mathrm{m}^{2} \mathrm{~s}\right)\end{array}$} \\
\hline & & & & $\begin{array}{l}\text { Ocupación } \\
\text { de suelo } \\
\text { ( \% de sup.) }\end{array}$ & $\begin{array}{c}\text { Ratio } \\
\text { por vivda. } \\
\left(\mathrm{m}^{2} / \text { vivda. }\right)\end{array}$ & \\
\hline 0,15 & 333.333 & 33.333 & 16.667 & 15,00 & 100,00 & 0,19 \\
\hline 0,35 & 142.857 & 14.286 & 10.000 & 17,00 & 48,57 & 0,51 \\
\hline 0,55 & 90.909 & 10.000 & 10.000 & 22,00 & 40,00 & 0,98 \\
\hline 0,75 & 66.667 & 10.000 & 10.000 & 30,00 & 40,00 & 1,88 \\
\hline 0,85 & 58.824 & 10.000 & 10.000 & 34,00 & 40,00 & 2,66 \\
\hline 1,00 & 50.000 & 10.000 & 10.000 & 40,00 & 40,00 & 5,00 \\
\hline
\end{tabular}

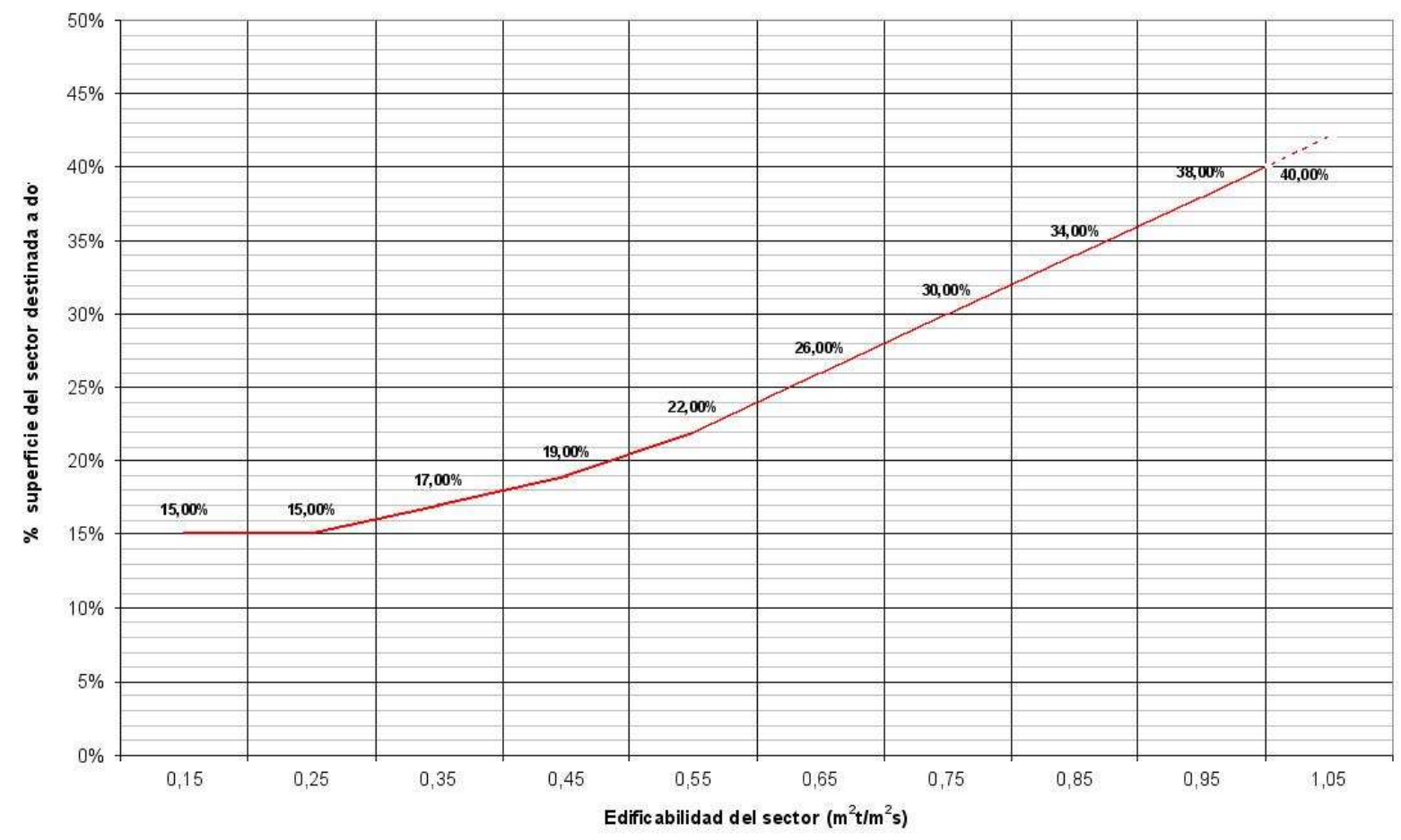

FIgURA 10: Superficie ocupada (\%) por las dotaciones en sectores tipo de uso residencial. Normativa urbanística de Cataluña 


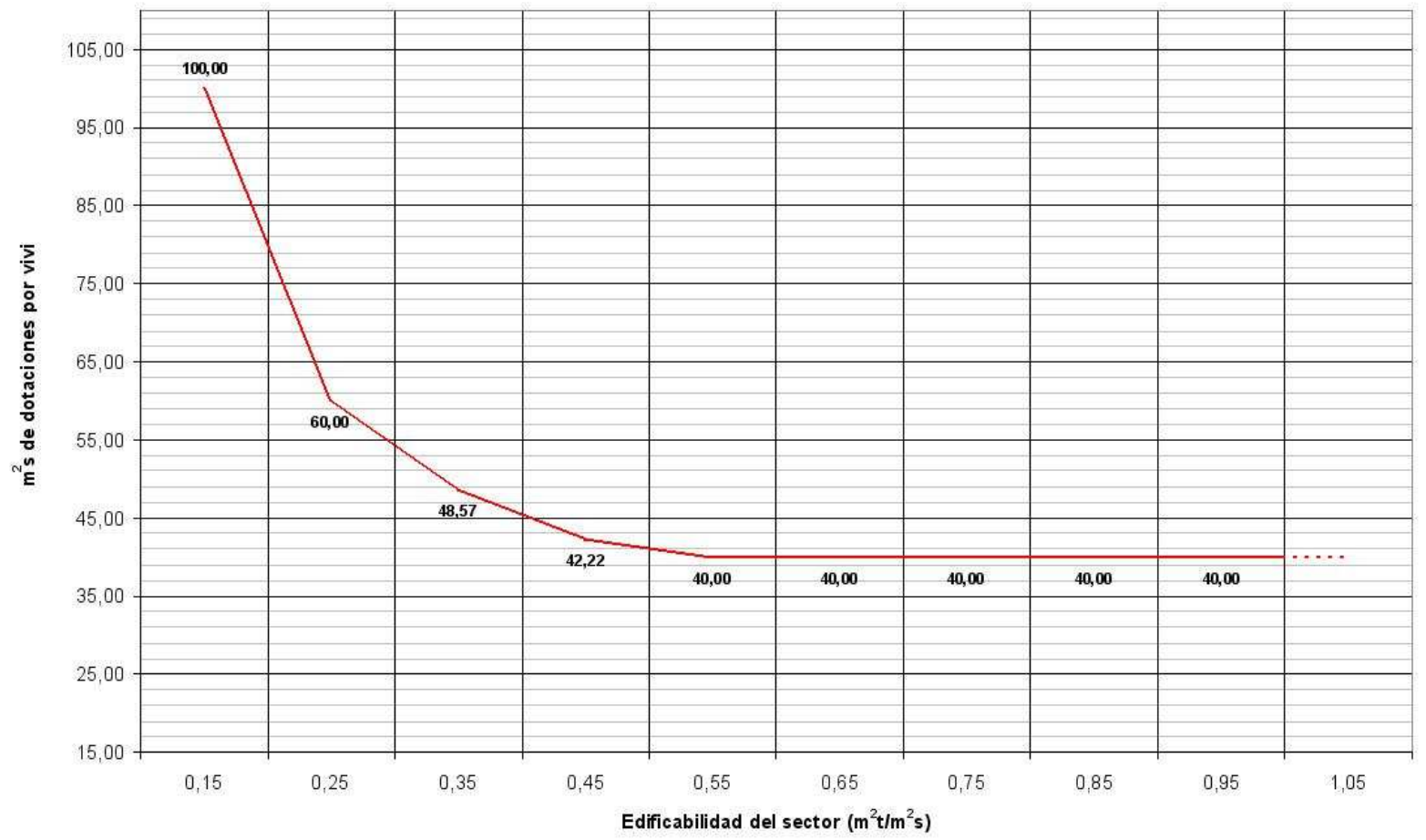

Figura 11: Dotaciones por vivienda en sectores tipo de uso residencial. Normativa urbanística de Cataluña

Elaboración propia 
de Ordenación del Territorio y Urbanismo). La actual ley no ha sido desarrollada reglamentariamente, mientras que la ley anterior contaba con un Reglamento (Decreto foral 85/1995, de 3 de abril, por el que se aprueba el Reglamento de Desarrollo de la Ley Foral 10/1994, de 4 de julio, de Ordenación del Territorio y Urbanismo) que establecía un considerable abanico de estándares, sobre todo dotacionales. Por tanto, vamos a estudiar una normativa que en su mayor parte no está en vigor, pero que tal vez por esa razón resulte interesante analizar algunas de sus determinaciones y aventurar algunos de los motivos que causaron su sustitución.

El Reglamento de desarrollo de la Ley navarra de 1994 fue el primero que sustituyó al Reglamento de Planeamiento de 1978 en el ámbito de una comunidad autónoma. Quizá por ello fue continuista con las determinaciones de aquél, como veremos en este apartado.

\section{Datos recogidos}

Densidad

La Ley urbanística de Navarra de 1994 estableció unas densidades máximas de viviendas para los nuevos desarrollos muy bajas en comparación con las existentes hasta entonces. Además establecía límites distintos dependiendo del tamaño del municipio, al igual que han hecho otras comunidades autónomas posteriormente, reduciendo las densidades para las poblaciones con menos habitantes (ver cuadro 15).

CuAdro 15: Densidades reguladas por la Ley de Ordenación del Territorio y Urbanismo de Navarra de 1995

\begin{tabular}{|c|c|c|c|}
\hline & $\begin{array}{l}\text { Municipio }>25.000 \\
\text { hab. }\end{array}$ & $\begin{array}{l}\text { Municipio } 2.000- \\
25.000 \text { hab. (y en- } \\
\text { torno de Pamplona) }\end{array}$ & Resto de municipios \\
\hline Densidad máxima & $\begin{array}{l}50 \text { viviendas ó } 5.500 \mathrm{~m}^{2} \mathrm{c} \\
\text { por hectárea }\end{array}$ & $\begin{array}{l}40 \text { viviendas ó } 4.500 \mathrm{~m}^{2} \mathrm{c} \\
\text { por hectárea }\end{array}$ & $\begin{array}{l}35 \text { viviendas ó } 4.500 \mathrm{~m}^{2} \mathrm{c} \\
\text { por hectárea }\end{array}$ \\
\hline $\begin{array}{l}\text { Densidad máxima } \\
\text { excepcional }\end{array}$ & $\begin{array}{l}75 \text { viviendas por hectá- } \\
\text { rea }\end{array}$ & \multicolumn{2}{|c|}{50 viviendas por hectárea } \\
\hline
\end{tabular}

Los límites a la densidad se establecen tanto en viviendas por hectárea como en metros cuadrados construidos/hectárea, por lo que se limita la edificabilidad de todos los usos del sector, no solo del residencial.

Las densidades máximas excepcionales que se indican en el cuadro 15 sólo pueden darse en circunstancias muy especiales.

Excepcionalmente, el Consejero de Ordenación del Territorio y Medio Ambiente podrá autorizar justificadamente, mediante Orden Foral que se publicará en el Boletín Oficial de Navarra, la superación de los límites a que se refiere el número anterior cuando las circunstancias urbanísticas de la localidad así lo aconsejen, [...]

Ley foral de Ordenación del Territorio y Urbanismo de Navarra, art. 20.2

\section{Dotaciones}

Como comentábamos en la introducción a la normativa de Navarra, la continuidad respecto a los estándares dotacionales del Reglamento de Planeamiento de 1978 es manifiesta. Basta comparar el cuadro 16 con el cuadro 2 para ver que sigue una estructura similar, e incluso los valores son muy parecidos.

\section{Sectores tipo}

Al igual que el Reglamento de Planeamiento de 1978, el Reglamento navarro establece una equivalencia de una vivienda por cada $100 \mathrm{~m}^{2}$ edificables de uso residencial, lo cual apoya la hipótesis adoptada en este trabajo para el establecimiento de los sectores tipo.

En el cuadro 17 se han representado los sectores tipo para edificabilidades de hasta $0,75 \mathrm{~m}^{2} \mathrm{t} / \mathrm{m}^{2} \mathrm{~s}$, puesto que la densidad máxima excepcional puede llegar a 75 viviendas por hectárea. No obstante, se han sombreado los datos correspondientes a esta edificabilidad puesto que se trata de casos muy excepcionales. La densidad máxima no excepcional se establece en 50 viviendas por hectárea para ciudades de más de 20.000 habitantes, y menor aún para el resto de municipios. 
CuAdro 16: Estándares dotacionales en sectores de uso residencial. Reglamento de Navarra de 1995

\begin{tabular}{|c|c|c|c|c|c|c|}
\hline & $\begin{array}{l}0-100 \\
\text { viv. }\end{array}$ & $\begin{array}{l}101-250 \\
\text { viv. }\end{array}$ & $\begin{array}{l}251-500 \\
\text { viv. }\end{array}$ & $\begin{array}{l}501- \\
1.000 \\
\text { viv. }\end{array}$ & $\begin{array}{l}1.001- \\
2.000 \\
\text { viv. }\end{array}$ & $\begin{array}{l}>2.000 \\
\text { viv. }\end{array}$ \\
\hline \multicolumn{7}{|c|}{ Espacios libres públicos } \\
\hline $\begin{array}{ll}\text { Espacios } & \text { libres } \\
\text { públicos } & \\
\end{array}$ & \multicolumn{6}{|c|}{$15 \mathrm{~m}^{2} \mathrm{~s} /$ viv. ó $100 \mathrm{~m}^{2}$ de uso residencial (mínimo $10 \%$ de la superficie) } \\
\hline Zonas verdes & - & \multicolumn{5}{|c|}{$8 \mathrm{~m}^{2} \mathrm{~s} /$ viv. (dentro de la reserva de espacios libres públicos) } \\
\hline \multicolumn{7}{|l|}{ Equipamientos } \\
\hline Docente y cultural & \multicolumn{2}{|c|}{$10 \mathrm{~m}^{2} \mathrm{~s} / \mathrm{viv}}$. & \multicolumn{3}{|c|}{$11 \mathrm{~m}^{2} \mathrm{~s} / \mathrm{viv}}$. & $15 \mathrm{~m}^{2} \mathrm{~s} /$ viv. \\
\hline Polivalente & \multicolumn{2}{|c|}{$10 \mathrm{~m}^{2} \mathrm{~s} / \mathrm{viv}$} & $3 \mathrm{~m}^{2} \mathrm{~s} /$ viv. & $4 \mathrm{~m}^{2} \mathrm{~s} / \mathrm{viv}$ & \multicolumn{2}{|c|}{$6 \mathrm{~m}^{2} \mathrm{~s} /$ viv. } \\
\hline Deportivo & \multicolumn{2}{|c|}{-} & \multicolumn{2}{|c|}{$6 \mathrm{~m}^{2} \mathrm{~s} /$ viv } & \multicolumn{2}{|c|}{$8 \mathrm{~m}^{2} \mathrm{~s} / \mathrm{viv}$} \\
\hline $\begin{array}{l}\text { Áreas de juego para } \\
\text { ñiños y de recreo }\end{array}$ & \multicolumn{3}{|c|}{$3 \mathrm{~m}^{2} \mathrm{~s} / \mathrm{viv}$} & \multicolumn{3}{|c|}{$6 \mathrm{~m}^{2} \mathrm{~s} / \mathrm{viv}}$. \\
\hline Comercial & \multicolumn{3}{|c|}{$1 \mathrm{~m}^{2} \mathrm{c} / \mathrm{viv}$} & $2 \mathrm{~m}^{2} \mathrm{c} / \mathrm{viv}$ & $3 \mathrm{~m}^{2} \mathrm{c} / \mathrm{viv}$ & $4 \mathrm{~m}^{2} \mathrm{c} / \mathrm{viv}$ \\
\hline $\begin{array}{l}\text { Totales } \\
\left(\text { sólo } \mathrm{m}^{2} \mathrm{~s}\right)\end{array}$ & \multicolumn{2}{|c|}{$28 \mathrm{~m}^{2} \mathrm{~s} / \mathrm{viv}$} & $35 \mathrm{~m}^{2} \mathrm{~s} / \mathrm{viv}$ & $38 \mathrm{~m}^{2} \mathrm{~s} / \mathrm{viv}$ & $40 \mathrm{~m}^{2} \mathrm{~s} / \mathrm{viv}$ & $44 \mathrm{~m}^{2} \mathrm{~s} / \mathrm{viv}$ \\
\hline
\end{tabular}

1 vivienda $=100 \mathrm{~m}^{2}$ construidos uso residencial

$\mathrm{m}^{2} \mathrm{~s}=$ metro cuadrado de suelo

$\mathrm{m}^{2} \mathrm{c}=$ metro cuadrado construido

Los resultados correspondientes al porcentaje de ocupación del sector y a las dotaciones correspondientes a cada vivienda resultan similares a los del Reglamento de Planeamiento de 1978, puesto que también Navarra mantiene los tramos en función del número de viviendas del sector, así como los porcentajes mínimos para los espacios libres, tal como se ve en las figuras 12 y 13 . En estas gráficas se han señalado con línea discontinua los datos correspondientes a las densidades "excepcionales" mayores de 50 viviendas por hectárea (a partir de $0,50 \mathrm{~m}^{2} \mathrm{t} / \mathrm{m}^{2} \mathrm{~s}$ de edificabilidad).

La figura 13 nos muestra un hecho curioso: para las densidades consideradas "no excepcionales" (menores de 50 viviendas por hectárea), se aplica la obligación de ceder el 10/libres. No puede aplicarse el módulo de $15 \mathrm{~m}^{2}$ por vivienda, puesto que es inferior al $10 \%$ de la superficie del sector. Por ejemplo, un sector con una edificabilidad de $0,50 \mathrm{~m}^{2} \mathrm{t} / \mathrm{m}^{2} \mathrm{~s}$, y una hectárea de superficie, deberá ceder:

- $1.000 \mathrm{~m}^{2}$ para espacios libres según la norma del $10 \%$ de la superficie del sector.

- $750 \mathrm{~m}^{2}$ según el módulo de $15 \mathrm{~m}^{2}$ por vivienda, puesto que el sector tiene 50 viviendas.

Por tanto, no se aplica el módulo, sino el porcentaje mínimo. Se puede afirmar que el Reglamento navarro estableció una determinación inútil al señalar un módulo por vivienda que no tiene aplicación, salvo cuando las densidades son excepcionales.

\section{Normativa urbanística del País Vasco}

La Comunidad Autónoma del País Vasco ha aprobado recientemente su propia legislación urbanística (Ley 2/2006, de 30 de junio, de Suelo y Urbanismo), pues hasta ahora seguía vigente la legislación urbanística del Estado. Aunque aún no se ha desarrollado reglamentariamente, se recoge en este estudio porque introduce novedades en los estándares cuya comparación con el resto de normativas puede ser interesante, sobre todo en lo relativo a la densidad.

\section{Datos recogidos}

Densidad

La novedad más interesante de la reciente Ley vasca en relación a los estándares urbanísticos es el incremento de los límites de edificabilidad y la inclusión de límites mínimos de densidad para los nuevos desarrollos residenciales (aunque este aspecto ya aparecía en el reglamento de Urbanismo de Castilla y 
Cundro 17: Aplicación de estándares dotacionales a sectores tipo de uso residencial. Normativa urbanística de Navarra de 1995

Sector de 250 viviendas

\begin{tabular}{|c|c|c|c|c|c|c|}
\hline Edifica- & Superf. & Espacios & Equipa- & Dota & iones & Edificab. \\
\hline $\begin{array}{l}\text { bilidad } \\
\left(\mathrm{m}^{2} \mathrm{t} / \mathrm{m}^{2} \mathrm{~s}\right)\end{array}$ & $\begin{array}{l}\text { del sector } \\
\qquad\left(\mathrm{m}^{2}\right)\end{array}$ & $\begin{array}{l}\text { libres } \\
\left(\mathrm{m}^{2}\right)\end{array}$ & $\begin{array}{l}\text { mientos } \\
\left(\mathrm{m}^{2}\right)\end{array}$ & $\begin{array}{l}\text { Ocupación } \\
\text { de suelo } \\
\text { (\% de sup.) }\end{array}$ & $\begin{array}{c}\text { Ratio } \\
\text { por vivda. } \\
\left(\mathrm{m}^{2} / \text { vivda. }\right)\end{array}$ & $\begin{array}{c}\text { parcela } \\
\text { neta } \\
\left(\mathrm{m}^{2} \mathrm{t} / \mathrm{m}^{2} \mathrm{~s}\right)\end{array}$ \\
\hline 0,15 & 166.667 & 16.667 & 3.250 & 11,95 & 79,67 & 0,18 \\
\hline 0,35 & 71.429 & 7.143 & 3.250 & 14,55 & 41,57 & 0,49 \\
\hline 0,55 & 45.455 & 4.545 & 3.250 & 17,15 & 31,18 & 0,90 \\
\hline 0,75 & 33.333 & 3.750 & 3.250 & 21,00 & 28,00 & 1,53 \\
\hline
\end{tabular}

Sector de 500 viviendas

\begin{tabular}{|c|c|c|c|c|c|c|}
\hline Edifica- & Superf. & Espacios & Equipa- & \multicolumn{2}{|c|}{ Dotaciones } & Edificab. \\
\hline $\begin{array}{c}\text { bilidad } \\
\left(\mathrm{m}^{2} \mathrm{t} / \mathrm{m}^{2} \mathrm{~s}\right)\end{array}$ & $\begin{array}{l}\text { del sector } \\
\qquad\left(\mathrm{m}^{2}\right)\end{array}$ & $\begin{array}{l}\text { libres } \\
\left(\mathrm{m}^{2}\right)\end{array}$ & $\begin{array}{l}\text { mientos } \\
\left(\mathrm{m}^{2}\right)\end{array}$ & $\begin{array}{l}\text { Ocupación } \\
\text { de suelo } \\
\text { (\% de sup.) }\end{array}$ & $\begin{array}{c}\text { Ratio } \\
\text { por vivda. } \\
\text { ( } \mathrm{m}^{2} / \text { vivda.) }\end{array}$ & $\begin{array}{c}\text { parcela } \\
\text { neta } \\
\left(\mathrm{m}^{2} \mathrm{t} / \mathrm{m}^{2} \mathrm{~s}\right)\end{array}$ \\
\hline 0,15 & 333.333 & 33.333 & 10.000 & 13,00 & 86,67 & 0,19 \\
\hline 0,35 & 142.857 & 14.286 & 10.000 & 17,00 & 48,57 & 0,51 \\
\hline 0,55 & 90.909 & 9.091 & 10.000 & 21,00 & 38,18 & 0,96 \\
\hline 0,75 & 66.667 & 7.500 & 10.000 & 26,25 & 35,00 & 1,71 \\
\hline
\end{tabular}

Sector de 1.000 viviendas

\begin{tabular}{|c|c|c|c|c|c|c|}
\hline Edifica- & Superf. & Espacios & Equipa- & \multicolumn{2}{|c|}{ Dotaciones } & Edificab. \\
\hline $\begin{array}{l}\text { bilidad } \\
\left(\mathrm{m}^{2} \mathrm{t} / \mathrm{m}^{2} \mathrm{~s}\right)\end{array}$ & $\begin{array}{l}\text { del sector } \\
\qquad\left(\mathrm{m}^{2}\right)\end{array}$ & $\begin{array}{l}\text { libres } \\
\left(\mathrm{m}^{2}\right)\end{array}$ & $\begin{array}{l}\text { mientos } \\
\left(\mathrm{m}^{2}\right)\end{array}$ & $\begin{array}{c}\text { Ocupación } \\
\text { de suelo } \\
\text { (\% de sup.) }\end{array}$ & $\begin{array}{c}\text { Ratio } \\
\text { por vivda. } \\
\left(\mathrm{m}^{2} / \text { vivda. }\right)\end{array}$ & $\begin{array}{c}\text { parcela } \\
\text { neta } \\
\left(\mathrm{m}^{2} \mathrm{t} / \mathrm{m}^{2} \mathrm{~s}\right)\end{array}$ \\
\hline 0,15 & 666.667 & 66.667 & 23.000 & 13,45 & 89,67 & 0,19 \\
\hline 0,35 & 285.714 & 28.571 & 23.000 & 18,05 & 51,57 & 0,52 \\
\hline 0,55 & 181.818 & 18.182 & 23.000 & 22,65 & 41,18 & 0,99 \\
\hline 0,75 & 133.333 & 15.000 & 23.000 & 28,50 & 38,00 & 1,81 \\
\hline
\end{tabular}

Sector de 2.000 viviendas

\begin{tabular}{|c|c|c|c|c|c|c|}
\hline Edifica- & Superf. & Espacios & Equipa- & \multicolumn{2}{|c|}{ Dotaciones } & Edificab. \\
\hline $\begin{array}{c}\text { bilidad } \\
\left(\mathrm{m}^{2} \mathrm{t} / \mathrm{m}^{2} \mathrm{~s}\right)\end{array}$ & $\begin{array}{l}\text { del sector } \\
\qquad\left(\mathrm{m}^{2}\right)\end{array}$ & $\begin{array}{l}\text { libres } \\
\left(\mathrm{m}^{2}\right)\end{array}$ & $\begin{array}{l}\text { mientos } \\
\left(\mathrm{m}^{2}\right)\end{array}$ & $\begin{array}{c}\text { Ocupación } \\
\text { de suelo } \\
\text { (\% de sup.) }\end{array}$ & $\begin{array}{c}\text { Ratio } \\
\text { por vivda. } \\
\text { ( } \mathrm{m}^{2} / \text { vivda.) }\end{array}$ & $\begin{array}{c}\text { parcela } \\
\text { neta } \\
\left(\mathrm{m}^{2} \mathrm{t} / \mathrm{m}^{2} \mathrm{~s}\right) \\
\end{array}$ \\
\hline 0,15 & 1.333 .333 & 133.333 & 50.000 & 13,75 & 91,67 & 0,19 \\
\hline 0,35 & 571.429 & 57.143 & 50.000 & 18,75 & 53,57 & 0,52 \\
\hline 0,55 & 363.636 & 36.364 & 50.000 & 23,75 & 43,18 & 1,01 \\
\hline 0,75 & 266.667 & 30.000 & 50.000 & 30,00 & 40,00 & 1,88 \\
\hline
\end{tabular}

Sector de 4.000 viviendas

\begin{tabular}{|c|c|c|c|c|c|c|}
\hline Edifica- & Superf. & Espacios & Equipa- & \multicolumn{2}{|c|}{ Dotaciones } & lificab. \\
\hline $\begin{array}{l}\text { bilidad } \\
\left(\mathrm{m}^{2} \mathrm{t} / \mathrm{m}^{2} \mathrm{~s}\right)\end{array}$ & $\begin{array}{l}\text { del sector } \\
\qquad\left(\mathrm{m}^{2}\right)\end{array}$ & $\begin{array}{l}\text { libres } \\
\left(\mathrm{m}^{2}\right)\end{array}$ & $\begin{array}{c}\text { mientos } \\
\left(\mathrm{m}^{2}\right)\end{array}$ & $\begin{array}{c}\text { Ocupación } \\
\text { de suelo } \\
\text { (\% de sup.) }\end{array}$ & $\begin{array}{c}\text { Ratio } \\
\text { por vivda. } \\
\left(\mathrm{m}^{2} / \text { vivda. }\right)\end{array}$ & $\begin{array}{c}\text { parcela } \\
\text { neta } \\
\left(\mathrm{m}^{2} \mathrm{t} / \mathrm{m}^{2} \mathrm{~s}\right)\end{array}$ \\
\hline 0,15 & 2.666 .667 & 266.667 & 116.000 & 14,35 & 95,67 & 0,19 \\
\hline 0,35 & 1.142 .857 & 114.286 & 116.000 & 20,15 & 57,57 & 0,53 \\
\hline 0,55 & 727.273 & 72.727 & 116.000 & 25,95 & 47,18 & 1,06 \\
\hline 0,75 & 533.333 & 60.000 & 116.000 & 33,00 & 44,00 & 2,03 \\
\hline
\end{tabular}




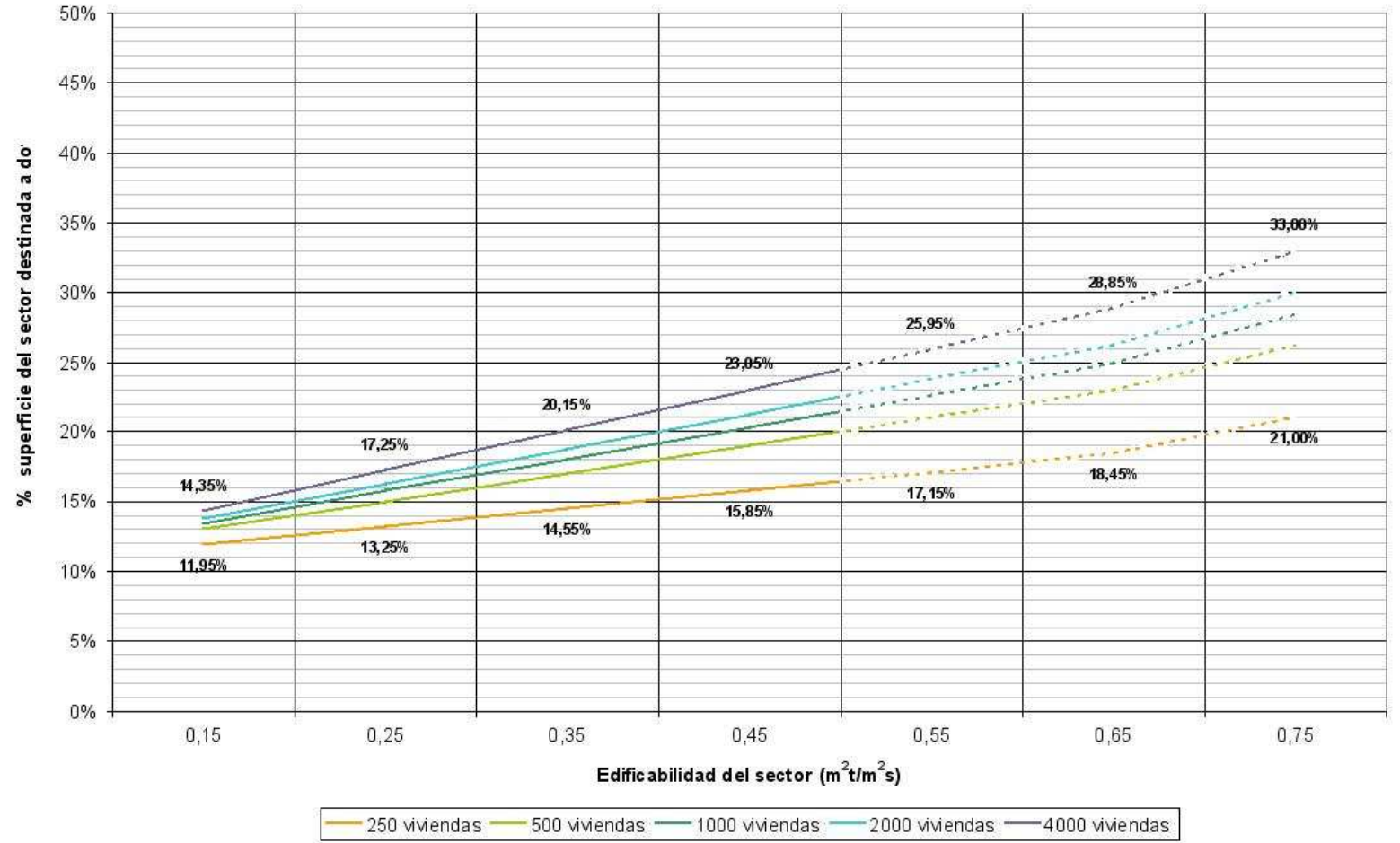

Figura 12: Superficie ocupada (\%) por las dotaciones en sectores tipo de uso residencial. Reglamento de Navarra de 1995

Elaboración propia 


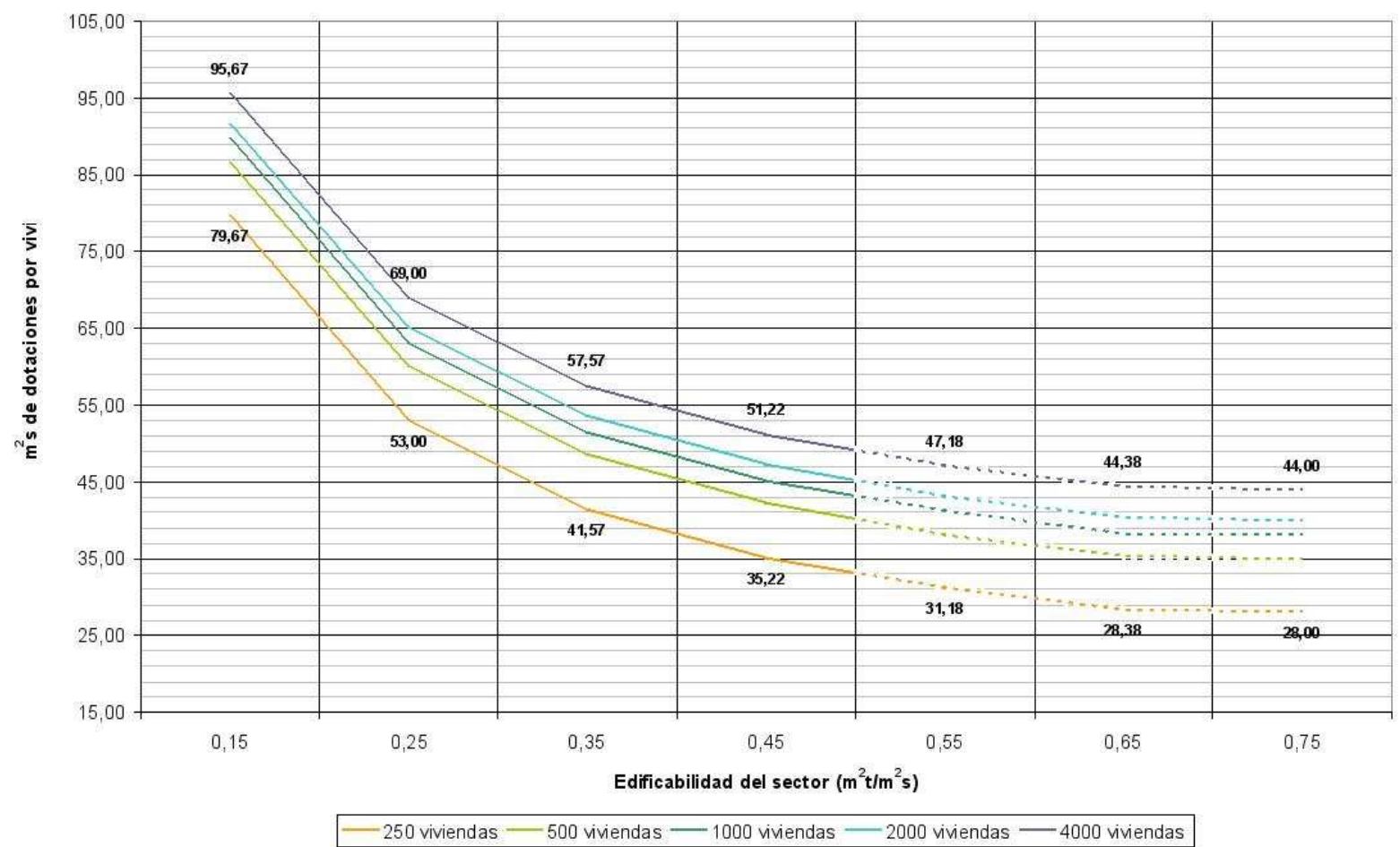

Figura 13: Dotaciones por vivienda en sectores tipo de uso residencial. Reglamento de Navarra de 1995

Elaboración propia 
León). El cuadro 18 resume las determinaciones que establece la Ley de Suelo y Urbanismo del País Vasco.

CuAdro 18: Edificabilidades máximas y mínimas para uso residencial. Ley de Suelo y Urbanismo del País Vasco

\begin{tabular}{|l|c|l|}
\hline & Suelo urbano no consolidado & \multicolumn{1}{c|}{ Suelo urbanizable } \\
\hline $\begin{array}{l}\text { Edificabilidad } \\
\text { máxima }\end{array}$ & $2,3 \mathrm{~m}^{2} \mathrm{t} / \mathrm{m}^{2} \mathrm{~s}$ & $\begin{array}{l}1,3 \mathrm{~m}^{2} \mathrm{t} / \mathrm{m}^{2} \mathrm{~s} \text { (población mayor } \\
\text { de } 7.000 \text { habitantes) }\end{array}$ \\
& & $\begin{array}{l}1,1 \mathrm{~m}^{2} \mathrm{t} / \mathrm{m}^{2} \mathrm{~s} \text { (población menor } \\
\text { de } 7.000 \text { habitantes que no se en- } \\
\text { cuentre en el entorno de Bilbao, } \\
\text { San Sebastián o Vitoria) }\end{array}$ \\
\hline $\begin{array}{l}\text { Edificabilidad } \\
\text { mínima } \\
\text { (sobre rasante) }\end{array}$ & $0,4 \mathrm{~m}^{2} \mathrm{t}^{2} \mathrm{~m}^{2} \mathrm{~s}$ (puede reducirse en algunos casos hasta $0,25 \mathrm{~m}^{2} \mathrm{t} / \mathrm{m}^{2} \mathrm{~s}$ ) \\
\hline
\end{tabular}

Aplicando la equivalencia entre edificabilidad y densidad de viviendas que estamos utilizando, resultaría que la densidad máxima sería de 130 viviendas por hectárea para el suelo urbanizable en las poblaciones de mayor tamaño, suponiendo que no se diera ningún otro uso en el sector aparte del residencial. Es casi el doble del límite establecido en los sectores residenciales por la legislación estatal de 1976, que lo fijó en 75 viviendas por hectárea.

\section{Dotaciones}

La nueva normativa del País Vasco define, en su artículo 54, distintos tipos de elementos dotacionales que debe contener los planes de ordenación:

- Zonas verdes y espacios libres

- Equipamientos colectivos

- Infraestructuras para la prestación en red de toda clase de servicios

- Vías públicas, peatonales y de circulación rodada

- Equipamientos privados

A pesar de esta distinción, los estándares que regula la Ley de Suelo y Urbanismo sobre cesiones obligatorias en los sectores residenciales de suelo urbanizable se simplifican considerablemente (ver cuadro 19). En realidad, sólo existe un módulo genérico destinado a dotaciones públicas de $10 \mathrm{~m}^{2} \mathrm{~s}$ por cada 25 $\mathrm{m}^{2}$ construidos de cualquier uso privado. Es genérico porque la Ley sólo indica que se podrá destinar a dotaciones públicas de la red de sistemas locales y entre estos sistemas locales se incluyen los viales. La única obligación similar a las otras normativas es la de que se destine a parques y zonas verdes al menos el $15 \%$ de la superficie del sector.

CuAdro 19: Estándares dotacionales para sectores residenciales en suelo urbanizable. Ley de Suelo y Urbanismo del País Vasco

\begin{tabular}{|c|c|}
\hline $\begin{array}{l}\text { Dotaciones públicas } \\
\text { de la red de sistemas locales }\end{array}$ & $\begin{array}{l}10 \mathrm{~m}^{2} \mathrm{~s} / 25 \mathrm{~m}^{2} \text { construidos (salvo dotaciones públicas) } \\
\text { Mínimo } 15 \% \text { de la superficie del sector destinado a zonas } \\
\text { verdes y espacios libres }\end{array}$ \\
\hline $\begin{array}{l}\text { Equipamientos privados } \\
\text { de la red de sistemas locales }\end{array}$ & $1 \mathrm{~m}^{2} \mathrm{~s} / 25 \mathrm{~m}^{2}$ construidos (salvo dotaciones públicas) \\
\hline
\end{tabular}

La Ley indica que se desarrollarán reglamentariamente las reservas dotacionales concretas que habrán de cumplirse en los nuevos desarrollo. Es de suponer que aumentarán las obligaciones para equipamientos 
y se limitará el uso como vial de la reserva obligatoria. No obstante, hasta que no se apruebe dicho reglamento, sólo se establece el módulo genérico.

\section{Sectores tipo}

El resto de normativas estudiadas en este trabajo no incluyen los viales públicos entre los estándares de cesiones obligatorias, por lo que el caso vasco, que si los incluye, pueden presentar datos distorsionados al ser comparados con el resto de casos estudiados. Por ello, vamos a hallar los datos de ocupación de suelo y ratio por vivienda de dos formas distintas:

- En la primera tabla del cuadro 20 hemos computado como dotaciones únicamente el estándar obligatorio que destina el $15 \%$ de la superficie del sector a zonas verdes y espacios libres, con el fin de poder comparar el resultado con el resto de casos de este estudio.

- En la segunda tabla hemos computado como dotaciones la cesión genérica de $40 \mathrm{~m}^{2}$ por vivienda que señala la Ley, una parte de la cual serán las zonas verdes y el resto son viales.

Así, estamos hablando de un sector tipo con 500 viviendas - aunque no es relevante el número de viviendas que contenga el sector puesto que la Ley vasca no establece ninguna distinción al respectoen ambos casos con la misma cantidad de zonas verdes (15\% de la superficie total), viales $\left(40 \mathrm{~m}^{2}\right.$ por vivienda) y parcelas edificables. La primera tabla del cuadro muestra unos datos que son comparables con el resto de casos estudiados, ya que no recoge la parte de viales que forma parte de las dotaciones, mientras la segunda tabla muestra una aplicación genérica del estándar dotacional del País Vasco, aunque parte del mismo está formado por los viales del sector.

Cundro 20: Aplicación de estándares dotacionales a sectores tipo de uso residencial. Ley de Suelo y Urbanismo del País Vasco

Sector de 500 viviendas (contando como dotación sólo el $15 \%$ mínimo de zonas verdes)

\begin{tabular}{|c|c|c|c|c|c|}
\hline \multirow{2}{*}{$\begin{array}{l}\text { Edifica- } \\
\text { bilidad } \\
\left(\mathrm{m}^{2} \mathrm{t} / \mathrm{m}^{2} \mathrm{~s}\right)\end{array}$} & \multirow{2}{*}{$\begin{array}{c}\text { Superf. } \\
\text { del sector } \\
\left(\mathrm{m}^{2}\right)\end{array}$} & \multirow{2}{*}{$\begin{array}{c}\text { Espacios } \\
\text { libres } \\
\left(\mathrm{m}^{2}\right)\end{array}$} & \multicolumn{2}{|c|}{ Dotaciones } & \multirow{2}{*}{$\begin{array}{c}\text { Edificab. } \\
\text { parcela } \\
\text { neta } \\
\left(\mathrm{m}^{2} \mathrm{t} / \mathrm{m}^{2} \mathrm{~s}\right)\end{array}$} \\
\hline & & & $\begin{array}{l}\text { Ocupación } \\
\text { de suelo } \\
\text { (\% de sup.) }\end{array}$ & $\begin{array}{c}\text { Ratio } \\
\text { por vivda. } \\
\left(\mathrm{m}^{2} / \text { vivda. }\right)\end{array}$ & \\
\hline 0,35 & 142.857 & 21.429 & 15,00 & 42,86 & 0,49 \\
\hline 0,55 & 90.909 & 13.636 & 15,00 & 27,27 & 0,87 \\
\hline 0,75 & 66.667 & 10.000 & 15,00 & 20,00 & 1,36 \\
\hline 0,95 & 52.632 & 7.895 & 15,00 & 15,79 & 2,02 \\
\hline 1,15 & 43.478 & 6.522 & 15,00 & 13,04 & 2,95 \\
\hline$\overline{1,30}$ & 38.462 & 5.769 & 15,00 & 11,54 & 3,94 \\
\hline
\end{tabular}

Sector de 500 viviendas (contando como dotación $40 \mathrm{~m}^{2}$ por vivienda, una parte de los cuales son viales)

\begin{tabular}{|c|c|c|c|c|c|}
\hline \multirow{2}{*}{$\begin{array}{l}\text { Edifica- } \\
\text { bilidad } \\
\left(\mathrm{m}^{2} \mathrm{t} / \mathrm{m}^{2} \mathrm{~s}\right)\end{array}$} & \multirow{2}{*}{$\begin{array}{c}\text { Superf. } \\
\text { del sector } \\
\left(\mathrm{m}^{2}\right)\end{array}$} & \multirow{2}{*}{$\begin{array}{c}\text { Dotaciones } \\
\text { públicas } \\
\left(\mathrm{m}^{2}\right)\end{array}$} & \multicolumn{2}{|c|}{ Dotaciones } & \multirow{2}{*}{$\begin{array}{c}\text { Edificab. } \\
\text { parcela } \\
\text { neta } \\
\left(\mathrm{m}^{2} \mathrm{t} / \mathrm{m}^{2} \mathrm{~s}\right)\end{array}$} \\
\hline & & & $\begin{array}{l}\text { Ocupación } \\
\text { de suelo } \\
\text { (\% de sup.) }\end{array}$ & $\begin{array}{c}\text { Ratio } \\
\text { por vivda. } \\
\left(\mathrm{m}^{2} / \text { vivda. }\right)\end{array}$ & \\
\hline 0,35 & 142.857 & 21.429 & 15,00 & 42,86 & 0,49 \\
\hline 0,55 & 90.909 & 20.000 & 22,00 & 40,00 & 0,87 \\
\hline 0,75 & 66.667 & 20.000 & 30,00 & 40,00 & 1,36 \\
\hline 0,95 & 52.632 & 20.000 & 38,00 & 40,00 & 2,02 \\
\hline 1,15 & 43.478 & 20.000 & 46,00 & 40,00 & 2,95 \\
\hline 1,30 & 38.462 & 20.000 & 52,00 & 40,00 & 3,94 \\
\hline
\end{tabular}

Las dos clases de sectores tipo que hemos calculado dan lugar a gráficos de ocupación de superficie del sector sensiblemente distintos. Vemos que el porcentaje mínimo es del 15\%, mientras que los porcentajes máximos alcanzan cifras importantes, pero es necesario recordar que, al poderse incluir los viales del sector entre las dotaciones, aún queda superficie suficiente para los usos privados (ver figura 14). 


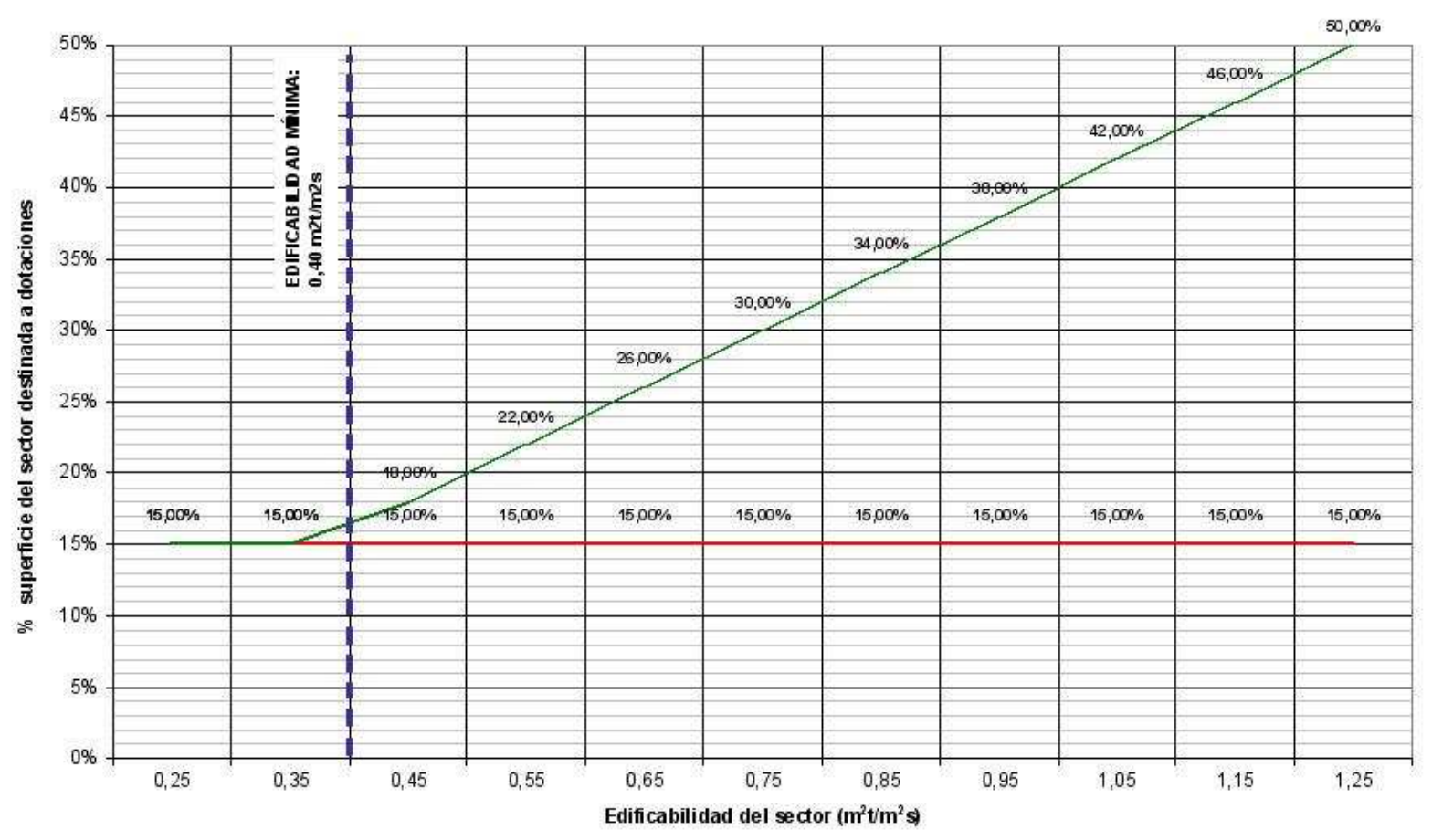

-Dotaciones (sin viales) —-Dotaciones (incluyendo viales)

FigurA 14: Superficie ocupada (\%) por las dotaciones en sectores tipo de uso residencial. Ley de Suelo y Urbanismo del País Vasco

Elaboración propia 
En cuanto a las cesiones correspondientes a cada vivienda, hay que diferenciar igualmente entre las dos posibilidades: cesiones obligatorias incluyendo viales y cesiones mínimas contando sólo el $15 \%$ de la superficie destinado a zonas verdes (ver figura 15). En el caso del País Vasco, al estar limitada la edificabilidad mínima de los sectores, no se da la desproporción de dotaciones por vivienda en casos de baja densidad, como sí ocurre en el resto de normativas que hemos estudiado. Además, se garantiza un mínimo de $40 \mathrm{~m}^{2}$ de dotaciones públicas por vivienda en todo caso, aunque buena parte de estas dotaciones puede materializarse en viales.

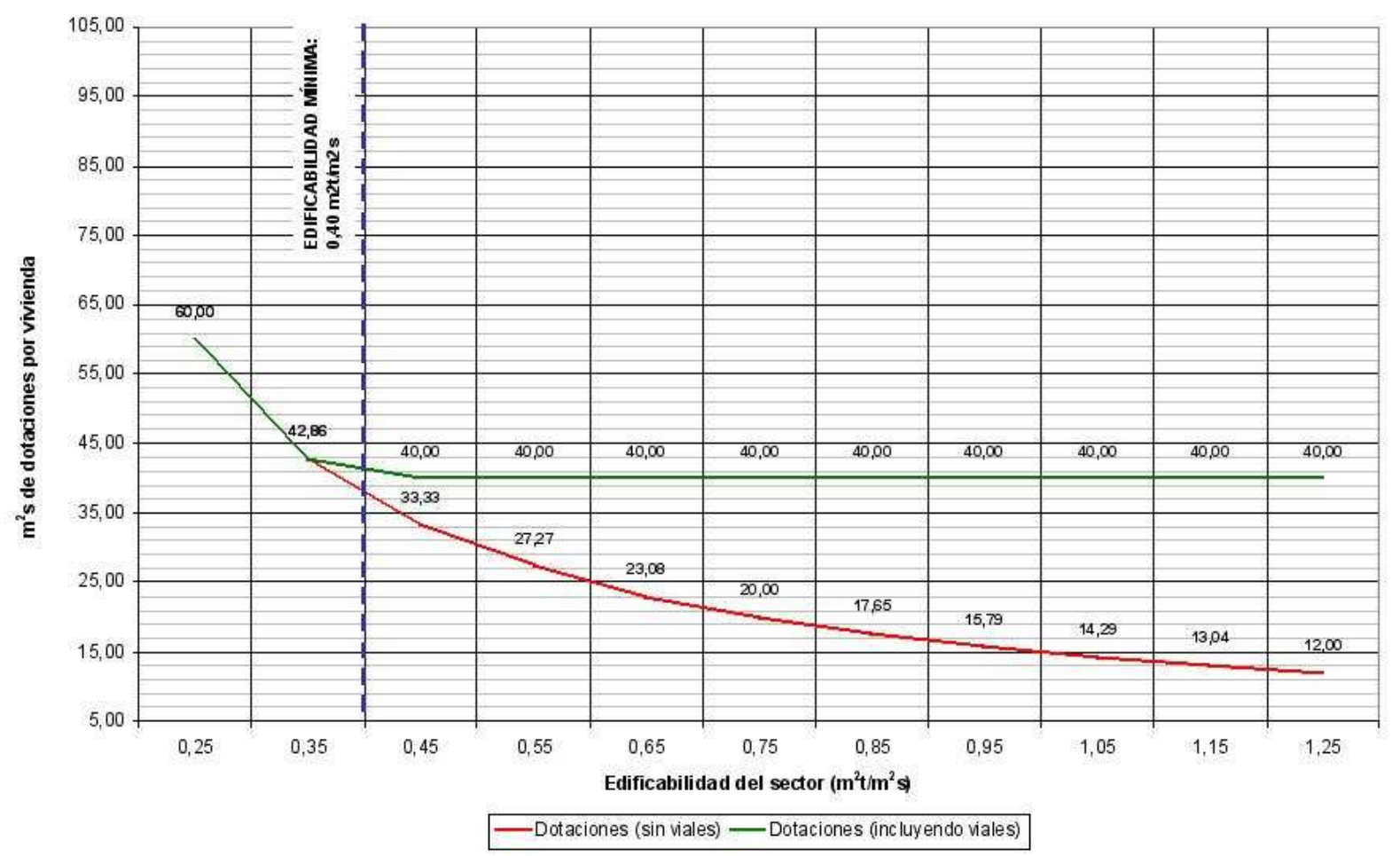

Figura 15: Dotaciones por vivienda en sectores tipo de uso residencial. Ley de Suelo y Urbanismo del País Vasco

\author{
Elaboración propia
}

\title{
Normativa urbanística de la Comunidad Valenciana
}

La Comunidad Valenciana fue, al igual que Navarra, una de las primeras comunidades autónomas que desarrollaron legislación urbanística propia. Tal vez por su antigüedad, se ha reformado recientemente toda la normativa, tanto la Ley como el Reglamento. En la fecha de elaboración de este trabajo, la Comunidad Valenciana cuenta con un reglamento (Decreto 67/2006, de 19 de mayo, por el que se aprueba el Reglamento de Ordenación y Gestión Territorial y Urbanística) que desarrolla, en un solo texto, las tres leyes autonómicas que tienen relación con el urbanismo: la Ley 4/2004, de 30 de junio, de Ordenación del Territorio y Protección del Paisaje, la Ley 10/2004, de 9 de diciembre, del Suelo No Urbanizable y la Ley 16/2005, de 30 de diciembre, Urbanística Valenciana.

A pesar del extraordinario volumen del Reglamento, 587 artículos en total, éste establece muy pocos estándares urbanísticos. Eso si, les dedica todo un capítulo, dejando muy claro el objeto de los mismos:

Los estándares urbanísticos son determinaciones normativas que se establecen con la finalidad de garantizar unos mínimos de calidad urbana de las actuaciones urbanísticas.

Reglamento de Ordenación y Gestión Territorial y Urbanística de la Comunidad Valenciana, art. 193, concepto de estándar urbanístico 


\section{Datos recogidos}

Densidad

El Reglamento valenciano, en su artículo 194, limita la edificabilidad con el objetivo expreso de que «las intensidades de edificación resultantes de la ordenación urbanística no superen unos umbrales máximos a partir de los cuales se reduce sensiblemente la calidad urbana de los espacios públicos y privados».

Sin embargo, a pesar del énfasis de la cita anterior y de que se dedican tres artículos completos del Reglamento valenciano a definir los conceptos de edificabilidad bruta y neta, índice de edificabilidad, etc. (del artículo 196 al 199), éste sólo señala un límite:

En el suelo urbanizable, el índice de edificabilidad residencial no superará el valor de un metro cuadrado de techo por cada metro cuadrado de suelo, referido a la superficie computable del sector.

Reglamento de Ordenación y Gestión Territorial y Urbanística de la Comunidad Valenciana, limitaciones de edificabilidad

No se establecen más parámetros numéricos que el anterior para el tema de la densidad: el Reglamento indica que serán los planes de ordenación general los que deberán establecer los límites.

\section{Dotaciones}

En cuanto a las reservas obligatorias en los nuevos desarrollos de uso residencial, el reglamento valenciano fija un único estándar de $35 \mathrm{~m}^{2}$ de suelo por cada $100 \mathrm{~m}^{2}$ edificables de uso residencial. Esta reserva puede destinarse a zonas verdes o a equipamientos, con unos mínimos que se resumen en el cuadro 21. Además, para otros posibles usos dentro de un sector mayoritariamente residencial, se establecen módulos de reserva de menor cuantía. No obstante, estos no afectarán para nuestro análisis de sectores, puesto que hemos adoptado la hipótesis de considerar que toda la edificabilidad se destina a uso residencial.

CUADRo 21: Estándares dotacionales para sectores residenciales en suelo urbanizable. Normativa urbanística valenciana

\begin{tabular}{|l|l|}
\hline Reserva dotacional pública total & $\mathbf{3 5} \mathbf{~ m}^{\mathbf{2}} \mathrm{s} / \mathbf{1 0 0} \mathbf{~ m}^{\mathbf{2}} \mathbf{c}$ de uso residencial \\
\hline \hline Zonas verdes públicas & $15 \mathrm{~m}^{2} \mathrm{~s} / 100 \mathrm{~m}^{2} \mathrm{c}$ de uso residencial \\
\hline & $\begin{array}{l}5 \mathrm{~m}^{2} \mathrm{~s} / 100 \mathrm{~m}^{2} \mathrm{c} \text { de uso terciario o residencial } \\
\text { en parcela exclusiva }\end{array}$ \\
\hline \hline & $\begin{array}{l}3 \mathrm{~m}^{2} \mathrm{~s} / 100 \mathrm{~m}^{2} \mathrm{c} \text { de uso terciario o industrial } \\
\text { en edificio residencial }\end{array}$ \\
\hline \hline \multicolumn{2}{|c|}{$\left(\mathrm{m}^{2} \mathrm{~s}=\right.$ metro cuadrado de suelo $\mathrm{m}^{2} \mathrm{c}=$ metro cuadrado construido $)$}
\end{tabular}

\section{Sectores tipo}

Para calcular los sectores tipo hemos considerado que se destinarán $15 \mathrm{~m}^{2}$ de suelo para espacios libres y $20 \mathrm{~m}^{2}$ de suelo para equipamientos, aunque el Reglamento sólo establece unos mínimos de 15 y $10 \mathrm{~m}^{2}$ respectivamente (es decir, la normativa permite que los planes destinen $10 \mathrm{~m}^{2}$ a espacios libres o a equipamientos, según su propio criterio, con la condición de que, globalmente, haya $35 \mathrm{~m}^{2}$ de dotaciones públicas por vivienda). Con esta hipótesis, y puesto que no tiene importancia el número de viviendas del sector, podemos obtener los resultados que se reflejan en el cuadro 22.

La representación gráfica de la ocupación de suelo por parte de las dotaciones resulta sencilla (ver figura 16). No se llega a ocupar porcentajes excesivos de la superficie del sector por parte de las dotaciones, por lo que la edificabilidad media de las parcelas privadas no resulta elevada: $4,00 \mathrm{~m}^{2} \mathrm{t} / \mathrm{m}^{2} \mathrm{~s}$ en el caso más extremo.

A diferencia de otras normativas, en la Comunidad Valenciana no hay porcentajes mínimos de espacios libres, por lo que en el caso de sectores de baja densidad, las dotaciones por vivienda son iguales que para otras densidades. Esto se aprecia claramente en la figura 17, en la que resulta una línea horizontal con un valor de $35 \mathrm{~m}^{2}$ por vivienda. 
Cuadro 22: Aplicación de estándares dotacionales a sectores tipo de uso residencial. Normativa urbanística valenciana

Sector de 500 viviendas

\begin{tabular}{|c|c|c|c|c|c|c|}
\hline \multirow{2}{*}{$\begin{array}{l}\text { Edifica- } \\
\text { bilidad } \\
\left(\mathrm{m}^{2} \mathrm{t} / \mathrm{m}^{2} \mathrm{~s}\right)\end{array}$} & \multirow{2}{*}{$\begin{array}{c}\text { Superf. } \\
\text { del sector } \\
\left(\mathrm{m}^{2}\right)\end{array}$} & \multirow{2}{*}{$\begin{array}{c}\text { Espacios } \\
\text { libres } \\
\left(\mathrm{m}^{2}\right)\end{array}$} & \multirow{2}{*}{$\begin{array}{l}\text { Equipa- } \\
\text { mientos } \\
\left(\mathrm{m}^{2}\right)\end{array}$} & \multicolumn{2}{|c|}{ Dotaciones } & \multirow{2}{*}{$\begin{array}{c}\text { Edificab. } \\
\text { parcela } \\
\text { neta } \\
\left(\mathrm{m}^{2} \mathrm{t} / \mathrm{m}^{2} \mathrm{~s}\right)\end{array}$} \\
\hline & & & & $\begin{array}{l}\text { Ocupación } \\
\text { de suelo } \\
\text { ( \% de sup.) }\end{array}$ & $\begin{array}{c}\text { Ratio } \\
\text { por vivda. } \\
\left(\mathrm{m}^{2} / \text { vivda. }\right)\end{array}$ & \\
\hline 0,15 & 333.333 & 7.500 & 10.000 & 5,25 & 35,00 & 0,17 \\
\hline 0,35 & 142.857 & 7.500 & 10.000 & 12,25 & 35,00 & 0,47 \\
\hline 0,55 & 90.909 & 7.500 & 10.000 & 19,25 & 35,00 & 0,94 \\
\hline 0,75 & 66.667 & 7.500 & 10.000 & 26,25 & 35,00 & 1,71 \\
\hline 0,95 & 52.632 & 7.500 & 10.000 & 33,25 & 35,00 & 3,30 \\
\hline 1,00 & 50.000 & 7.500 & 10.000 & 35,00 & 35,00 & 4,00 \\
\hline
\end{tabular}

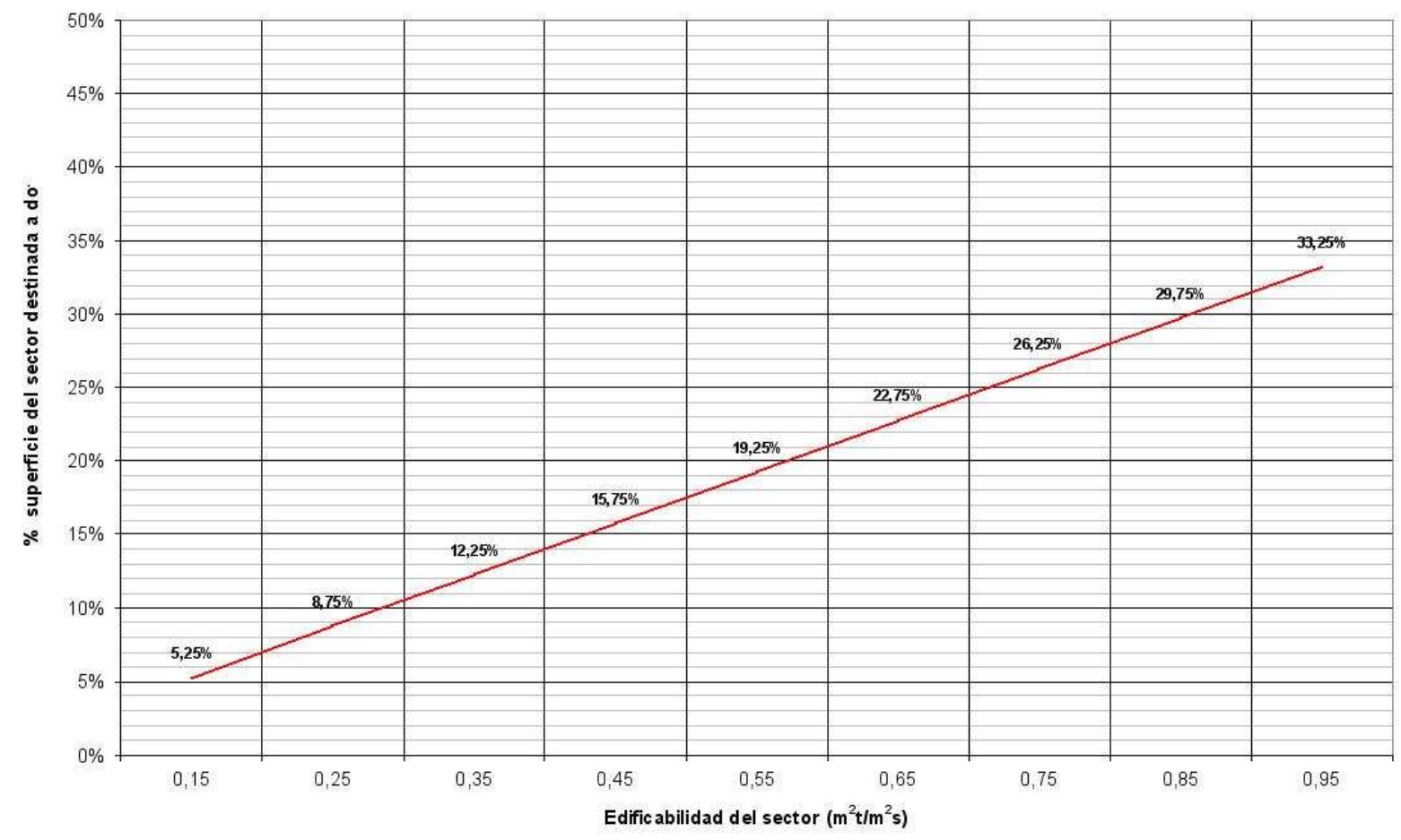

FIguRA 16: Superficie ocupada (\%) por las dotaciones en sectores tipo de uso residencial. Normativa urbanística valenciana 


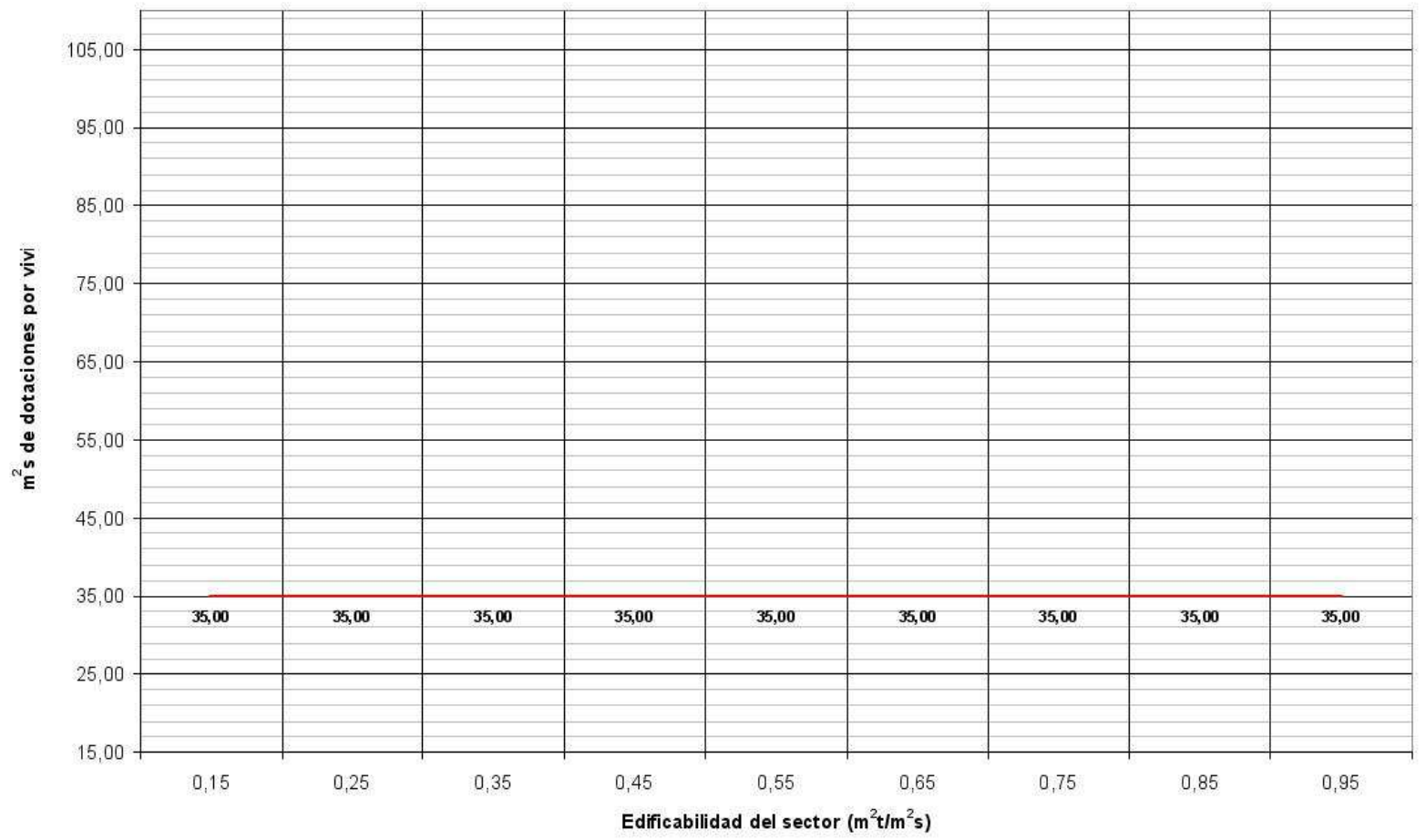

FIGURA 17: Dotaciones por vivienda en sectores tipo de uso residencial. Normativa urbanística valenciana

Elaboración propia 


\section{Estándares urbanísticos comparados}

En el capítulo anterior se han recogido los estándares que fija cada normativa y que afectan al diseño de los sectores residenciales de suelo urbanizable. Además, hemos realizado un análisis de la ocupación de suelo por parte de las dotaciones en sectores con distintas edificabilidades, así como del ratio de dotaciones por vivienda.

En este capítulo vamos a comparar los estándares relativos a densidad y dotaciones de cada una de las normativas estudiadas. Dentro de las dotaciones vamos a diferenciar los espacios libres de los equipamientos, puesto que así lo hacen la mayoría de las normas. Con ello pondremos de relieve los diferentes criterios que existen respecto a lo que se considera dotación mínima necesaria para asegurar una cierta calidad de vida.

\section{Densidad}

El concepto de densidad, o intensidad, o límite de edificabilidad, o cualquiera otra de las denominaciones que aparecen en las normativas, tiene la función de establecer límites a la cantidad de edificación en los nuevos sectores. Aunque no hay un criterio uniforme sobre qué tipo de edificación es necesario limitar, pues en unos casos estos límites sólo afectan al uso residencial, mientras que en otros casos se refieren a todos los usos constructivos. Tampoco existe consenso sobre la cuantía de los límites, al contrario, la disparidad al establecer los límites es notoria.

Todas las normativas estudiadas establecen algún tipo de estándar relacionado con la densidad. En general se cuantifican estos estándares de alguna de las tres formas siguientes:

- Viviendas por hectárea (viv./ha), limitando el número de unidades de vivienda por unidad de superficie.

- Edificabilidad por hectárea $\left(\mathrm{m}^{2} \mathrm{t} / \mathrm{ha}\right)$, que puede referirse sólo al uso residencial o a todos los usos lucrativos.

- Índice de edificabilidad $\left(\mathrm{m}^{2} \mathrm{t} / \mathrm{m}^{2} \mathrm{~s}\right)$, limitando la edificabilidad bruta del sector.

La utilización de la vivienda como unidad de referencia presenta la dificultad de que el tamaño medio de la vivienda varía con el paso del tiempo para adaptarse a nuevas necesidades sociales o a distintas demandas del mercado. Los límites de densidad referidos a viviendas suelen estar pensados para un tamaño de viviendas en un momento determinado, por lo que corren el riesgo de no ser adecuados si se produce una reducción o aumento del tamaño medio de la vivienda, o de la cantidad de personas por vivienda.

El Reglamento de Planeamiento de 1978 limitó la densidad utilizando como unidad de medida las viviendas por hectárea. Sin embargo, ésta es una práctica que ya sólo perdura en tres comunidades autónomas de las que hemos estudiado; y en dos de ellas se complementa con límites referidos a edificabilidad por hectárea (Navarra, Castilla y León).

En las demás comunidades autónomas, la tendencia se dirige a regular los límites de densidad en función de una unidad más definida, como es la edificabilidad por unidad de superficie, abandonando la vivienda como unidad de medida, ya que es poco fiable debido a su variabilidad.

\section{Limitación de la edificación residencial o de la edificación en general}

Todas las normativas, salvo la del País Vasco, establecen límites al uso residencial, ya sea en viviendas por hectárea o en metros cuadrados construidos de uso residencial. Sin embargo, sobre la edificabilidad total materializable en los sectores (que nos daría una noción precisa sobre la cantidad de edificación por unidad de superficie en los nuevos desarrollos), sólo Castilla y León, Navarra y el País Vasco establecen limitaciones (ver cuadro 23). El resto de normativas no ponen trabas a la cantidad de edificación de otros usos que pueden ejecutarse en un sector de uso predominante residencial. Esto puede deberse a que sólo se quiere limitar el número de habitantes que habrá en el sector, sin preocuparse por la población estacional que puede existir en el mismo debido a otros usos (comercial, oficinas, dotacional, etc.).

Como hemos indicado, el País Vasco es la única región que no pone límites a la edificabilidad residencial, por lo que las elevadas edificabilidades permitidas podrían, en principio, destinarse íntegramente a viviendas. De esta forma, adoptando la hipótesis de que una vivienda equivale a $100 \mathrm{~m}^{2}$ construidos, se pueden alcanzar densidades de hasta 130 viviendas por hectárea en suelo urbanizable (en suelo urbano se pueden alcanzar edificabilidades de hasta $2,3 \mathrm{~m}^{2} \mathrm{t} / \mathrm{m}^{2} \mathrm{~s}$, lo que supondría 230 viviendas por hectárea aplicando la misma equivalencia). 
Cuadro 23: Límites de densidad en las normativas estudiadas. Conceptos limitados

\begin{tabular}{|l|c|c|c|c|c|c|c|}
\hline Límites & Aragón & $\begin{array}{l}\text { Castilla } \\
\text { y León }\end{array}$ & $\begin{array}{l}\text { Cast.-La } \\
\text { Mancha }\end{array}$ & Cataluña & Navarra & $\begin{array}{l}\text { País } \\
\text { Vasco }\end{array}$ & $\begin{array}{l}\text { C. } \\
\text { lenciana }\end{array}$ \\
\hline Viviendas & & $\mathrm{X}$ & & $\mathrm{X}$ & $\mathrm{X}$ & & \\
\hline $\begin{array}{l}\text { Edificabilidad } \\
\text { residencial }\end{array}$ & $\mathrm{X}$ & & $\mathrm{X}$ & & & & $\mathrm{X}$ \\
\hline $\begin{array}{l}\text { Edificabilidad } \\
\text { total }\end{array}$ & & $\mathrm{X}$ & & & $\mathrm{X}$ & $\mathrm{X}$ & \\
\hline
\end{tabular}

El cuadro 24 resume los límites, máximos y mínimos, sobre densidad y edificabilidad propuestos por cada normativa.

CuAdro 24: Límites máximos y mínimos de densidad o edificabilidad en las normativas estudiadas

\begin{tabular}{|c|c|c|c|}
\hline \multicolumn{2}{|l|}{ Normativa } & Densidad máxima & Densidad mínima \\
\hline \multicolumn{2}{|l|}{ Aragón } & $\begin{array}{l}8.500 \mathrm{~m}^{2} \text { de edif. residen- } \\
\text { cial/ha }\end{array}$ & $\overline{-}-$ \\
\hline \multirow[t]{3}{*}{ Castilla y León } & PGOU > 20.000 hab. & $10.000 \mathrm{~m}^{2} / \mathrm{ha} ; 70$ viv./ha & 40 viv./ha \\
\hline & PGOU $<20.000$ hab. & $7.500 \mathrm{~m}^{2} / \mathrm{ha} ; 50$ viv./ha & 20 viv./ha \\
\hline & NUM & $5.000 \mathrm{~m}^{2} / \mathrm{ha} ; 30$ viv./ha & 20 viv./ha \\
\hline \multicolumn{2}{|c|}{ Castilla-La Mancha } & $\begin{array}{l}10.000 \mathrm{~m}^{2} \text { de edif. residen- } \\
\text { cial/ha }\end{array}$ & $\begin{array}{c}- \\
-\end{array}$ \\
\hline \multicolumn{2}{|l|}{ Cataluña } & "100 viv./ha & - \\
\hline \multicolumn{2}{|c|}{ Reglamento de Planeamiento de 1978} & $\begin{array}{l}75 \text { viv./ha (excepcionalmente } \\
100)\end{array}$ & 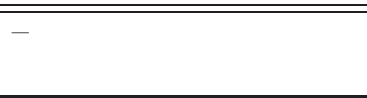 \\
\hline \multirow[t]{3}{*}{ Navarra } & $>25.000$ hab. & $5.500 \mathrm{~m}^{2} /$ ha ó 50 viv./ha & 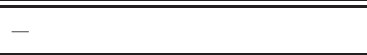 \\
\hline & $\begin{array}{l}2.000-25.000 \text { hab. (y } \\
\text { mpios. }>1.000 \text { hab. } \\
\text { contiguos a Pamplona })\end{array}$ & $4.500 \mathrm{~m}^{2} /$ ha ó $40 \mathrm{viv} . / \mathrm{ha}$ & - \\
\hline & Resto de municipios & $4.500 \mathrm{~m}^{2} /$ ha ó 35 viv./ha & - \\
\hline \multirow[t]{2}{*}{ País Vasco } & Población >7.000 hab. & $\begin{array}{l}\text { Edif. máxima sobre rasante: } \\
1,3 \mathrm{~m}^{2} \mathrm{t} / \mathrm{m}^{2} \mathrm{~s}\end{array}$ & $\begin{array}{l}\text { Edif. mínima sobre } \\
\text { rasante: } 0,4 \mathrm{~m}^{2} \mathrm{t} / \mathrm{m}^{2} \mathrm{~s} \\
\text { (excepcionalmente } \\
\left.0,25 \mathrm{~m}^{2} \mathrm{t} / \mathrm{m}^{2} \mathrm{~s}\right)\end{array}$ \\
\hline & $\begin{array}{l}\text { Población }<7.000 \text { hab. } \\
\text { fuera del entorno de } \\
\text { Bilbao, San Sebastián } \\
\text { y Vitoria }\end{array}$ & $\begin{array}{l}\text { Edif. máxima sobre rasante: } \\
1,1 \mathrm{~m}^{2} \mathrm{t} / \mathrm{m}^{2} \mathrm{~s}\end{array}$ & Ídem \\
\hline \multicolumn{2}{|l|}{ C. Valenciana } & Edif. residencial: $1 \mathrm{~m}^{2} \mathrm{t} / \mathrm{m}^{2} \mathrm{~s}$ & - \\
\hline
\end{tabular}

Como ya se ha señalado, hay dos comunidades autónomas que han introducido densidades mínimas. Se trata de Castilla y León y el País Vasco:

- En el caso castellanoleonés, el Reglamento de Urbanismo ha impuesto unas densidades mínimas para los sectores de uso residencial de 30 viviendas por hectárea para ciudades de más de 20.000 habitantes y de 20 viviendas por hectárea para el resto de poblaciones.

- En cuanto al País Vasco, el límite mínimo de densidad no se refiere explícitamente a viviendas, sino que se refiere a la edificabilidad total dentro de sectores de uso residencial. Este límite mínimo se establece en $0,4 \mathrm{~m}^{2} \mathrm{t} / \mathrm{m}^{2} \mathrm{~s}$, que excepcionalmente ${ }^{6}$ puede reducirse hasta $0,25 \mathrm{~m}^{2} \mathrm{t} / \mathrm{m}^{2} \mathrm{~s}$. Realizando

\footnotetext{
${ }^{6}$ La excepcionalidad requiere el permiso de la Administración autonómica.
} 
la equivalencia habitual de 1 vivienda $=100 \mathrm{~m}^{2}$ construidos, podríamos decir que la densidad mínima es de 40 viviendas por hectárea (25 viviendas por hectárea excepcionalmente).

La aplicación de estos estándares de densidad mínima pretende evitar el desarrollo de urbanizaciones de baja densidad. Este es un tipo de desarrollo que está teniendo cierto éxito comercial en nuestro país, muchas veces acompañados de campos de golf. Dicho modelo suele tener densidades muy reducidas, inferiores a 20 viviendas por hectárea, puesto que el campo de golf queda incluido en el sector, lo cual reduce la densidad del conjunto ${ }^{7}$.

La figura 18 nos permite comparar el rango de densidades de viviendas que admite cada una de las normativas estudiadas. Para ello ha sido necesario homogeneizar las diferentes unidades de medida y los límites se han referido a viviendas por hectárea. Se ha considerado la equivalencia de 1 vivienda $=100$ $\mathrm{m}^{2}$ construidos, como ya se hizo en el capítulo anterior para el desarrollo de los sectores tipo. En las normativas que establecen límites a la edificabilidad total del sector, sin distinguir si es de uso residencial o de cualquier otro, se ha considerado que toda la edificabilidad permitida se destina a uso residencial; siempre y cuando no exista un límite paralelo de viviendas por hectárea, como ocurre en los casos navarro y castellanoleonés, en los que se utiliza éste último.

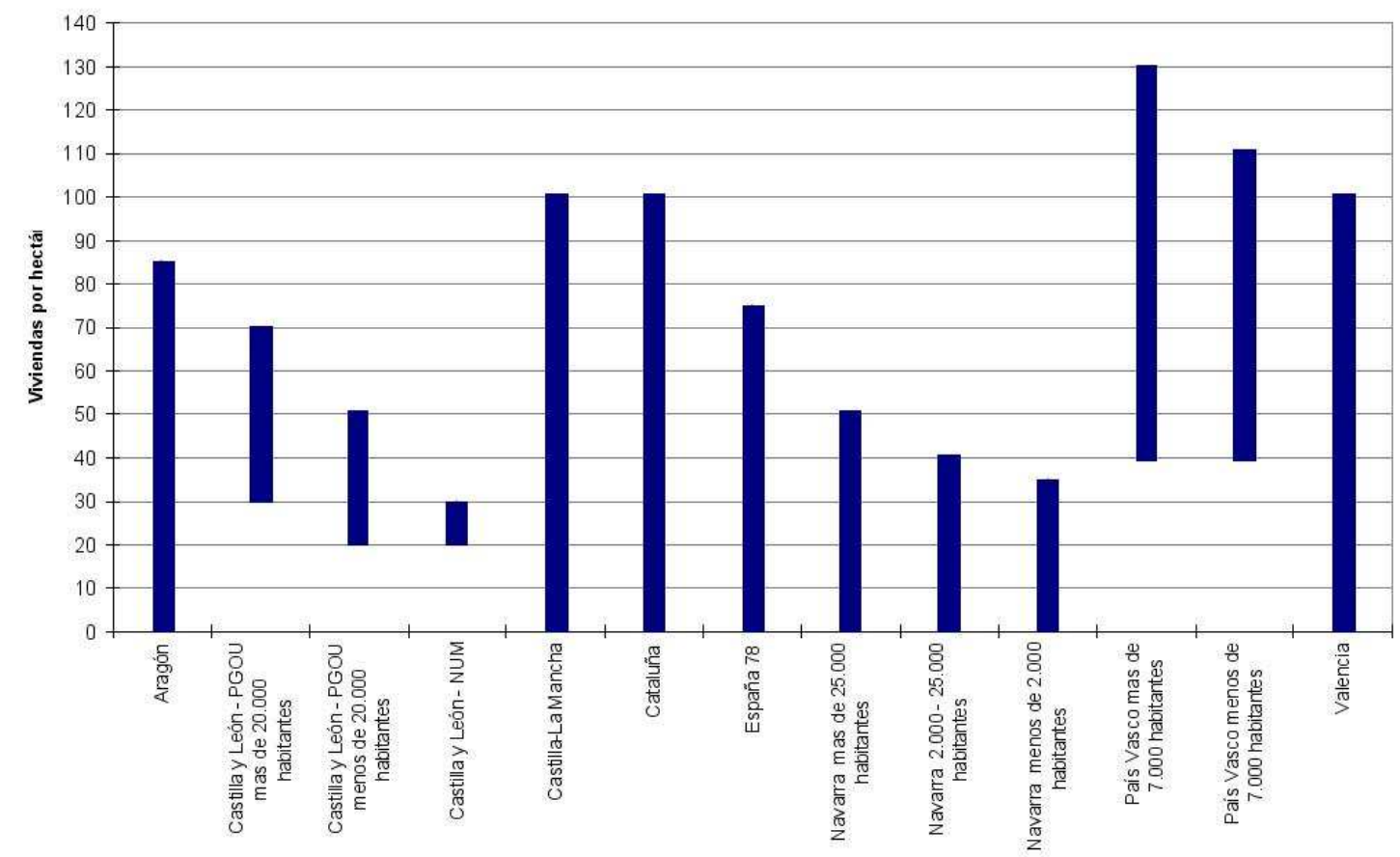

FigurA 18: Rangos de densidades permitidos por las normativas estudiadas Elaboración propia

Como vemos, existe una importante dispersión de criterios de densidad en las normativas estudiadas. Merece la pena llamar la atención sobre algunos aspectos:

- La densidad máxima permitida en el País Vasco (poblaciones de más de 7.000 habitantes) es más de cuatro veces superior a la densidad máxima permitida en los pequeños municipios de Castilla y León: 130 viviendas por hectárea frente a 30 viviendas por hectárea.

- Las densidades mínimas previstas en el País Vasco son más altas que algunas densidades máximas, como las de Navarra en municipios de menos de 25.000 habitantes y Castilla-León en el caso de los pequeños municipios con Normas urbanísticas municipales.

\footnotetext{
${ }^{7}$ En el capítulo cuarto se dedica algo más de espacio a este modelo de desarrollo.
} 
- Respecto al límite de 75 viviendas por hectárea de la Ley estatal del Suelo de 1976, todas las comunidades autónomas estudiadas han decidido elevarlo, salvo Navarra y Castilla-León, que lo han reducido (ostensiblemente en el caso de Navarra).

En definitiva, la comparación de los estándares de densidad muestra que no existe un consenso en cuanto a la densidad idónea para el desarrollo residencial de la ciudad.

\section{Espacios libres públicos}

El concepto de espacios libres públicos fue introducido por la Ley del Suelo de 1956, diferenciándolo de otros espacios sin edificar, como pueden ser los viales o los jardines privados ${ }^{8}$. El concepto quedó definido explícitamente como una serie de espacios calificados por el planeamiento para la ubicación de zonas verdes y para el uso de la población como elemento de ocio o recreo, de libre acceso e independiente de otras funciones como puede ser la movilidad. Desde entonces, perdura en la totalidad de las normativas estudiadas con escasas variaciones en cuanto a su nombre y definición. Tal vez por ello, en los estándares que regulan la implantación de los espacios libres existe una continuidad con las determinaciones de la legislación estatal, por lo que no se da la dispersión de criterios que observamos en el tema de la densidad.

\section{Tipologías de espacios libres}

En general, en la mayoría de las normativas se distinguen varios elementos que componen, en conjunto, el sistema de espacios libres públicos. La mayoría de las normativas establecen unas condiciones mínimas que han de cumplir los espacios que componen el sistema de espacios libres. El cuadro 25 muestra un resumen de estas condiciones cuando se establecen de forma numérica.

Como vemos, los diámetros y superficies, que son los parámetros utilizados para condicionar el diseño de los espacios libres, no varían mucho respecto a los que estableció el Reglamento de Planeamiento de 1978.

\section{Criterios para el diseño de los espacios libres}

Además de las condiciones "cuantitativas" que hemos comentado, las normativas establecen otras condiciones "cualitativas", como son los criterios de diseño y ubicación de los espacios libres. Por ejemplo, el Reglamento de Planeamiento de 1978, en el artículo 4.a de su anexo, señalaba que los jardines debían «poseer condiciones apropiadas para la plantación de especies vegetales y tener garantizado su adecuado soleamiento», lo cual implica una correcta ubicación.

Algunas de las normativas estudiadas, posteriores al Reglamento de Planeamiento de 1978, han profundizado en el establecimiento de criterios para el diseño de los espacios libres. Una de las cuestiones que ha merecido mayor atención es la de asegurar que se puedan plantar especies vegetales en, al menos, una parte de los espacios libres. Así lo recogen los reglamentos de Castilla y León y Valencia, que obligan a que el $50 \%$ de todo el sistema de espacios libres sea apto para la plantación de especies vegetales. En el Reglamento castellano-leonés, esta cuestión se regula en el artículo 80 a través del «índice de permeabilidad, o porcentaje de superficie destinado a la plantación de especies vegetales», lo cual da muestra del interés por paliar el problema de la excesiva impermeabilización del suelo en las ciudades mediante espacios permeables.

Otra preocupación reflejada en algunos reglamentos es la correcta ubicación de los espacios libres y su articulación en un sistema coherente. Así por ejemplo, el Reglamento de Planeamiento de CastillaLa Mancha indica en el artículo 24 que «las reservas de suelo para zonas verdes deberán ubicarse en localizaciones que presten el mejor servicio a los residentes y usuarios, estando prohibido las de difícil acceso y recorrido peatonal o faltas de centralidad».

El Reglamento de Navarra, por su parte, en el artículo 18, trata de evitar la fragmentación de las zonas verdes, indicando que «en la composición de los espacios libres y zonas verdes se evitará el fraccionamiento que invalide su finalidad esencial, debiendo justificarse que constituyen un elemento coherente y fundamental de la ordenación urbanística».

Pero el más explícito al regular la ubicación de las zonas verdes es el Reglamento de Ordenación y Gestión Territorial y Urbanística de la Comunidad Valenciana, que dedica un artículo completo a las condiciones de calidad que han de cumplir las zonas verdes públicas, del cual se extraen las siguientes citas literales:

\footnotetext{
${ }^{8}$ En la Ley de 1956, el concepto de espacio libre «era amplísimo y comprensivo prácticamente de todo terreno libre de edificación por prescripción urbanística» (GARCía DE EnTERRÍA Y PAREJo Alfonso, 1981:209).
} 
CuAdro 25: Condiciones de los distintos tipos de espacios libres en las normativas estudiadas (salvo Cataluña y País Vasco)

\begin{tabular}{|c|c|c|c|c|c|c|}
\hline & & \multicolumn{2}{|c|}{$<100$ viviendas } & \multicolumn{2}{|c|}{$>100$ viviendas } & $>1.000$ viviendas \\
\hline \multirow[t]{4}{*}{ Aragón } & $\begin{array}{l}\text { Parques, plazas } \mathbf{y} \\
\text { jardines }\end{array}$ & \multicolumn{2}{|c|}{$\begin{array}{l}\text { Sup. }>500 \mathrm{~m}^{2} \mathrm{y} \\
20 \mathrm{~m} \varnothing\end{array}$} & \multicolumn{2}{|c|}{$\begin{array}{l}\text { Sup. }>1.000 \mathrm{~m}^{2} \mathrm{y} \\
30 \mathrm{~m} \varnothing\end{array}$} & $\begin{array}{l}\text { Sup. }>8.000 \mathrm{~m}^{2} \mathrm{y} \\
80 \mathrm{~m} \varnothing\end{array}$ \\
\hline & Paseos peatonales & \multicolumn{5}{|c|}{$\begin{array}{l}500 \mathrm{~m}^{2} \text { de sup. y dimensiones largo-ancho de } 50 \text { y } 10 \\
\mathrm{~m} \text { respectivamente }\end{array}$} \\
\hline & Áreas de juego & \multicolumn{5}{|c|}{$\begin{array}{l}200 \mathrm{~m}^{2} \text { de sup. y sup. }>15 \% \text { del total del sistema de } \\
\text { espacios libres }\end{array}$} \\
\hline & \multicolumn{6}{|c|}{$\begin{array}{l}\text { La sup. ajardinada ha de ser igual o mayor del } 50 \% \text { de la sup. total del } \\
\text { sistema de espacios libres } \\
\text { También debe plantarse un árbol por cada } 30 \mathrm{~m}^{2} \text { de sup. del sistema de } \\
\text { espacios libres }\end{array}$} \\
\hline \multirow[t]{3}{*}{\begin{tabular}{ll|} 
Castilla & y \\
León &
\end{tabular}} & \multicolumn{2}{|c|}{$\begin{array}{l}\text { Zonas verdes (aptas pa- } \\
\text { ra la plantación de especies } \\
\text { vegetales) }\end{array}$} & \multicolumn{4}{|c|}{$\begin{array}{l}\text { Mínimo } 50 \% \text { de la sup. de todo el sistema de } \\
\text { espacios libres (también se denomina Índice de } \\
\text { Permeabilidad) }\end{array}$} \\
\hline & \multicolumn{2}{|c|}{ Espacios libres (en general) } & \multicolumn{4}{|c|}{ Sup. $>500 \mathrm{~m}^{2}$ y $20 \mathrm{~m} \varnothing$} \\
\hline & \multicolumn{2}{|c|}{$\begin{array}{l}\text { Áreas de juego (dentro de los } \\
\text { espacios libres) }\end{array}$} & \multicolumn{3}{|c|}{ Sup. $>200 \mathrm{~m}^{2}$} & \\
\hline \multirow{3}{*}{$\begin{array}{l}\text { Castilla-La } \\
\text { Mancha }\end{array}$} & Áreas de juego & \multicolumn{5}{|c|}{ Sup. $>200 \mathrm{~m}^{2}$ y $12 \mathrm{~m} \varnothing$} \\
\hline & Jardines & \multicolumn{5}{|c|}{ Sup. $>1.000 \mathrm{~m}^{2}$ y $30 \mathrm{~m} \varnothing$} \\
\hline & Parques & \multicolumn{5}{|c|}{ Sup. $>15.000 \mathrm{~m}^{2}$ y $100 \mathrm{~m} \varnothing$} \\
\hline \multirow{3}{*}{$\begin{array}{l}\text { Reglamento } \\
\text { de Planea- } \\
\text { miento de } \\
1978\end{array}$} & Jardines & \multicolumn{5}{|c|}{ Sup. $>1.000 \mathrm{~m}^{2}$ y $30 \mathrm{~m} \mathrm{\varnothing}$} \\
\hline & $\begin{array}{l}\text { Áreas de juego y } \\
\text { recreo para niños }\end{array}$ & \multicolumn{5}{|c|}{ Sup. $>200 \mathrm{~m}^{2}$ y $12 \mathrm{~m} \varnothing$} \\
\hline & Áreas peatonales & \multicolumn{5}{|c|}{ Sup. $>1.000 \mathrm{~m}^{2}$ y $30 \mathrm{~m} \varnothing$} \\
\hline \multirow[t]{4}{*}{ Navarra } & & \multicolumn{3}{|c|}{$<100$ viviendas } & \multicolumn{2}{|c|}{$>100$ viviendas } \\
\hline & $\begin{array}{l}\text { Zonas verdes } y \\
\text { plazas peatonales }\end{array}$ & \multicolumn{3}{|c|}{ Sup. $>500 \mathrm{~m}^{2}$ y $20 \mathrm{~m} \varnothing$} & \multicolumn{2}{|c|}{$\begin{array}{l}\text { Sup. }>1.000 \mathrm{~m}^{2}, 30 \mathrm{~m} \varnothing \mathrm{y} \\
\text { anchura }>15 \mathrm{~m}\end{array}$} \\
\hline & Paseos y bulevares & \multicolumn{5}{|c|}{\begin{tabular}{|l|l|} 
& Sup. $>1.000 \mathrm{~m}^{2}$ \\
\end{tabular}} \\
\hline & $\begin{array}{l}\text { Áreas de juego y } \\
\text { recreo para niños }\end{array}$ & \multicolumn{3}{|l|}{$8 \mathrm{~m} \varnothing$} & \multicolumn{2}{|c|}{ Sup. $>200 \mathrm{~m}^{2}$ y $12 \mathrm{~m} \varnothing$} \\
\hline \multirow{3}{*}{$\begin{array}{l}\text { C. Valen- } \\
\text { ciana }\end{array}$} & Área de juego & \multicolumn{5}{|c|}{ Sup. $>200 \mathrm{~m}^{2}$ y $12 \mathrm{~m} \varnothing$} \\
\hline & Jardines & \multicolumn{5}{|c|}{ Sup. $>1.000 \mathrm{~m}^{2}$ y $25 \mathrm{~m} \varnothing$} \\
\hline & Parques urbanos & \multicolumn{5}{|c|}{ Sup. $>25.000 \mathrm{~m}^{2}$ y $150 \mathrm{~m} \varnothing$} \\
\hline
\end{tabular}


Su posición [las zonas verdes] será la que preste mejor servicio a los residentes y usuarios, estando prohibidas las localizaciones de difícil acceso peatonal o cuya falta de centralidad no se compense con otras ventajas para aquellos. [...]

Nunca se destinarán a zona verde porciones residuales de la parcelación, ni se considerarán como tales las superficies de funcionalidad viaria estricta. A estos efectos, las rotondas no podrán computar como parte de las zonas verdes, pero sí podrán hacerlo las áreas lineales ajardinadas de bulevares y avenidas, [...].

En todo caso, [...] la zona de protección de las carreteras no computará como zona verde. [...]

Su emplazamiento evitará aquellas zonas de topografía natural que encarezcan en exceso la urbanización, o impliquen desmontes de impacto paisajístico inadecuado.

Reglamento de Ordenación y Gestión Territorial y Urbanística de la Comunidad Valenciana, art. 128

\section{Estándares de espacios libres}

Además del estándar de espacios libres para nuevos sectores residenciales, que ya hemos estudiado en el capítulo segundo, la mayoría de las normativas establecen un estándar mínimo de espacios libres con carácter de sistema general. Este estándar se refiere a espacios libres al servicio de toda la población, y no de un ámbito en particular. En todos los casos, es un estándar definido en función de la población del municipio, tanto la existente como la prevista por el planeamiento.

Por ello, el cálculo del número de habitantes previstos es un aspecto discutido. Ninguna normativa aporta un criterio al respecto, salvo la valenciana y la vasca:

- El Reglamento de Ordenación y Gestión Territorial y Urbanística de la Comunidad Valenciana, en el artículo 108, señala que 1 vivienda equivale a $100 \mathrm{~m}^{2}$ de techo residencial y se considera que aloja a 2,1 habitantes, aunque admite que se adopte otro criterio de forma justificada.

- En cuanto a la Ley de Suelo y Urbanismo del País Vasco, en el artículo 78, indica que se debe considerar 1 habitante por cada $25 \mathrm{~m}^{2}$ construidos destinados a vivienda, lo que equivale a 4 habitantes por cada $100 \mathrm{~m}^{2}$ construidos residenciales.

Para poder comparar los estándares de espacios libres referidos a habitantes con los estándares referidos a viviendas o edificabilidad, necesitamos homogeneizar los datos. Para ello, consideraremos 2,9 habitantes por vivienda, partiendo de los datos del censo de vivienda 2001 del Instituto Nacional de Estadística $^{9}$, exceptuando los casos valenciano y vasco, que ya aportan sus propios criterios.

En el cuadro 26 se resumen los estándares de espacios libres, tanto los correspondientes a sistemas generales como los sistemas locales. Además, se indican con sus valores obtenidos de la normativa y también homogeneizados en términos de cantidad de espacio libre por cada $100 \mathrm{~m}^{2}$ de uso residencial (equivalente a una vivienda, según la hipótesis que venimos utilizando en este trabajo).

En la mayoría de las normativas estudiadas, la previsión de sistemas generales de espacios libres tiene en cuenta los sectores de suelo urbanizable, es decir, los nuevos crecimientos. La normativa catalana, es la única que solo tiene en cuenta el suelo urbano para calcular el sistema general de espacios libres: los espacios libres que se correspondientes a los habitantes de suelo urbanizable serán exclusivamente los procedentes de las dotaciones locales.

Los estándares del cuadro 26 podemos representarlos gráficamente (ver figura 19), lo que nos permite observar algunas cuestiones:

- Los estándares de sistema local de espacios libres son relativamente uniformes, situándose entre los 15 y los $21 \mathrm{~m}^{2}$ por cada $100 \mathrm{~m}^{2}$ de uso residencial (no se incluye el País Vasco, que no tiene un módulo por vivienda definido). Estos dos valores límite sólo se diferencian en $3 \mathrm{~m}^{2}$ del estándar establecido por la legislación de 1976, lo que parece evidenciar la bondad de los parámetros ideados hace treinta años.

- Los estándares sobre los sistemas generales de espacios libres, sin embargo, son más variados, pues oscilan entre los $20 \mathrm{~m}^{2}$ por cada $100 \mathrm{~m}^{2}$ de uso residencial del caso vasco y ninguna previsión para los casos de Cataluña y de los municipios castellano-manchegos de menos de 2.000 habitantes.

\footnotetext{
${ }^{9}$ Cifras INE. Boletín informativo del Instituto Nacional de Estadística. 6/2004. Disponible en http://www.ine.es. El tamaño medio del hogar español tiene cada vez menos miembros, como reflejan los datos de este Boletín: ha pasado de 3,2 personas según el censo de 1991 a 2,9 personas en el censo de 2001. Es posible que se siga reduciendo esta cifra debido al aumento de las familias monoparentales y, sobre todo, de los hogares unipersonales.
} 
CuAdro 26: Estándares de espacios libres en las normativas estudiadas

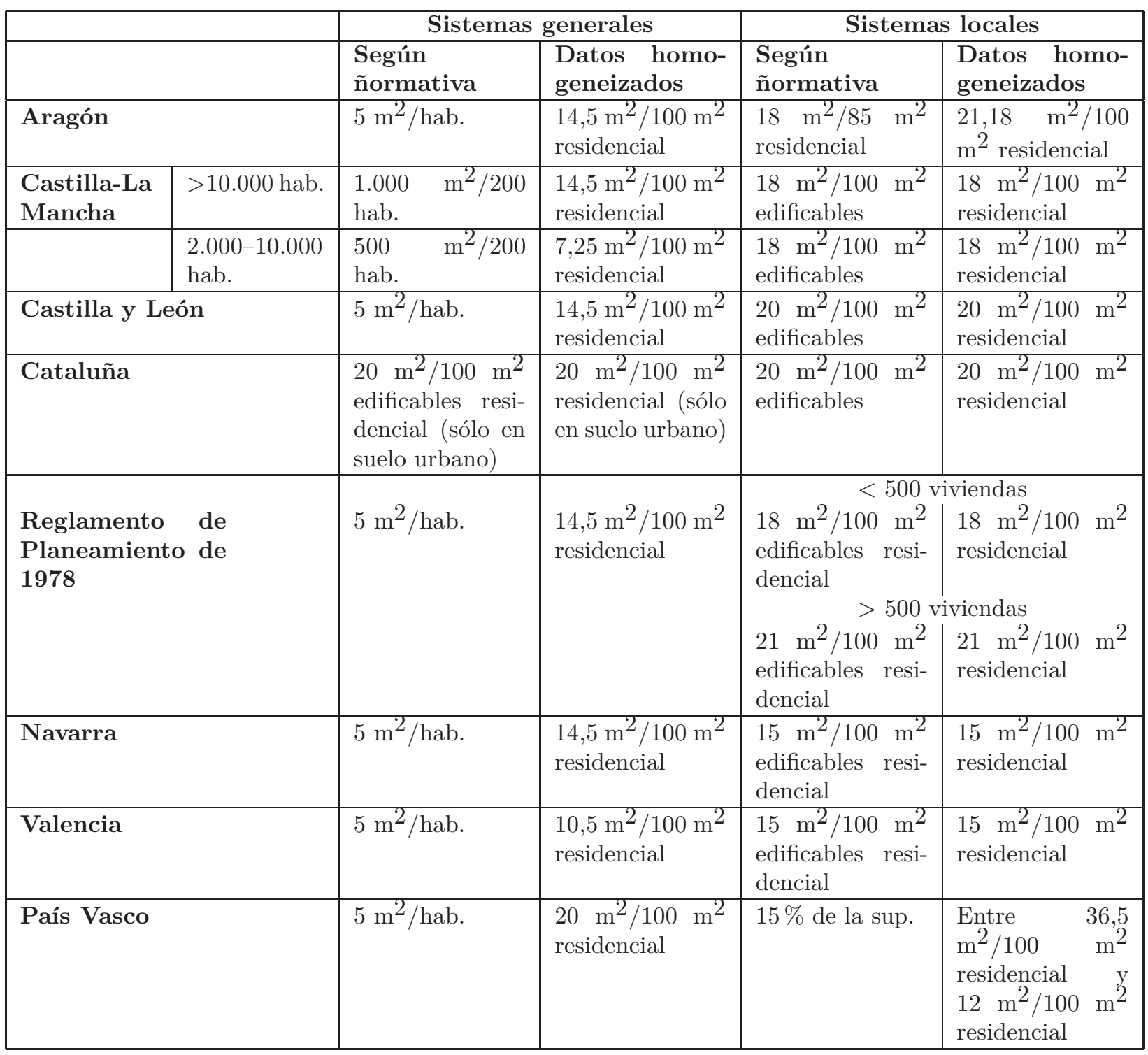




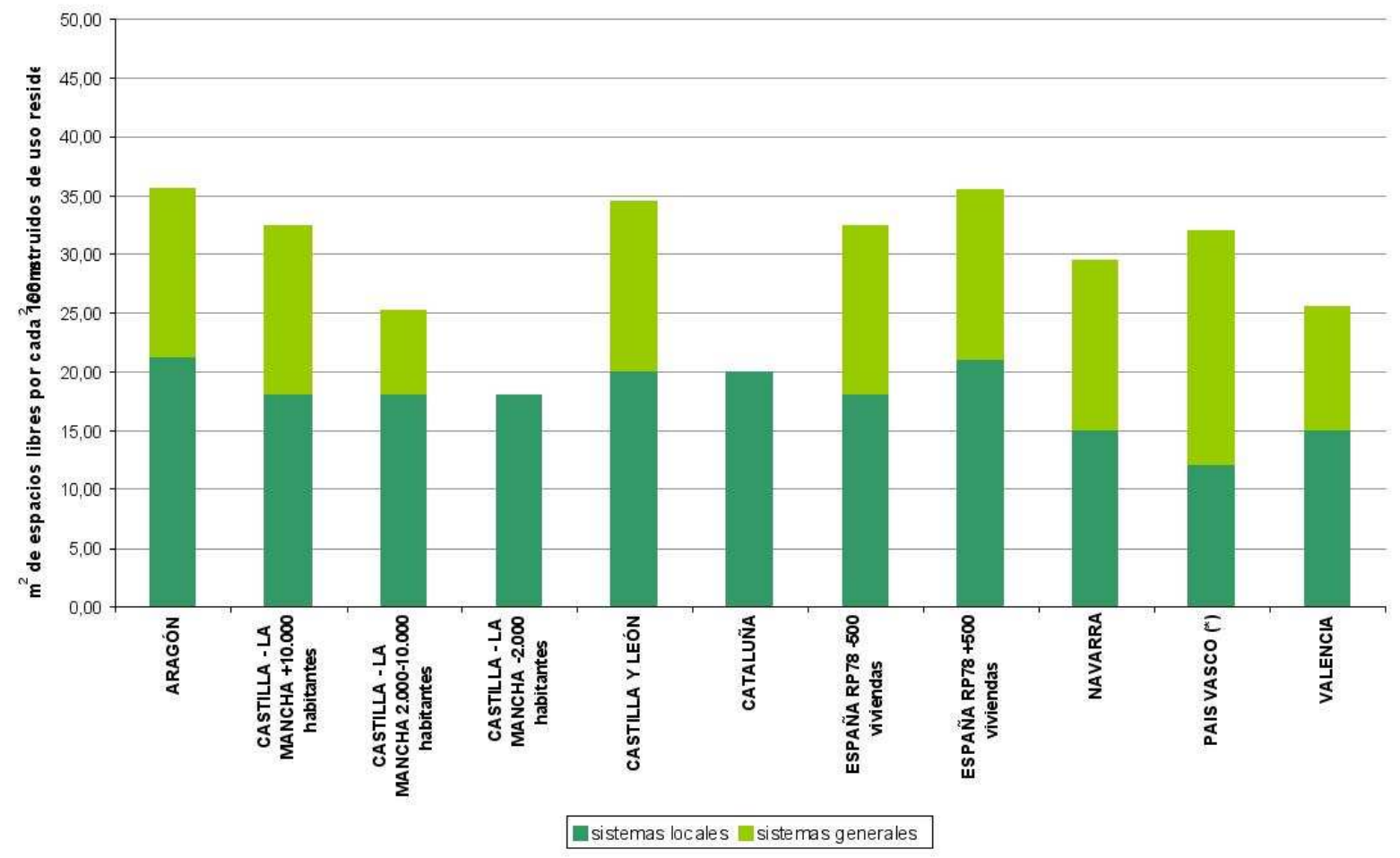

(*) El País Vasco no tiene módulo por vivienda para sectores, por lo que se ha representado la dotación mínima de $12 \mathrm{~m}^{2} / 100 \mathrm{~m}^{2}$ residencial, resultante de aplicar el $15 \%$ de la superficie de un sector con la máxima densidad permitida de 130 vivienda/hectárea.

FigURA 19: Estándar de espacios libres por vivienda correspondientes a sectores de suelo urbanizable

Elaboración propia 
- Así, las diferencias en el estándar de sistemas generales hace que el cómputo total de los espacios libres por vivienda sea dispar: varía entre los 18 y los $36 \mathrm{~m}^{2} / 100 \mathrm{~m}^{2}$ de uso residencial, una diferencia del doble de valor.

Es habitual la publicación de estadísticas de zonas verdes por habitante en las ciudades españolas, como indicador medio ambiental y de calidad de vida. Por ello, vamos a analizar las zonas verdes por habitante que resultan de la aplicación de las normativas estudiadas. Tomando la media española de composición del hogar (2,9 habitantes) y suponiendo que una vivienda equivale a $100 \mathrm{~m}^{2}$ construidos de uso residencial, podemos obtener el ratio de espacios libres por habitante que fijan las respectivas normativas (ver figura 20). Hay que recordar, no obstante, que los espacios libres públicos pueden tener un carácter distinto del de zonas verdes (también pueden ser plazas duras, áreas peatonales, etc.), por lo que no puede tomarse como un indicador de la cantidad de verde por habitante.

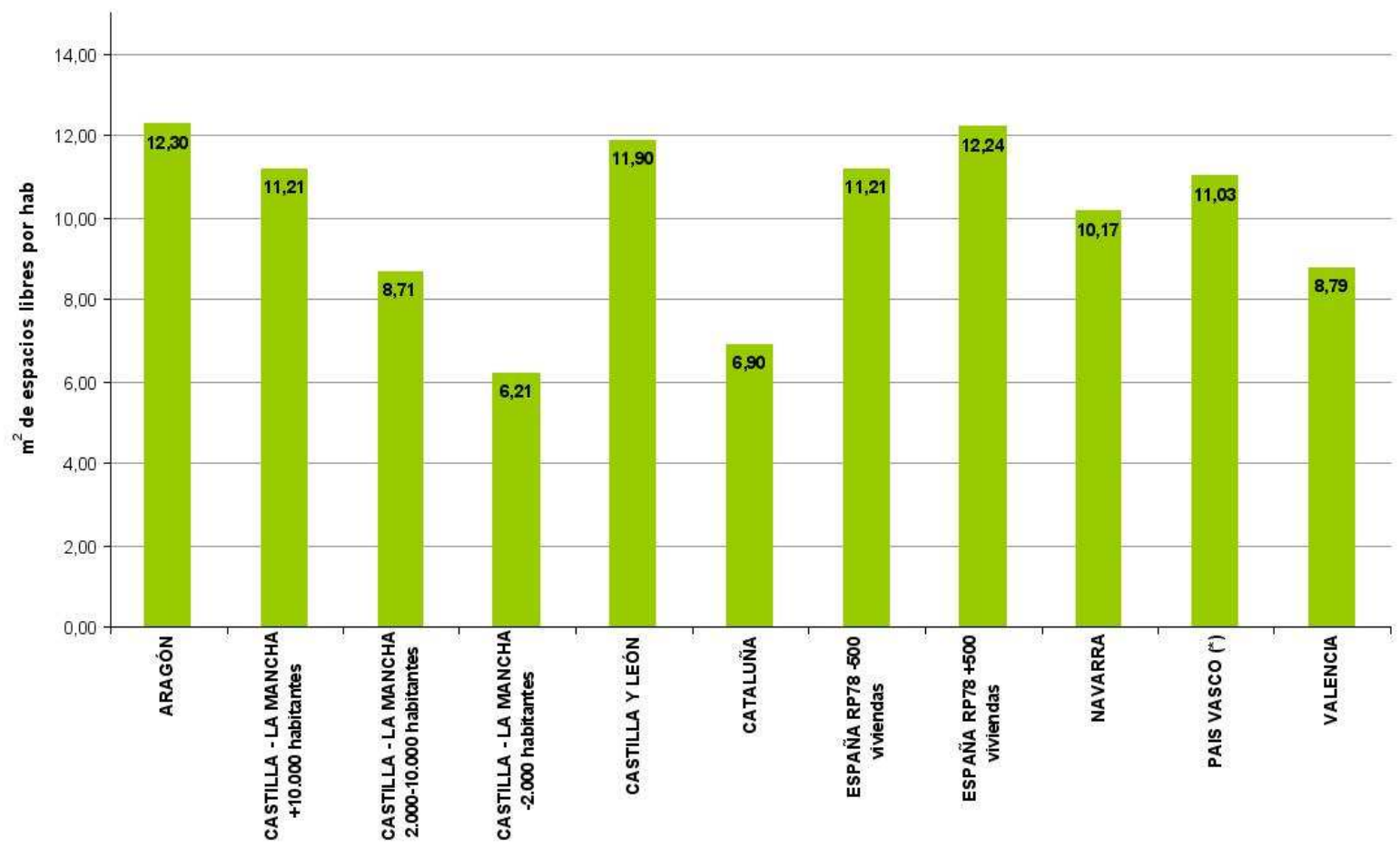

(*) El País Vasco no tiene módulo por vivienda para sectores, por lo que se ha representado la dotación mínima de $12 \mathrm{~m}^{2} / 100 \mathrm{~m}^{2}$ residencial, resultante de aplicar el $15 \%$ de la superficie de un sector con la máxima densidad permitida de 130 vivienda/hectárea.

FIguRA 20: Estándar de espacios libres por habitante de los nuevos sectores de suelo urbanizable (sistemas generales + sistemas locales)

Elaboración propia

\section{Equipamientos}

El concepto de equipamiento no es uniforme en las normativas estudiadas. Para nuestro trabajo, vamos a considerar equipamientos a las dotaciones restantes después de excluir los espacios libres y el viario. Aún así, la variedad de elementos que se recoge en este concepto tan amplio es significativa (ver cuadro 27).

Existe un cierto acuerdo al considerar como equipamientos los usos educativos, culturales, sanitarioasistenciales, recreativo-deportivos y administrativos. Sin embargo, otro tipo de usos son considerados como equipamientos sólo en algunas normativas, como por ejemplo:

- El uso comercial, aparece como equipamiento en el Reglamento de Planeamiento de 1978, en Castilla y León, en Navarra y en el País Vasco. En el resto de normativas estudiadas no está contemplado como equipamiento. 
CUADRO 27: Elementos que se consideran equipamientos en las normativas estudiadas

\begin{tabular}{|c|c|c|c|c|c|c|c|c|}
\hline & Aragón & $\begin{array}{l}\text { Castilla } \\
\text { y León }\end{array}$ & $\begin{array}{l}\text { Cast.-La } \\
\text { Mancha }\end{array}$ & Cataluña & RP-78 & Navarra & P. Vasco & $\begin{array}{l}\text { C. } \\
\text { Valen- } \\
\text { ciana }\end{array}$ \\
\hline Educativo & $\mathrm{X}$ & $\mathrm{X}$ & $\mathrm{X}$ & $\mathrm{X}$ & $\mathrm{X}$ & $\mathrm{X}$ & $\mathrm{X}$ & $\mathrm{X}$ \\
\hline Cultural & & $\mathrm{X}$ & $\mathrm{X}$ & $\mathrm{X}$ & & $\mathrm{X}$ & $\mathrm{X}$ & $\mathrm{X}$ \\
\hline Sanitario & & $\mathrm{X}$ & $\mathrm{X}$ & $\mathrm{X}$ & & $\mathrm{X}$ & $\mathrm{X}$ & \\
\hline Social & $\mathrm{X}$ & & & & $\mathrm{X}$ & $\mathrm{X}$ & & \\
\hline Asistencial & & $\mathrm{X}$ & $\mathrm{X}$ & $\mathrm{X}$ & & $\mathrm{X}$ & $\mathrm{X}$ & $\mathrm{X}$ \\
\hline Religioso & & $\mathrm{X}$ & & $\mathrm{X}$ & & $\mathrm{X}$ & $\mathrm{X}$ & \\
\hline Comercial & & $\mathrm{X}$ & & & $\mathrm{X}$ & $\mathrm{X}$ & $\mathrm{X}$ & \\
\hline Deportivo & $\mathrm{X}$ & $\mathrm{X}$ & $\mathrm{X}$ & $\mathrm{X}$ & $\mathrm{X}$ & & $\mathrm{X}$ & $\mathrm{X}$ \\
\hline $\begin{array}{l}\text { Adminis- } \\
\text { trativo }\end{array}$ & & $\bar{X}$ & $\mathrm{X}$ & & & $\bar{X}$ & $\bar{X}$ & $\bar{X}$ \\
\hline Ocio & & $\mathrm{X}$ & & & & & & \\
\hline Transporte & & $\mathrm{X}$ & & $\mathrm{X}$ & & & $\mathrm{X}$ & \\
\hline Seguridad & & $\mathrm{X}$ & & & & $\mathrm{X}$ & & \\
\hline $\begin{array}{l}\text { Servicios } \\
\text { urbanos }\end{array}$ & & & $\mathrm{X}$ & $\bar{X}$ & & & $\bar{X}$ & $\mathrm{X}$ \\
\hline Salubridad & & & & & & $\mathrm{X}$ & & \\
\hline $\begin{array}{l}\text { Protección } \\
\text { civil }\end{array}$ & & & & & & $\mathrm{X}$ & & \\
\hline Recreativo & & & & & & $\mathrm{X}$ & & $\mathrm{X}$ \\
\hline Abastos & & & & & & $\mathrm{X}$ & & \\
\hline
\end{tabular}

- Salvo en Aragón, Castilla y León y en el reglamento estatal, las normativas incluyen entre los equipamientos los servicios técnicos o urbanos que, en general, se refieren a instalaciones relacionadas con el abastecimiento de agua, saneamiento, recogida de residuos, etc.

No obstante, para este trabajo no vamos a valorar la definición de los equipamientos ni los distintos elementos que los componen. Nos centraremos en los estándares numéricos que las normativas consideran idóneos sobre la dotación de equipamientos. El cuadro 28 resume los datos recogidos; para elaborarla hemos empleado criterios similares a los del resto del trabajo: una vivienda equivale a $100 \mathrm{~m}^{2}$ construidos de uso residencial y en cada vivienda hay 2,9 habitantes ${ }^{10}$.

Además, hemos tenido en cuenta todos los módulos de equipamientos que aparecen en la normativa, incluyendo los sistemas generales (aunque esto sólo se da en Castilla y León) y también los estándares referidos a superficies construidas (como pueden ser las comerciales), que no se tuvieron en cuenta en el capítulo segundo.

En el cuadro 28 no aparece el País Vasco, puesto que su normativa no establece un módulo concreto para equipamientos. También hay que tener en cuenta que en Cataluña se consideran las viviendas de promoción pública como un equipamiento, lo que sin duda distorsiona el cuadro comparativo ${ }^{11}$.

La representación gráfica de los datos de dotaciones expuestos en el cuadro 28 permite visualizar la considerable dispersión respecto a los estándares mínimos.

Las mayores divergencias en cuanto a la cuantificación de los equipamientos se producen en las normativas que diferencian los módulos obligatorios para los sectores dependiendo del número de viviendas que éstos incluyan. Así, vemos como en Aragón se da la máxima cantidad de equipamientos por vivienda, de $42,35 \mathrm{~m}^{2}$ cuando el sector supera las 1.000 viviendas; y también se da una de las mínimas, 11,76 $\mathrm{m}^{2}$ cuando el sector no tiene más de 100 viviendas. Lo mismo ocurre con los módulos del reglamento navarro, e igual ocurría en el Anexo del Reglamento de Planeamiento de 1978, en los que se dan valores muy distintos en función del número de viviendas.

Podemos concluir que no existe un criterio uniforme a la hora de cuantificar las necesidades de equipamientos, ni tampoco sobre los elementos que pueden considerase como tal.

\footnotetext{
${ }^{10}$ Cifras INE. Boletín informativo del Instituto Nacional de Estadística. 6/2004.

${ }^{11}$ En nuestra opinión, las viviendas, aunque sean de propiedad pública, no son un equipamiento al servicio de los habitantes de un sector. Al contrario, añaden población y restan espacio para la implantación de dichos equipamientos, con lo cual no puede decirse que mejoren la calidad de vida de los habitantes del sector.
} 
CuAdro 28: Estándares de equipamientos en las normativas estudiadas

\begin{tabular}{|c|c|c|c|}
\hline & Según normativa & Datos homogeneizados \\
\hline \multirow[t]{5}{*}{ Aragón } & 50-100 viviendas & $10 \mathrm{~m}^{2} /$ vivienda & $11,76 \mathrm{~m}^{2} / 100 \mathrm{~m}^{2}$ residencial \\
\hline & $101-250$ viviendas & $12 \mathrm{~m}^{2} /$ vivienda & $14,12 \mathrm{~m}^{2} / 100 \mathrm{~m}^{2}$ residencial \\
\hline & $251-500$ viviendas & $17 \mathrm{~m}^{2} /$ vivienda & $16,47 \mathrm{~m}^{2} / 100 \mathrm{~m}^{2}$ residencial \\
\hline & $501-1.000$ viviendas & $25 \mathrm{~m}^{2} /$ vivienda & $29,41 \mathrm{~m}^{2} / 100 \mathrm{~m}^{2}$ residencial \\
\hline & $>1.000$ viviendas & $36 \mathrm{~m}^{2} /$ vivienda & $42,35 \mathrm{~m}^{2} / 100 \mathrm{~m}^{2}$ residencial \\
\hline \multicolumn{2}{|c|}{ Castilla-La Mancha } & $20 \mathrm{~m}^{2} / 100 \mathrm{~m}^{2}$ edificables & $20 \mathrm{~m}^{2} / 100 \mathrm{~m}^{2}$ residencial \\
\hline \multirow[t]{2}{*}{$\begin{array}{l}\text { Castilla } \quad \text { y } \\
\text { León }\end{array}$} & PGOU & $\begin{array}{l}20 \mathrm{~m}^{2} / 100 \mathrm{~m}^{2} \text { edificables }+5 \\
\mathrm{~m}^{2} / \text { hab. para sistema general } \\
\text { de equipamientos }\end{array}$ & "34,5 $\mathrm{m}^{2} / 100 \mathrm{~m}^{2}$ residencial \\
\hline & NUM & $20 \mathrm{~m}^{2} / 100 \mathrm{~m}^{2}$ edificables & $20 \mathrm{~m}^{2} / 100 \mathrm{~m}^{2}$ residencial \\
\hline \multicolumn{2}{|l|}{ Cataluña } & 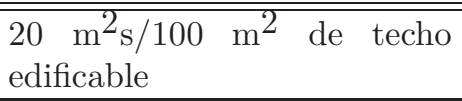 & $20 \mathrm{~m}^{2} / 100 \mathrm{~m}^{2}$ residencial \\
\hline \multirow[t]{5}{*}{ RP-78 } & $<250$ viviendas & $1212 \mathrm{~m}^{2} / 100 \mathrm{~m}^{2}$ residencial & $1212 \mathrm{~m}^{2} / 100 \mathrm{~m}^{2}$ residencial \\
\hline & $251-500$ viviendas & $22 \mathrm{~m}^{2} / 100 \mathrm{~m}^{2}$ residencial & $22 \mathrm{~m}^{2} / 100 \mathrm{~m}^{2}$ residencial \\
\hline & $501-1.000$ viviendas & $24 \mathrm{~m}^{2} / 100 \mathrm{~m}^{2}$ residencial & $24 \mathrm{~m}^{2} / 100 \mathrm{~m}^{2}$ residencial \\
\hline & $1.001-2.000$ viviendas & $29 \mathrm{~m}^{2} / 100 \mathrm{~m}^{2}$ residencial & $29 \mathrm{~m}^{2} / 100 \mathrm{~m}^{2}$ residencial \\
\hline & $>2.000$ viviendas & $34 \mathrm{~m}^{2} / 100 \mathrm{~m}^{2}$ residencial & $34 \mathrm{~m}^{2} / 100 \mathrm{~m}^{2}$ residencial \\
\hline \multirow[t]{5}{*}{ Navarra } & $<250$ viviendas & $13 \mathrm{~m}^{2} / 100 \mathrm{~m}^{2}$ residencial & $13 \mathrm{~m}^{2} / 100 \mathrm{~m}^{2}$ residencial \\
\hline & $251-500$ viviendas & $20 \mathrm{~m}^{2} / 100 \mathrm{~m}^{2}$ residencial & $20 \mathrm{~m}^{2} / 100 \mathrm{~m}^{2}$ residencial \\
\hline & $501-1.000$ viviendas & $23 \mathrm{~m}^{2} / 100 \mathrm{~m}^{2}$ residencial & $23 \mathrm{~m}^{2} / 100 \mathrm{~m}^{2}$ residencial \\
\hline & $1.001-2.000$ viviendas & $25 \mathrm{~m}^{2} / 100 \mathrm{~m}^{2}$ residencial & $25 \mathrm{~m}^{2} / 100 \mathrm{~m}^{2}$ residencial \\
\hline & $>2.000$ viviendas & $29 \mathrm{~m}^{2} / 100 \mathrm{~m}^{2}$ residencial & $29 \mathrm{~m}^{2} / 100 \mathrm{~m}^{2}$ residencial \\
\hline \multicolumn{2}{|l|}{$\overline{\text { Valencia }}$} & "10 $\mathrm{m}^{2} / 100 \mathrm{~m}^{2}$ residencial & $10 \mathrm{~m}^{2} / 100 \mathrm{~m}^{2}$ residencial \\
\hline
\end{tabular}




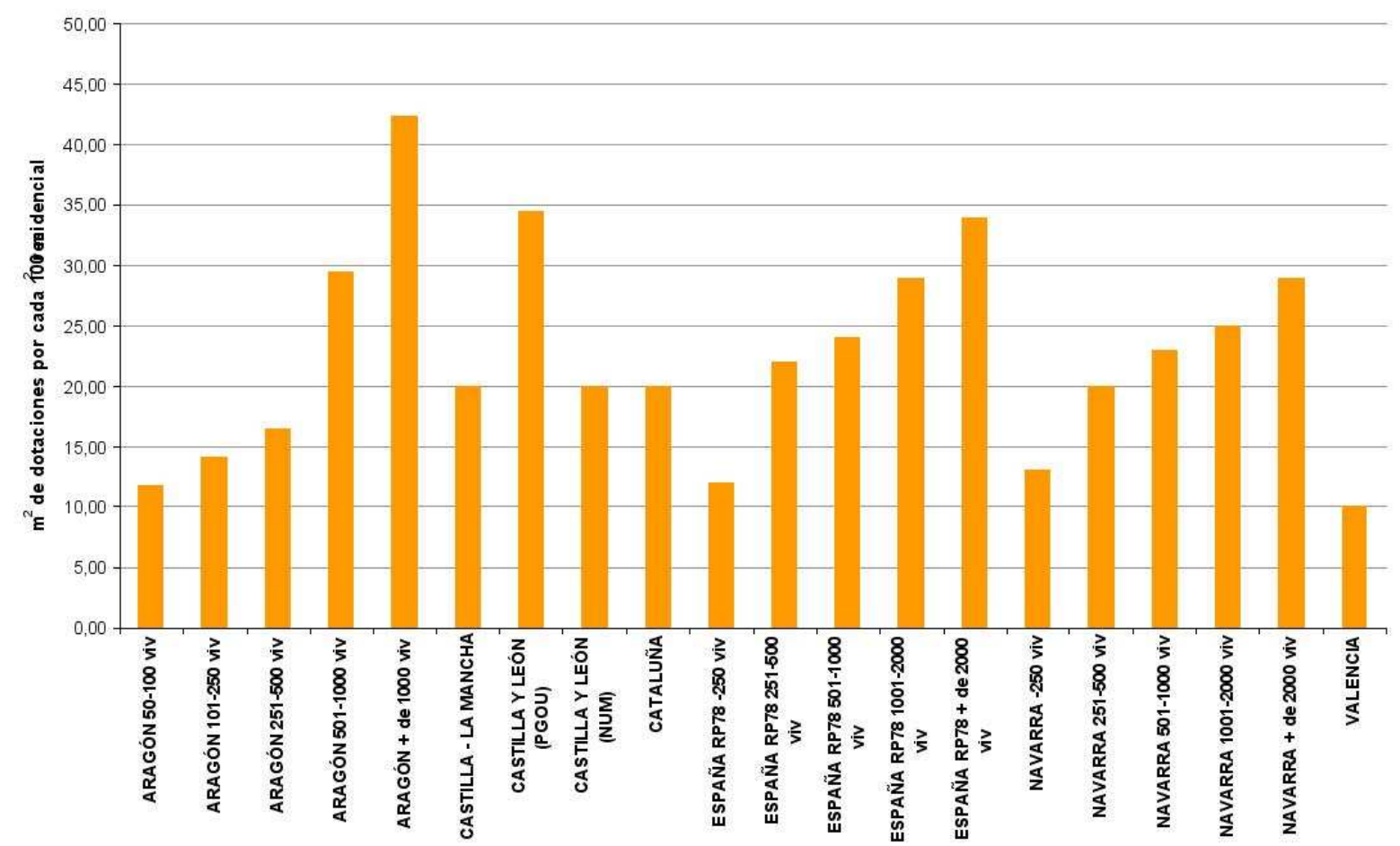

FIGURA 21: Estándar de equipamientos por vivienda en los nuevos sectores de suelo urbanizable

Elaboración propia 


\section{Dotaciones comparadas}

En este punto del trabajo, una vez obtenidos los módulos dotacionales que establecen las normativas para los sectores residenciales, es conveniente comparar los resultados con otros criterios. Para ello, utilizaremos una propuesta teórica sobre el equipamiento idóneo de la ciudad que se recoge ampliamente en el libro La ciudad de los ciudadanos (HERnándeZ AJA, 1997) y en la publicación Parámetros dotacionales para la ciudad de los ciudadanos (HERnÁNDEZ AJA y LeIva RodRígUez, 2006), donde se revisan algunos datos del libro anterior.

Estas publicaciones aportan una serie de propuestas sobre las dotaciones adecuadas para satisfacer las necesidades de los ciudadanos. Estas propuestas se elaboran para distintos tipos de tejido urbano y para distintas composiciones demográficas de la población que los habita.

El tipo de tejido, que puede ser residencial, medio o central, se distingue por la mayor o menor edificabilidad y por la cantidad de usos distintos al residencial que tienen cabida en él:

- Residencial: tejido con un $85 \%$ de la superficie construida destinada a viviendas (sin contar las construcciones dotacionales) y edificabilidades medias de $1 \mathrm{~m}^{2} \mathrm{t} / \mathrm{m}^{2} \mathrm{~s}$ por parcela neta.

- Medio: Tejido con un $75 \%$ de superficie construida de uso residencial y edificabilidades medias de $2 \mathrm{~m}^{2} \mathrm{t} / \mathrm{m}^{2}$ s por parcela neta.

- Central: Tejido con un $66 \%$ de superficie construida destinada a uso residencial y edificabilidades medias de $3 \mathrm{~m}^{2} \mathrm{t} / \mathrm{m}^{2} \mathrm{~s}$ por parcela neta.

En cuanto a la composición demográfica, se plantean distintas posibilidades:

- Población joven, que se refiere a una estructura de grupos de edad en la que la población con menos de 15 años supera en más de un $5 \%$ a la población de más de 65 años.

- Población envejecida, cuando el grupo de más de 65 años agrupa más población que el de los menores de 15 años.

- Población sostenible, cuando la estructura poblacional tiene una composición tal que se asegura la renovación y estabilidad de la población, gracias a que los menores de 15 años son ligeramente más numerosos que los mayores de 65 años.

Los autores de La ciudad de los ciudadanos establecen cuadros de necesidades dotacionales para cada tejido con cada una de las estructuras de población. En el cuadro 29 se muestran estas propuestas para una «población sostenible» (HERNÁNDEZ AJA, 1997:317).

CuAdro 29: Propuesta de dotaciones de La ciudad de los ciudadanos

\begin{tabular}{|l|c|c|c|c|}
\hline \multicolumn{5}{|c|}{ Suelo total para dotaciones en el Barrio-Ciudad con población sostenible $\left(\mathbf{m}^{\mathbf{2}} \mathbf{\text { s}} / \mathbf{v i v}\right.$. $)$} \\
\hline & Viario & Espacio libre & Dotación & Total \\
\hline Tejido residencial & 40 & 24 & 32 & $\mathbf{9 6}$ \\
\hline Tejido medio & 35 & 18 & 20 & $\mathbf{7 3}$ \\
\hline Tejido central & 29 & 15 & 12 & $\mathbf{5 6}$ \\
\hline
\end{tabular}

Las propuestas sobre dotaciones se desglosan según el tamaño del área a la que deben servir, distinguiendo entre Vecindario (500 viviendas), Barrio (3.000 viviendas), Barrio-Ciudad (10.000 viviendas) y Ciudad (unas 33.000 viviendas). Se trata de una división más compleja que la recogida por las normativas, que distinguen entre sistemas locales, al servicio de un barrio; y sistemas generales, al servicio de todo el municipio.

Vemos que también se asigna al viario una cantidad por vivienda, algo que no se propone por parte de ninguna de las normativas estudiadas. Tan sólo el País Vasco, en la reciente Ley, incluye el viario dentro del módulo general de $10 \mathrm{~m}^{2} \mathrm{~s} / 25 \mathrm{~m}^{2}$ construidos destinado a dotaciones públicas, pero no señala una cantidad concreta para viales.

La tabla propone los módulos dotacionales idóneos para un ámbito con tamaño de Barrio-Ciudad (unas 10.000 viviendas y 30.000 habitantes). Estas dotaciones incluyen todas las que tienen carácter local y, además, algunas con rango de ciudad (lo que serían sistemas generales) que habitualmente se distribuyen 
entre los distintos barrios. Por tanto, dentro de los módulos propuestos se incluyen los sistemas locales y parte de los sistemas generales.

Esta propuesta teórica podemos compararla con los valores totales de dotaciones que las normativas consideran como cantidades mínimas necesarias por vivienda dentro de los sectores (ver cuadro 30), aunque sólo tendremos en cuenta los sistemas locales que necesariamente han de formar parte de la ordenación del sector. También se incluyen en los módulos resultantes las dotaciones que no se tuvieron en cuenta para el cálculo de los sectores tipo, porque no consumían superficie de suelo, sino que podían albergarse dentro de otras construcciones (por ejemplo, el equipamiento comercial); en el cuadro 30 se recogen como «equipamientos superficie construida».

CuAdro 30: Módulos dotacionales por vivienda en las normativas estudiadas

\begin{tabular}{|c|c|c|c|c|c|}
\hline & \multicolumn{4}{|c|}{$\begin{array}{l}\text { Dotaciones por vivienda } \\
\left(\mathrm{m}^{2} / 100 \mathrm{~m}^{2} \mathrm{c} \text { uso residencial }\right)\end{array}$} \\
\hline & & \multirow{2}{*}{ Espacios libres } & \multicolumn{2}{|c|}{ Equipamientos } & \multirow{2}{*}{ Total } \\
\hline & & & Sup. suelo & Sup. construida & \\
\hline \multirow[t]{5}{*}{ Aragón } & $50-100$ viv. & $18 \mathrm{~m}^{2}$ & $10 \mathrm{~m}^{2}$ & & $28 \mathrm{~m}^{2}$ \\
\hline & $101-250$ viv. & $18 \mathrm{~m}^{2}$ & $12 \mathrm{~m}^{2}$ & & $30 \mathrm{~m}^{2}$ \\
\hline & $251-500$ viv. & $18 \mathrm{~m}^{2}$ & $17 \mathrm{~m}^{2}$ & & $35 \mathrm{~m}^{2}$ \\
\hline & $501-1.000$ viv. & $18 \mathrm{~m}^{2}$ & $25 \mathrm{~m}^{2}$ & & $43 \mathrm{~m}^{2}$ \\
\hline & $>500$ viv. & $18 \mathrm{~m}^{2}$ & $36 \mathrm{~m}^{2}$ & & $54 \mathrm{~m}^{2}$ \\
\hline \multicolumn{2}{|c|}{ Castilla-La Mancha } & $18 \mathrm{~m}^{2}$ & $20 \mathrm{~m}^{2}$ & & $38 \mathrm{~m}^{2}$ \\
\hline \multicolumn{2}{|c|}{ Castilla y León } & $20 \mathrm{~m}^{2}$ & $20 \mathrm{~m}^{2}$ & & $40 \mathrm{~m}^{2}$ \\
\hline \multicolumn{2}{|c|}{ Cataluña } & $20 \mathrm{~m}^{2}$ & $20 \mathrm{~m}^{2}$ & & $40 \mathrm{~m}^{2}$ \\
\hline \multirow[t]{5}{*}{ RP-78 } & $<250$ viv. & $18 \mathrm{~m}^{2}$ & $10 \mathrm{~m}^{2}$ & $2 \mathrm{~m}^{2}$ & $30 \mathrm{~m}^{2}$ \\
\hline & $251-500$ viv. & $18 \mathrm{~m}^{2}$ & $18 \mathrm{~m}^{2}$ & $4 \mathrm{~m}^{2}$ & $40 \mathrm{~m}^{2}$ \\
\hline & $501-1.000$ viv. & $21 \mathrm{~m}^{2}$ & $18 \mathrm{~m}^{2}$ & $6 \mathrm{~m}^{2}$ & $45 \mathrm{~m}^{2}$ \\
\hline & $1.001-2.000$ viv. & $21 \mathrm{~m}^{2}$ & $20 \mathrm{~m}^{2}$ & $9 \mathrm{~m}^{2}$ & $50 \mathrm{~m}^{2}$ \\
\hline & $>2.000$ viv. & $21 \mathrm{~m}^{2}$ & $24 \mathrm{~m}^{2}$ & $10 \mathrm{~m}^{2}$ & $56 \mathrm{~m}^{2}$ \\
\hline \multirow[t]{5}{*}{ Navarra } & $<250$ viv. & $15 \mathrm{~m}^{2}$ & $13 \mathrm{~m}^{2}$ & $1 \mathrm{~m}^{2}$ & $29 \mathrm{~m}^{2}$ \\
\hline & $251-500$ viv. & $15 \mathrm{~m}^{2}$ & $20 \mathrm{~m}^{2}$ & $4 \mathrm{~m}^{2}$ & $39 \mathrm{~m}^{2}$ \\
\hline & $501-1.000$ viv. & $15 \mathrm{~m}^{2}$ & $23 \mathrm{~m}^{2}$ & $6 \mathrm{~m}^{2}$ & $44 \mathrm{~m}^{2}$ \\
\hline & $1.001-2.000$ viv. & $15 \mathrm{~m}^{2}$ & $25 \mathrm{~m}^{2}$ & $9 \mathrm{~m}^{2}$ & $49 \mathrm{~m}^{2}$ \\
\hline & $>2.000$ viv. & $15 \mathrm{~m}^{2}$ & $29 \mathrm{~m}^{2}$ & $10 \mathrm{~m}^{2}$ & $54 \mathrm{~m}^{2}$ \\
\hline \multicolumn{2}{|c|}{ C. Valenciana (*) } & & & & $35 \mathrm{~m}^{2}$ \\
\hline \multicolumn{2}{|c|}{ País Vasco $(* *)$} & & & & $44 \mathrm{~m}^{2}$ \\
\hline
\end{tabular}

$(*)$ Valencia establece un módulo mínimo global de $35 \mathrm{~m}^{2}$, que puede distribuirse entre espacios libres y equipamientos, con un mínimo de $15 \mathrm{~m}^{2}$ para espacios libres y $10 \mathrm{~m}^{2}$ para equipamientos.

(**) El País Vasco sólo establece un módulo para dotaciones públicas (en el que se incluyen viales) de $40 \mathrm{~m}^{2}$ y otro de dotaciones privadas de $4 \mathrm{~m}^{2}$.

La visualización de los datos del cuadro 30 nos permite ilustrar algunas conclusiones de este capítulo (ver figura 22):

- La dotación de espacios libres es constante en los casos estudiados. Prácticamente puede dibujarse una línea horizontal donde concluyen las barras correspondientes a los espacios libres.

- Sin embargo, los equipamientos muestran importantes saltos entre unos casos y otros, sobre todo cuando una normativa diferencia los sectores por el $n^{\circ}$ de viviendas que contienen.

- Todos los valores se encuentran por encima de la propuesta de dotaciones para tejidos centrales. Sin embargo, ninguna alcanza el nivel dotacional propuesto para tejidos residenciales. 


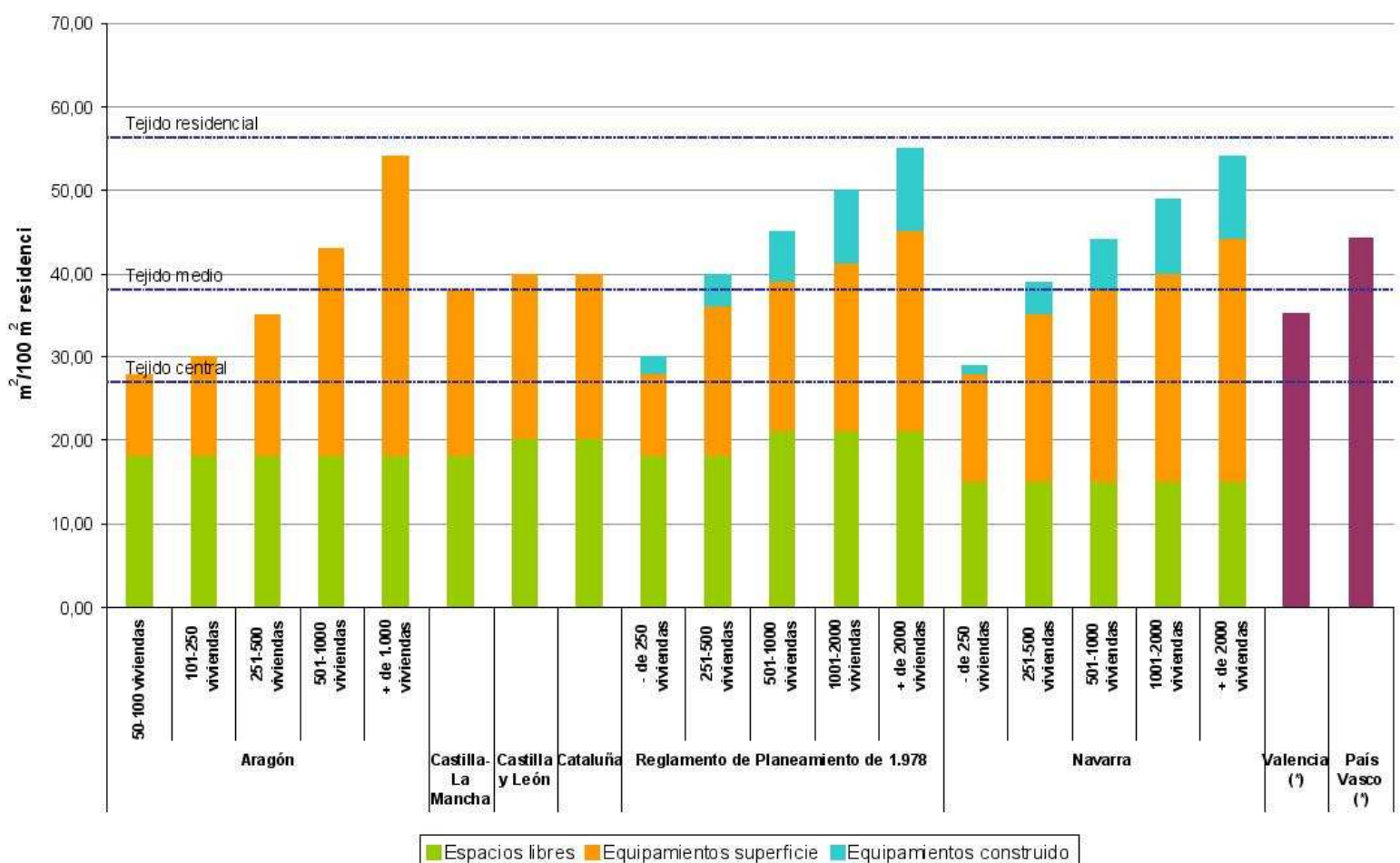

(*) La Comunidad Valenciana y el País Vasco sólo establecen módulos dotacionales de carácter general.

FigURA 22: Estándares dotacionales por vivienda (sistemas locales) en las normativas estudiadas

Elaboración propia 
En conclusión, podemos decir que existe cierto consenso sobre los espacios libres, pero no sobre los equipamientos, lo que evidencia diferencias importantes sobre lo que se consideran dotaciones mínimas para los nuevos sectores residenciales.

\section{Influencia de los estándares en los nuevos desarrollos urbanos}

En este capítulo recuperaremos los datos de los sectores tipo que obtuvimos en el capítulo segundo, con el fin de determinar la influencia de los estándares sobre la forma urbana y la calidad de vida de los habitantes en los nuevos desarrollos.

Para apoyar las conclusiones contenidas en este capítulo emplearemos un tipo de representación gráfica que nos permite visualizar de forma conjunta los dos datos fundamentales de este trabajo: el porcentaje de superficie ocupada por las dotaciones y el ratio de dotaciones por vivienda. Esta gráfica se construye con la suma de las gráficas que vimos en el capítulo segundo. A modo de ejemplo, se muestran las gráficas del apartado correspondiente a la normativa española (ver figuras 23 y 24) y su representación en una única gráfica (ver figura 25).

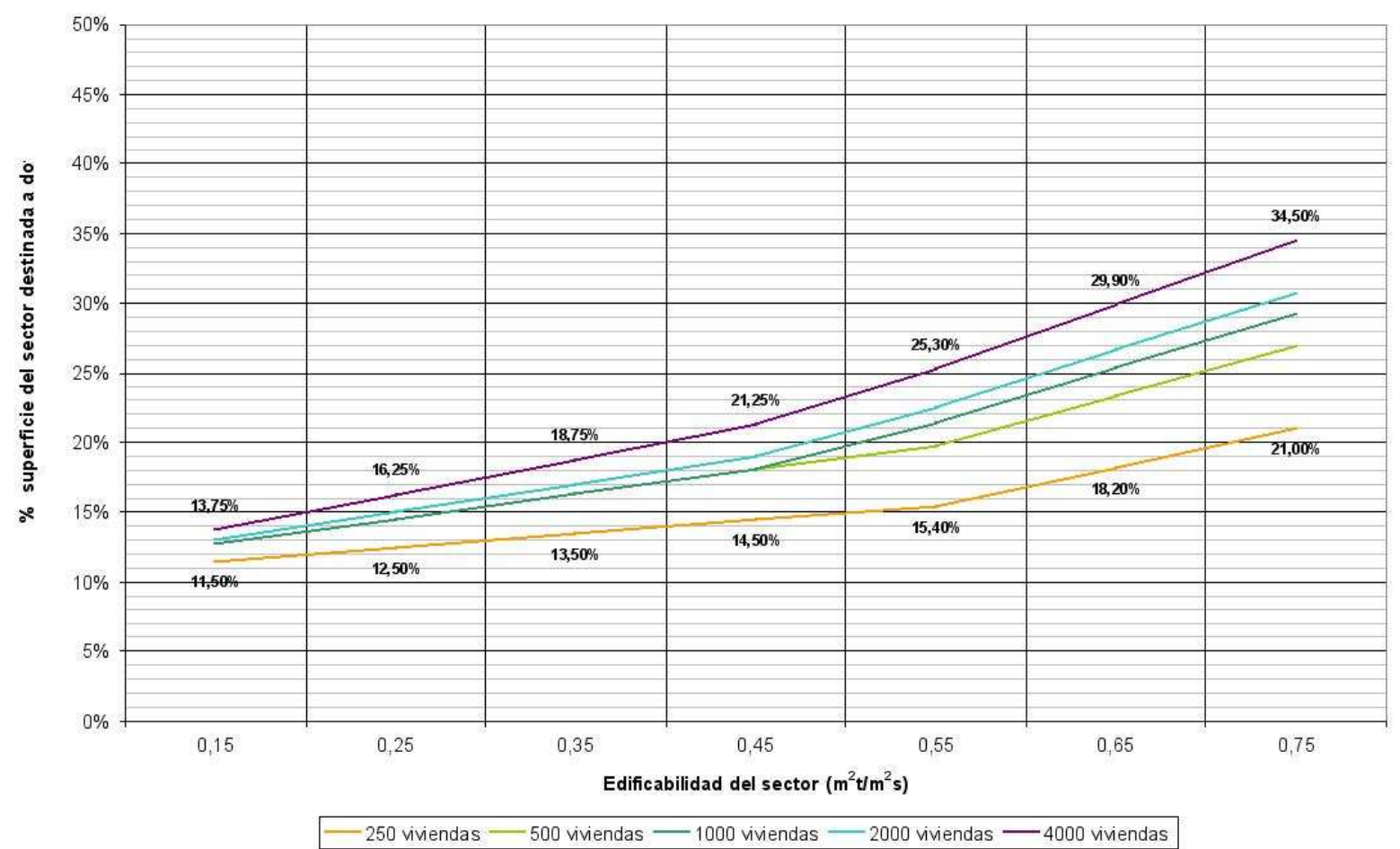

Figura 23: Superficie ocupada (\%) por las dotaciones en sectores tipo de uso residencial. Reglamento de Planeamiento de 1978

Elaboración propia

Cada uno de los sectores tipo calculados en el capítulo segundo se simboliza mediante un punto en la figura 4.3. En la figura 4.4 se representan todos los sectores tipo que calculamos en aquel capítulo. Los puntos obtenidos se distribuyen a lo largo de líneas de igual edificabilidad, lo que permite establecer una relación entre la edificabilidad, el ratio de dotaciones por vivienda y la superficie del sector consumida por las dotaciones. La representación gráfica así obtenida nos permitirá ilustrar las conclusiones que se exponen en los siguientes apartados.

La figura 33 recoge el mismo gráfico de la figura 27 ampliado, con indicación de las normativas a que corresponden los puntos representados. 


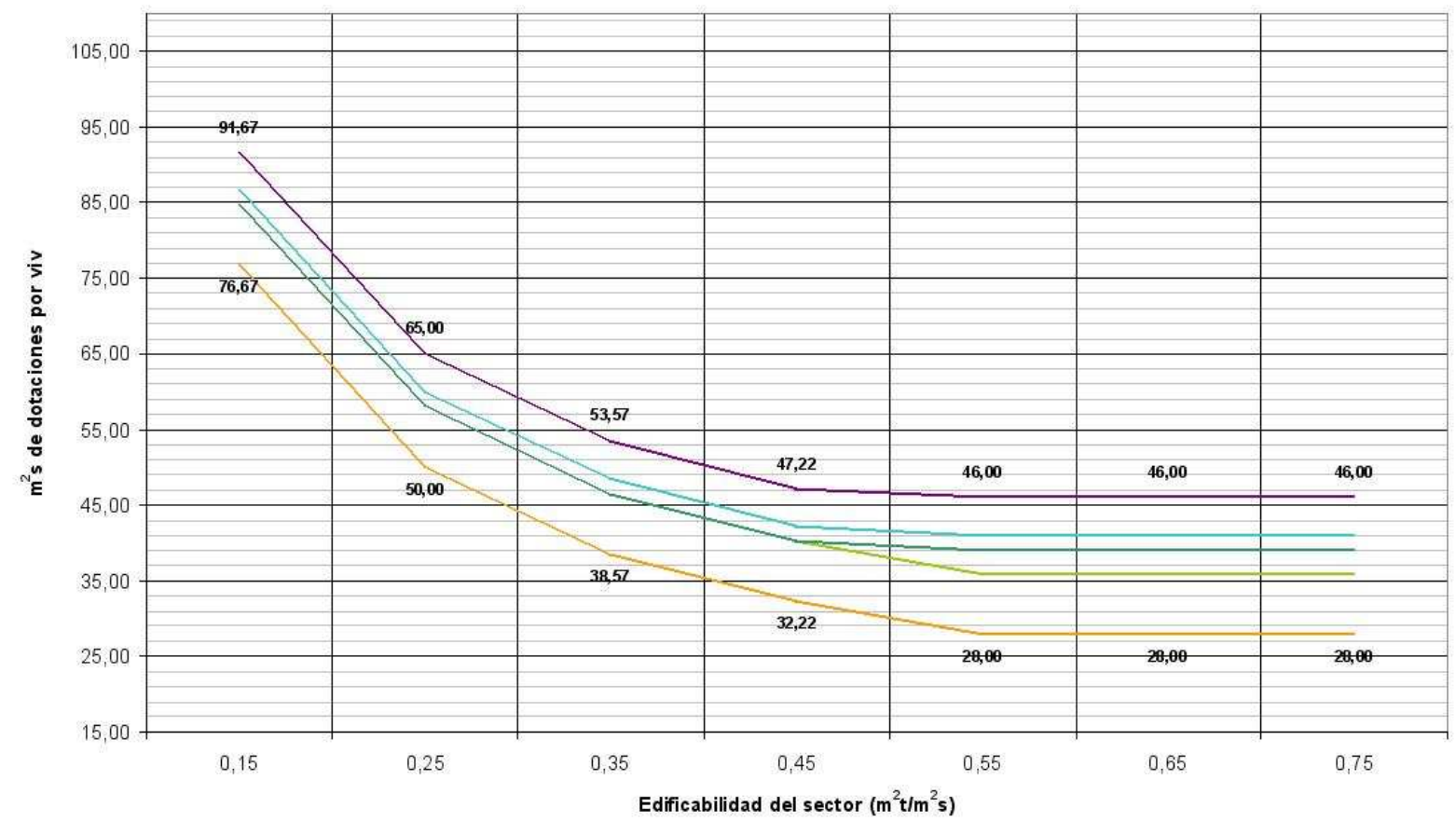

250 viviendas -500 viviendas -1000 viviendas -2000 viviendas -+ de 2000 viviendas

Figura 24: Dotaciones por vivienda en sectores tipo de uso residencial. Reglamento de Planeamiento de 1978

Elaboración propia 
REGLAMENTO DE PLANEAMIENTO 1.978

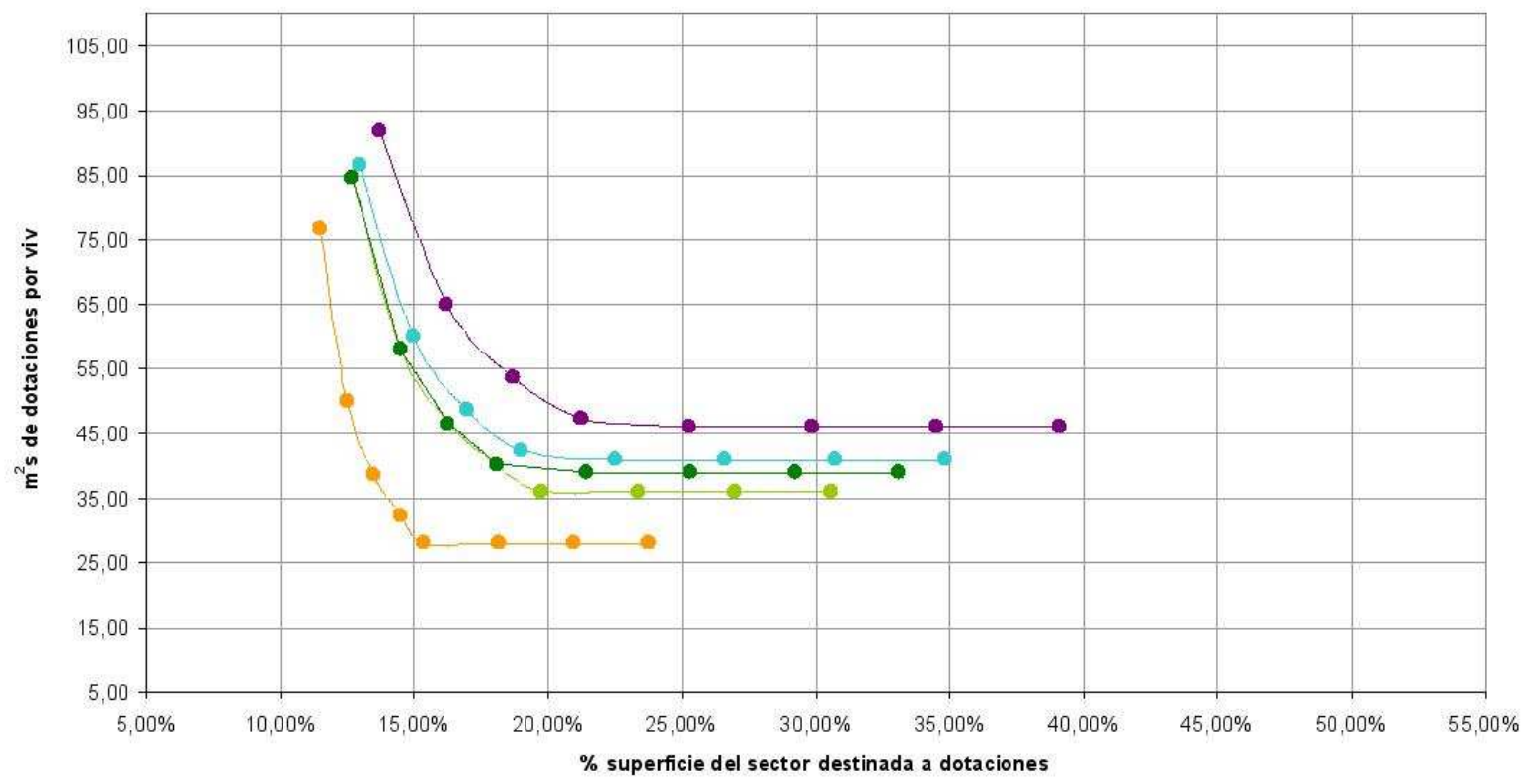

-250 viviendas $\longrightarrow-500$ viviendas -1000 viviendas -2000 vivendas -4000 viviendas

FIGURA 25: Relación entre superficie ocupada y dotaciones por vivienda en sectores tipo de uso residencial. Reglamento de Planeamiento de 1978

Elaboración propia 


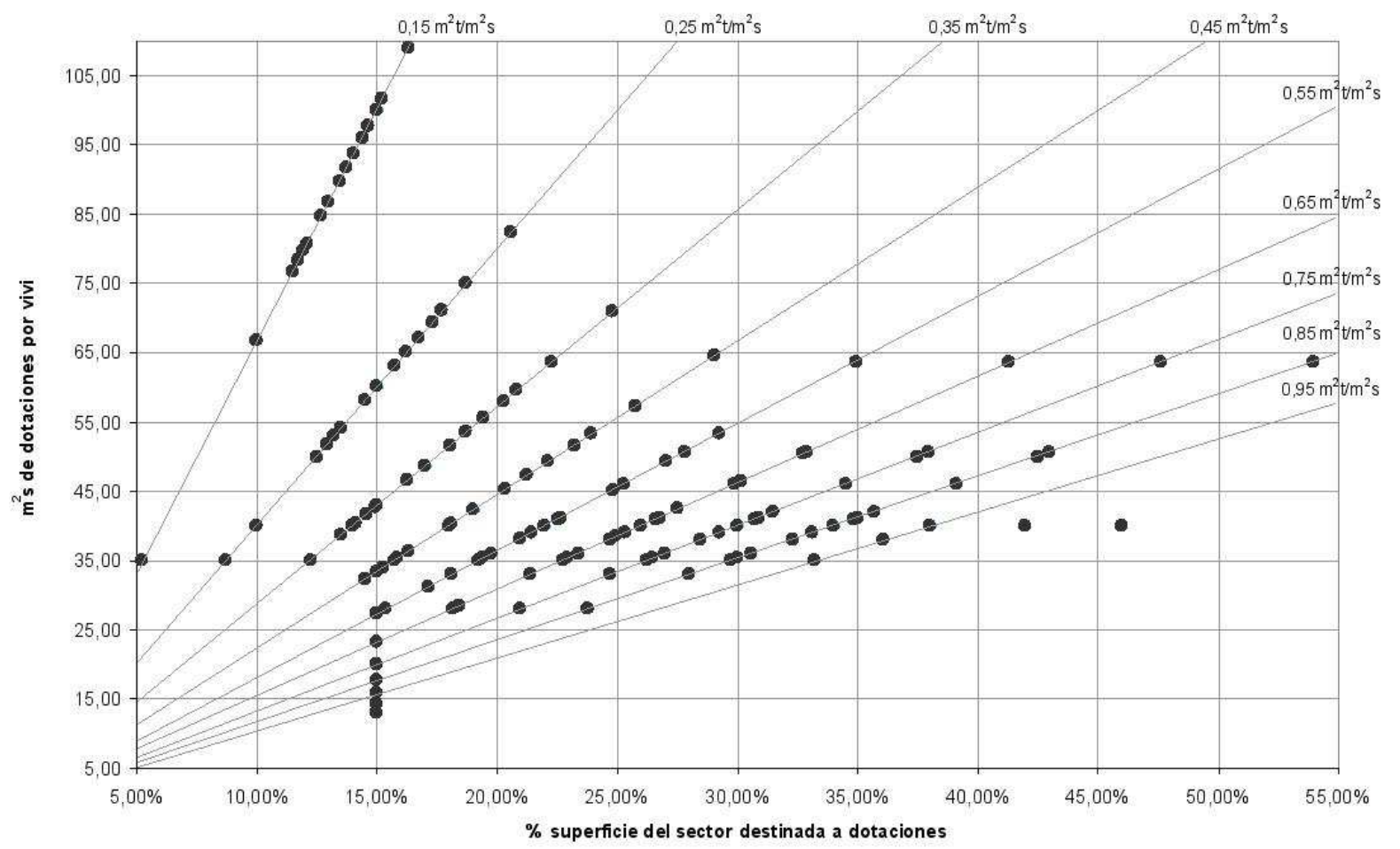

FIGURA 26: Relación entre superficie ocupada y dotaciones por vivienda en sectores tipo de uso residencial de todas las normativas estudiadas

Elaboración propia 


\section{Modulación de los estándares dotacionales en función del número total de viviendas del sector}

El Reglamento de Planeamiento de 1978 establecía distintas obligaciones en cuanto a cesiones dotacionales para los sectores de suelo urbanizable: la cantidad de dotaciones por vivienda es mayor en aquellos sectores con mayor número de viviendas. Este sistema ha sido continuado por las normativas aragonesa y navarra. El resto de normativas estudiadas no han recogido este sistema de la legislación estatal. La figura 27 muestra las diferentes modulaciones por número de viviendas de estas comunidades autónomas.

En las tres normativas hay grandes diferencias en las cesiones por vivienda dependiendo de si el sector tiene pocas o muchas viviendas, aunque la edificabilidad sea la misma.

Utilizaremos la normativa aragonesa para ilustrar la contradicción que encierra este sistema, puesto que, dentro de las tres normativas, es la que establece mayores diferencias por número de viviendas. Podemos poner el ejemplo de 4 sectores de 500 viviendas (a la izquierda en la figura 28) y un sector de 2.000 viviendas (a la derecha), todos ellos con una edificabilidad de $0,85 \mathrm{~m}^{2} \mathrm{t} / \mathrm{m}^{2} \mathrm{~s}$. La superficie de suelo ocupada por las dotaciones (espacios libres y equipamientos) es del 34,6\% en el conjunto de los cuatro sectores, mientras que llega al 53,2\% en el caso del sector de 2.000 viviendas. Sin embargo, el número total de viviendas, la superficie y la edificabilidad son las mismas en los dos casos.

De esta forma, no parece razonable diferenciar la cantidad de dotaciones que corresponden a cada vivienda sólo por el hecho de que estas viviendas formen sectores de mayor o menor tamaño. Un motivo es que mayores obligaciones para sectores con más viviendas pueden provocar que los ayuntamientos traten de desarrollar el suelo urbanizable en pequeños sectores, sobre todo los ayuntamientos menos resistentes a las presiones de la iniciativa privada. Además, la delimitación de sectores por parte del planeamiento general puede responder a condiciones derivadas de diversos factores: elementos topográficos, estructura de la propiedad, criterios de diseño, etc., que pueden dar lugar a sectores de tamaños muy diversos.

En definitiva, el hecho de que buena parte de las normativas estudiadas no hayan hecho esta diferenciación por número de viviendas da cuenta de la dudosa lógica de este sistema. Otra cuestión es el distinto nivel de necesidades que pueden tener los ciudadanos de poblaciones de distintos tamaños: puede ser necesaria una mayor dotación de zonas verdes en una gran ciudad que en un pueblo rodeado de terreno natural. Pero esto no se soluciona utilizando el sector como unidad de medida, puesto que su tamaño puede ser muy variable en respuesta a diversos condicionantes.

\section{Exceso de dotaciones en los sectores de baja densidad}

Los sectores tipo con menor edificabilidad presentan un exceso de dotaciones por vivienda, tal como se aprecia en la figura 29 (consideramos sectores de baja densidad aquellos cuya edificabilidad es menor de $0,25 \mathrm{~m}^{2} \mathrm{t} / \mathrm{m}^{2} \mathrm{~s}$; se han resaltado en el gráfico).

En casi todas las normativas se produce esta situación, salvo en el caso de la Comunidad Valenciana, donde no hay porcentajes mínimos; y en los casos de Castilla y León y País Vasco, donde los sectores de baja densidad están limitados. Esta situación se produce porque las normativas estudiadas fijan un porcentaje mínimo de los sectores que se debe dedicar a espacios libres, en general señalada en torno al $10 \%$. De esta forma, cuando la edificabilidad es baja, el porcentaje mínimo supone una superficie considerable a repartir entre las escasas viviendas del sector.

Esta situación plantea una paradoja importante: si tenemos en cuenta que los sectores de baja densidad suelen componerse de viviendas de gran tamaño, con jardines privados de gran superficie, resulta que estas viviendas disponen de un ratio de espacios libres públicos mayor que el de barrios más densos, donde son más necesarios.

Como ya hemos comentado anteriormente, los campos de golf con urbanización residencial responden al modelo de sectores de baja densidad en los que se produce un exceso de espacios libres (ver figura 30). Este tipo de desarrollo suele tener una edificabilidad bruta de inferior a $0,20 \mathrm{~m}^{2} \mathrm{t} / \mathrm{m}^{2} \mathrm{~s}$, puesto que prácticamente la mitad de la superficie del sector se destina al campo de golf, quedando la superficie restante para las parcelas privadas, el viario y las dotaciones (una vez descontado el campo de juego la edificabilidad aumenta hasta $0,40 \mathrm{~m}^{2} \mathrm{t} / \mathrm{m}^{2} \mathrm{~s}$ ). Las obligaciones legales en cuanto a estándares dotacionales son semejantes a las de cualquier otro sector, y se incluye la superficie del campo de golf para los cálculos. De esta forma, sólo con el cumplimiento del $10 \%$ mínimo de la superficie del sector para zonas verdes que fijan muchas de las normativas, el ratio de dotaciones por vivienda aumenta considerablemente.

Este ejemplo muestra la verosimilitud de los sectores tipo de densidades reducidas, en los que se da una elevada cantidad de espacios libres, un viario reducido y también escasa proporción de dotaciones en cuanto a la superficie (que no en cuanto al ratio por vivienda). 
REGLAMENTO DE PLANEAMIENTO 1.978

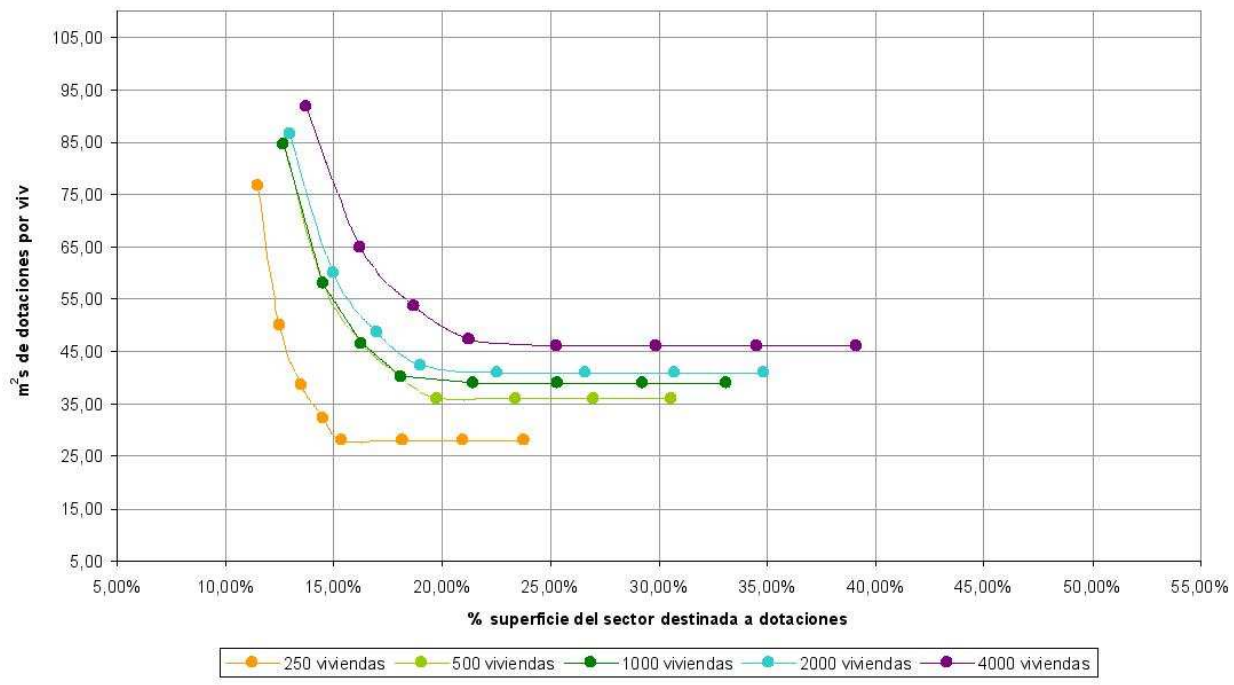

ARAGON

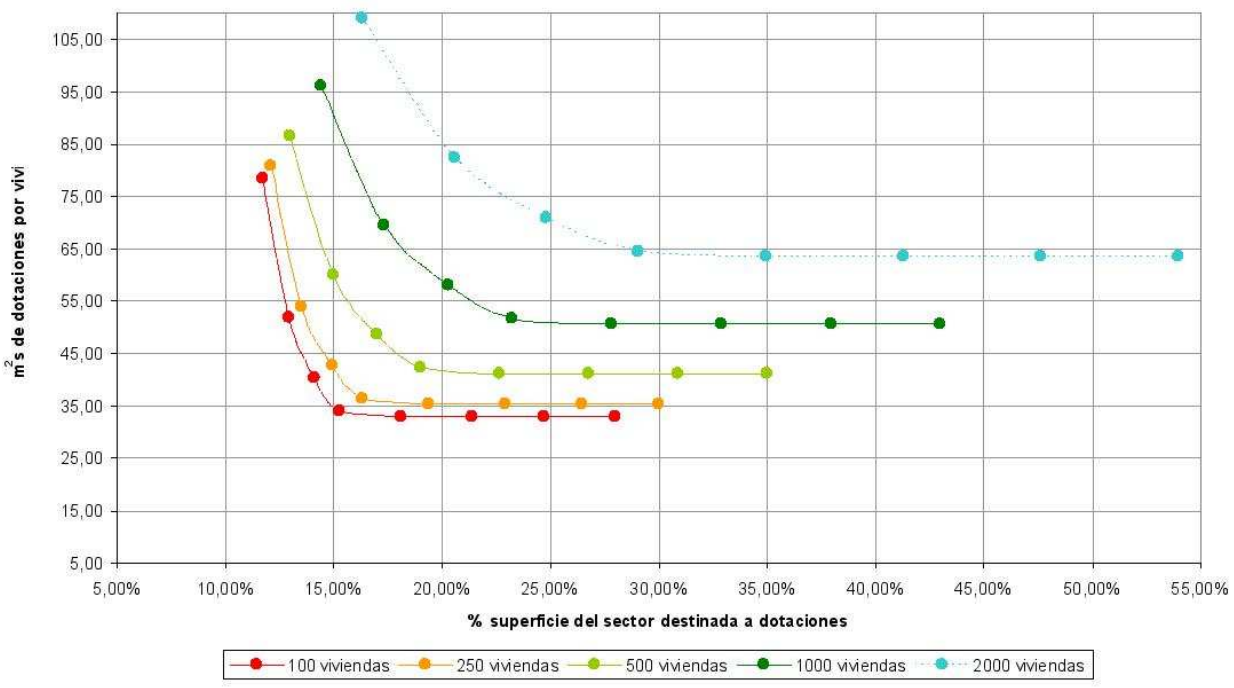

NAVARRA

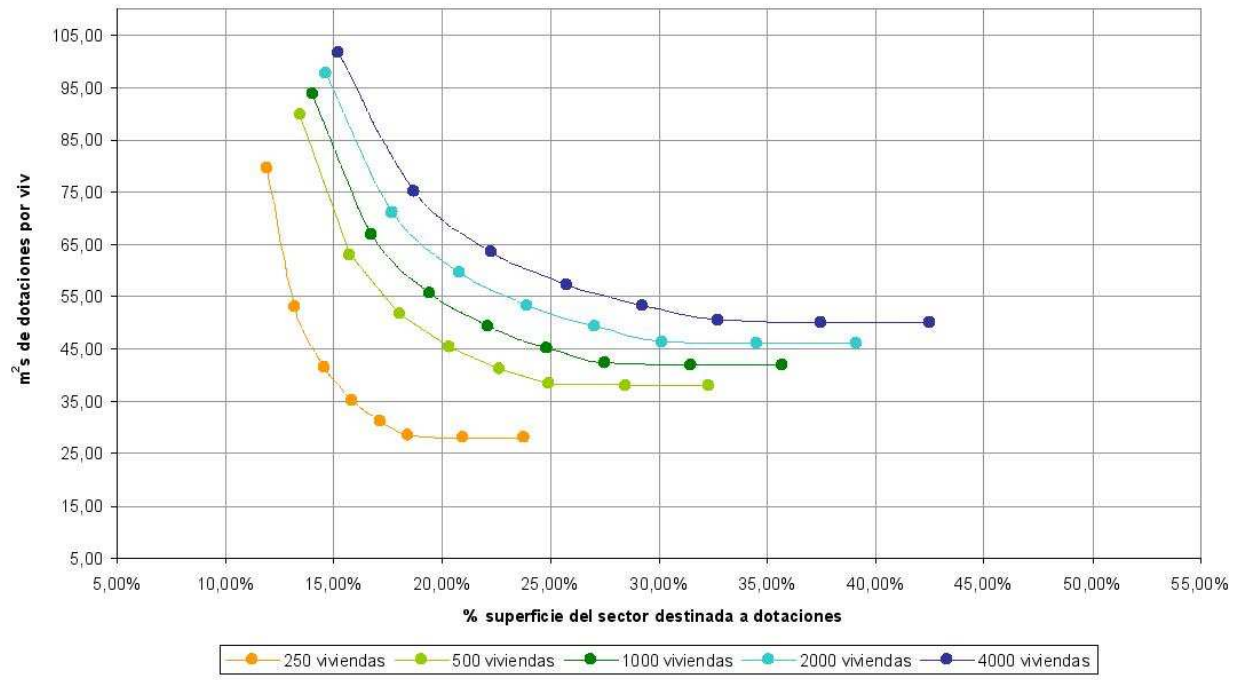

Figura 27: Superficie ocupada y dotaciones por vivienda en sectores tipo de uso residencial. Normativa española, aragonesa y navarra

Elaboración propia 

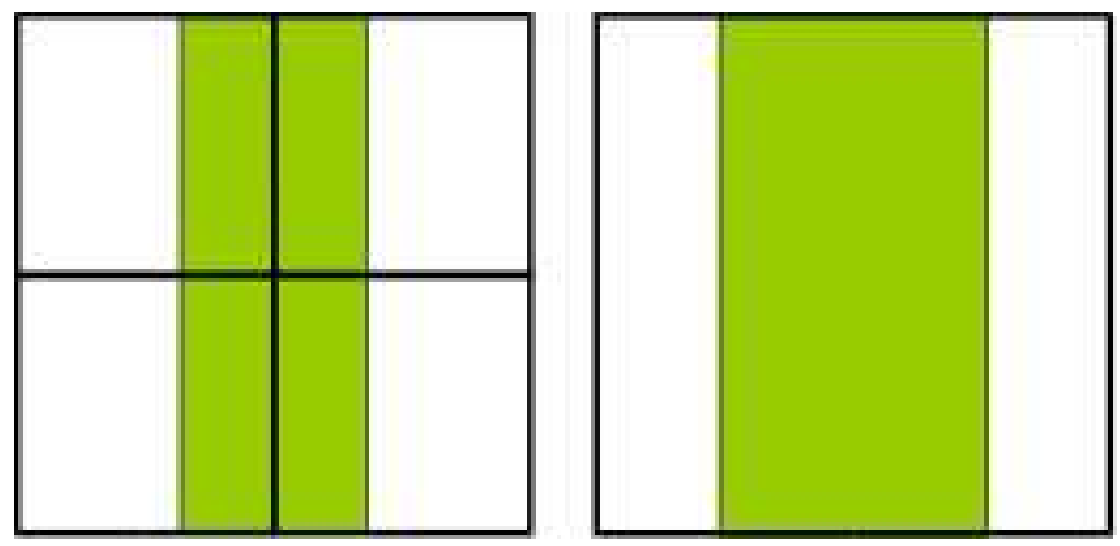

Figura 28: Comparación entre 4 sectores de 500 viviendas cada uno y un sector de 2.000 viviendas. En verde, suelo ocupado por las dotaciones (espacios libres y equipamientos)

Elaboración propia

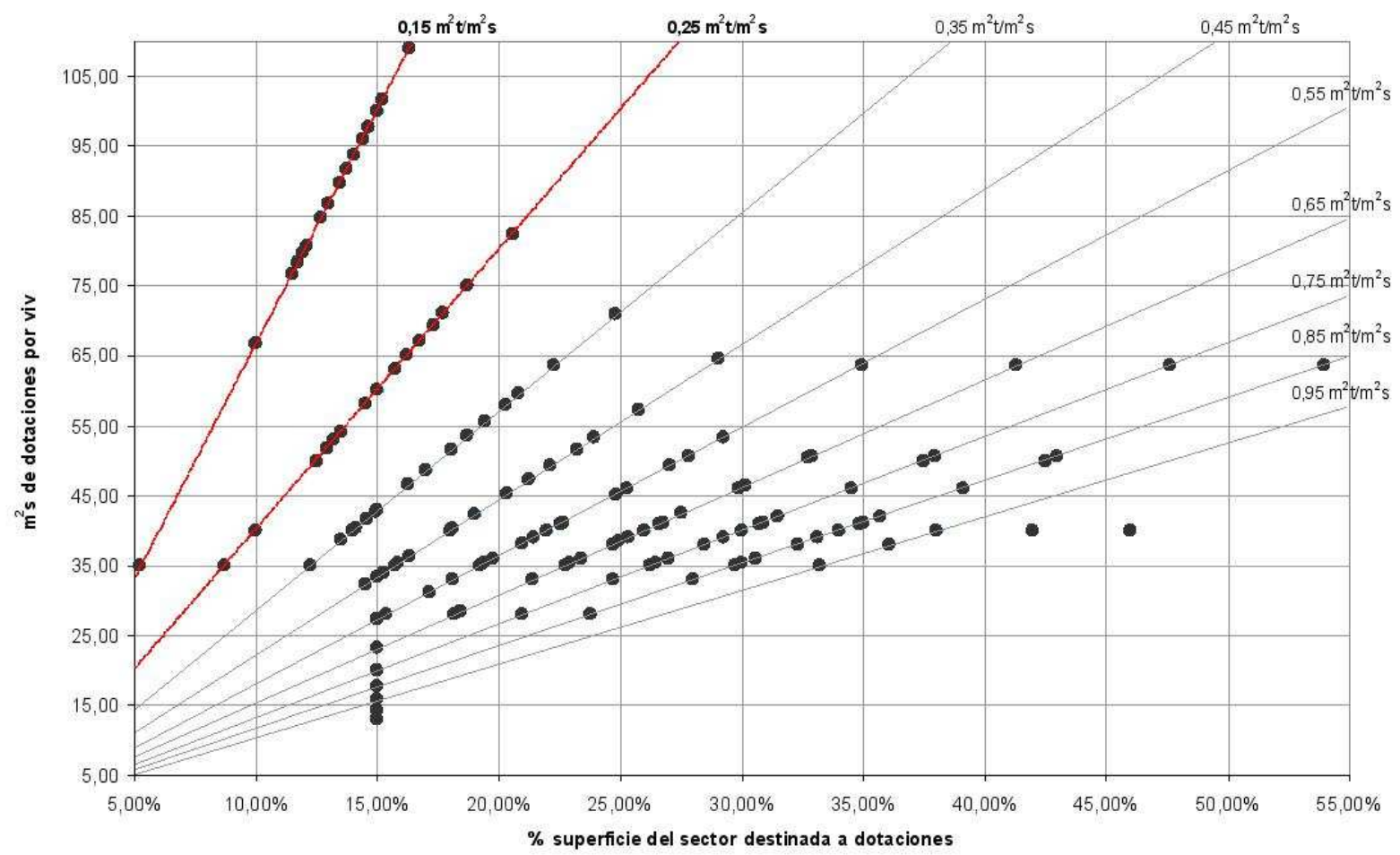

FiguRA 29: Relación entre superficie ocupada y dotaciones por vivienda en sectores tipo de baja densidad (en rojo)

Elaboración propia 


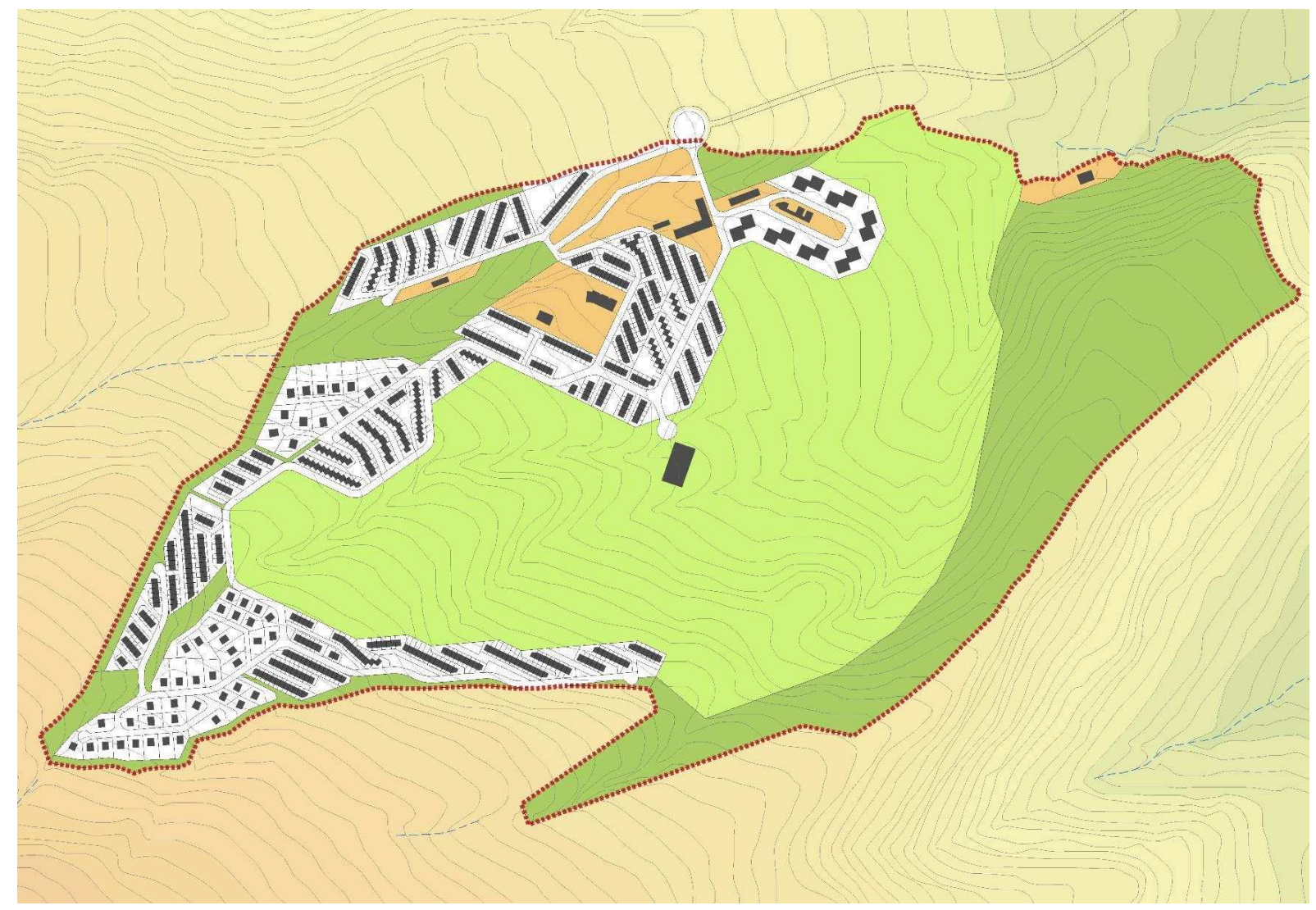

Figura 30: Ordenación general de campo de golf y urbanización residencial en Sojuela (La Rioja). Promotor: FADESA

Elaboración propia 
En conclusión, en sectores de baja densidad la cantidad de dotaciones por vivienda es excesiva, debido a la aplicación de porcentajes mínimos de superficie destinada a espacios libres.

\section{Exceso de ocupación de suelo en los modelos de alta densidad}

En los sectores con edificabilidades elevadas se produce un exceso en la superficie que debe destinarse a dotaciones, de tal forma que puede comprometer la ordenación del conjunto (ver figura 31). Muchos de los sectores tipo con edificabilidades superiores a $0,75 \mathrm{~m}^{2} \mathrm{t} / \mathrm{m}^{2} \mathrm{~s}$ deben destinar a dotaciones más del $30 \%$ de su superficie.

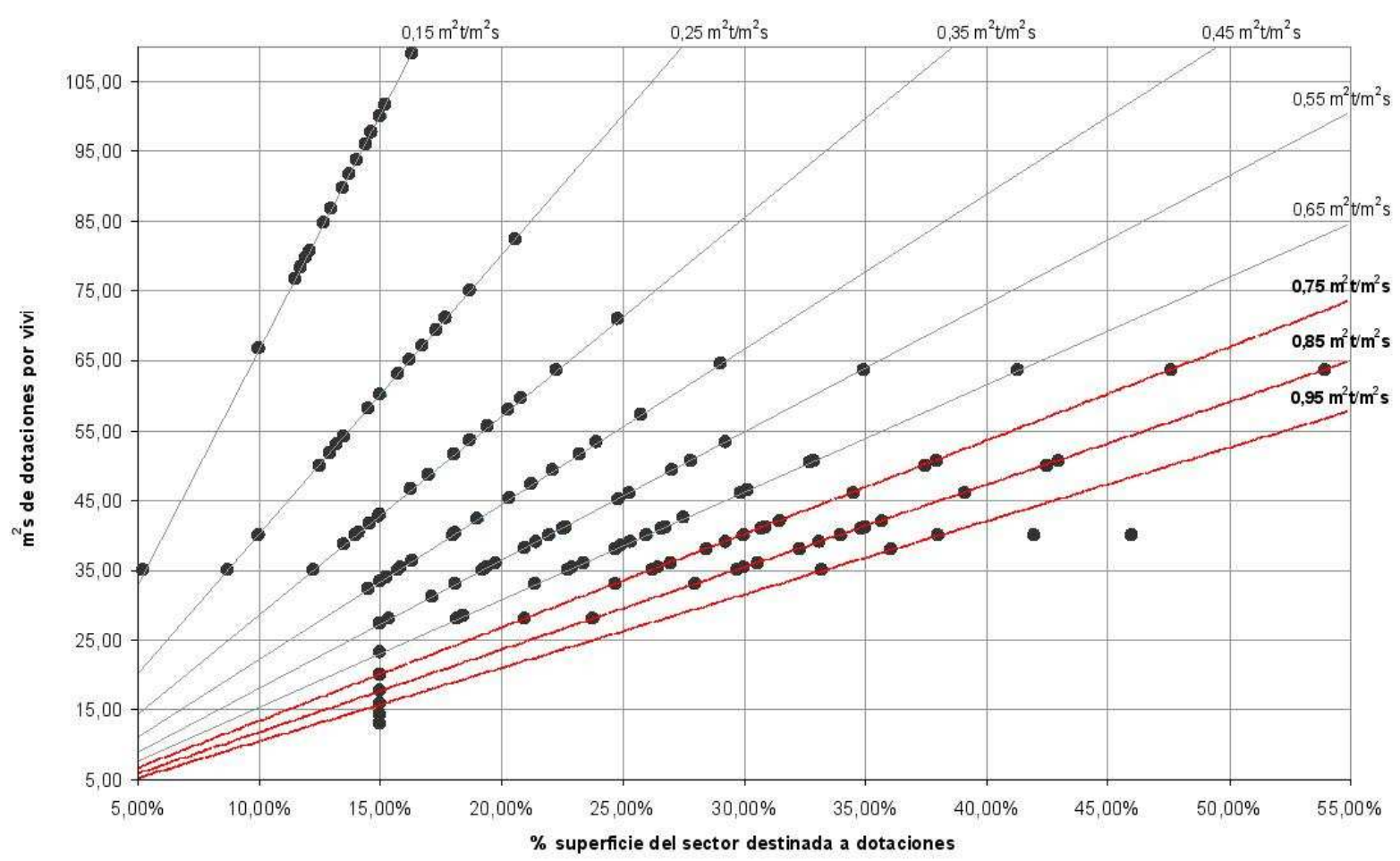

FIGURA 31: Relación entre superficie ocupada y dotaciones por vivienda en sectores tipo de alta densidad (en rojo)

Elaboración propia

El porcentaje de ocupación del sector por parte de las cesiones obligatorias se incrementa con el aumento de la edificabilidad. Esto es algo lógico, puesto que a mayor cantidad de viviendas deberá corresponder mayor dotación de equipamientos. Sin embargo, las dotaciones pueden llegar a ocupar un espacio de suelo considerable, precisamente en los sectores en los que hay que ubicar mayor edificabilidad residencial y el viario se hace más necesario.

Podemos realizar una estimación del porcentaje de suelo del sector que puede ocupar el viario suponiendo una dotación de $40 \mathrm{~m}^{2}$ de superficie de viales por vivienda. Es el mismo supuesto que hemos empleado para el cálculo de la edificabilidad media de las parcelas privadas en los sectores tipo del capítulo segundo. El cuadro 31 muestra los porcentajes que alcanza el viario en sectores con distinta densidad.

Lógicamente, el porcentaje de suelo que ocupa el viario crece con la densidad de viviendas, llegando a valores máximos de algo más de un tercio de la superficie cuando la densidad alcanza 95 viviendas por hectárea. Las dotaciones de espacios libres y equipamientos también ocupan mayor superficie cuando aumenta la densidad, alcanzando valores máximos de hasta el $54 \%$ en el caso de un sector con una edificabilidad de $0,85 \mathrm{~m}^{2} \mathrm{t} / \mathrm{m}^{2}$ s y más de 2.000 viviendas en la Comunidad Autónoma de Aragón. En este caso, como vimos en el apartado correspondiente a la normativa aragonesa, el espacio público ocuparía más del $80 \%$ de la superficie del sector, dejando parcelas privadas con una edificabilidad media de 7,09 $\mathrm{m}^{2} \mathrm{t} / \mathrm{m}^{2} \mathrm{~s}$. La ordenación de este hipotético sector recuerda a los modelos del movimiento moderno: unas 
CuAdro 31: Superficie de sector ocupada por el viario en función de la densidad

\begin{tabular}{|c|c|}
\hline Densidad & $\begin{array}{l}\text { Superficie del sector } \\
\text { destinada al viario }\end{array}$ \\
\hline 15 viviendas por hectárea & $6,00 \%$ \\
\hline 35 viviendas por hectárea & $14,00 \%$ \\
\hline 55 viviendas por hectárea & $22,00 \%$ \\
\hline 75 viviendas por hectárea & $30,00 \%$ \\
\hline 95 viviendas por hectárea & $38,00 \%$ \\
\hline
\end{tabular}

pocas torres de vivienda ocupando un décimo de la superficie del sector y el resto del espacio destinado a viario, dotaciones y espacios libres.

Una ocupación por parte de los usos privados de menos de un tercio de la superficie del sector conlleva una desproporción excesiva entre el espacio público y el privado, que puede conducir a modelos de desarrollo urbano carentes de carácter.

$\mathrm{Al}$ igual que ocurría con las bajas densidades, los estándares dotacionales ocupan una gran superficie en sectores de alta densidad, reduciendo el espacio disponible para viario y, sobre todo, para las parcelas privadas, precisamente cuando hay que ubicar mayor cantidad de edificabilidad.

\section{Límites de los estándares dotacionales}

En este apartado, trataremos de establecer los límites a partir de los cuales se producen los problemas tratados en los dos apartados anteriores. Estos límites afectarán a las dos variables representadas en el gráfico de la figura 4.4: metros cuadrados por vivienda y porcentaje de superficie ocupada.

\section{Ratio de dotaciones por vivienda (eje de ordenadas)}

Vamos a recuperar las propuestas de La ciudad de los ciudadanos (HeRnández AJA, 1997) como base para establecer unos límites teóricos sobre el nivel de dotaciones por vivienda. Con estos límites podremos valorar aquellos sectores (puntos representados en la figura 26) que superan estos límites. En la figura 32 se muestra la representación gráfica de estos límites. Estableceremos un límite mínimo, por debajo del cual se daría una insuficiencia dotaciones por vivienda; y un límite máximo, por encima del cual se daría un exceso de dotaciones por vivienda:

- Superficie de dotaciones mínima por vivienda: Como límite inferior hemos escogido la propuesta dotacional para tejidos centrales, puesto que es el mínimo considerado razonable por los autores del estudio. Así, este límite se establece en $27 \mathrm{~m}^{2} \mathrm{~s}$ por vivienda. Los sectores tipo que quedan por debajo de este umbral se puede afirmar que tienen un ratio de dotaciones por vivienda realmente escaso. Esto sólo podría ocurrir en el País Vasco, en sectores con edificabilidades superiores a 0,55 $\mathrm{m}^{2} \mathrm{t} / \mathrm{m}^{2} \mathrm{~s}$, puesto que esta normativa establece un módulo por vivienda que admite el viario y como única exigencia tiene un porcentaje mínimo destinado a zonas verdes del $15 \%$. El resto de puntos se encuentra por encima del umbral.

- Superficie de dotaciones máxima por vivienda: Como límite superior hemos considerado razonable utilizar la propuesta de La ciudad de los ciudadanos para tejidos residenciales, incrementada en un $50 \%$, lo que supone un máximo de $84 \mathrm{~m}^{2}$ s/vivienda. En este caso se dan varios puntos que superan el umbral: son sectores tipo que podemos considerar excesivamente dotados, lo cual no es razonable porque ello conlleva unos costes de mantenimiento importantes. Todos los casos tienen una edificabilidad muy baja, de $0,15 \mathrm{~m}^{2} \mathrm{t} / \mathrm{m}^{2} \mathrm{~s}$.

\section{Porcentaje de superficie ocupada por las dotaciones (eje de coordenadas)}

Como hemos comentado en el apartado 4.3 de este capítulo, el espacio ocupado por las dotaciones (espacios libres y equipamientos, excluido el viario) no debe superar un tercio de la superficie del sector, ni tampoco ser inferior a un $10 \%$, tal como coinciden en garantizar todas las normativas estudiadas, salvo la valenciana, que es la única que no fija un porcentaje mínimo de suelo destinado a dotaciones públicas.

La figura 32 muestra el gráfico con los límites propuestos. La mayor parte de los sectores tipo estudiados quedan dentro de la zona establecida por los umbrales máximos y mínimos. Los casos que exceden estos 


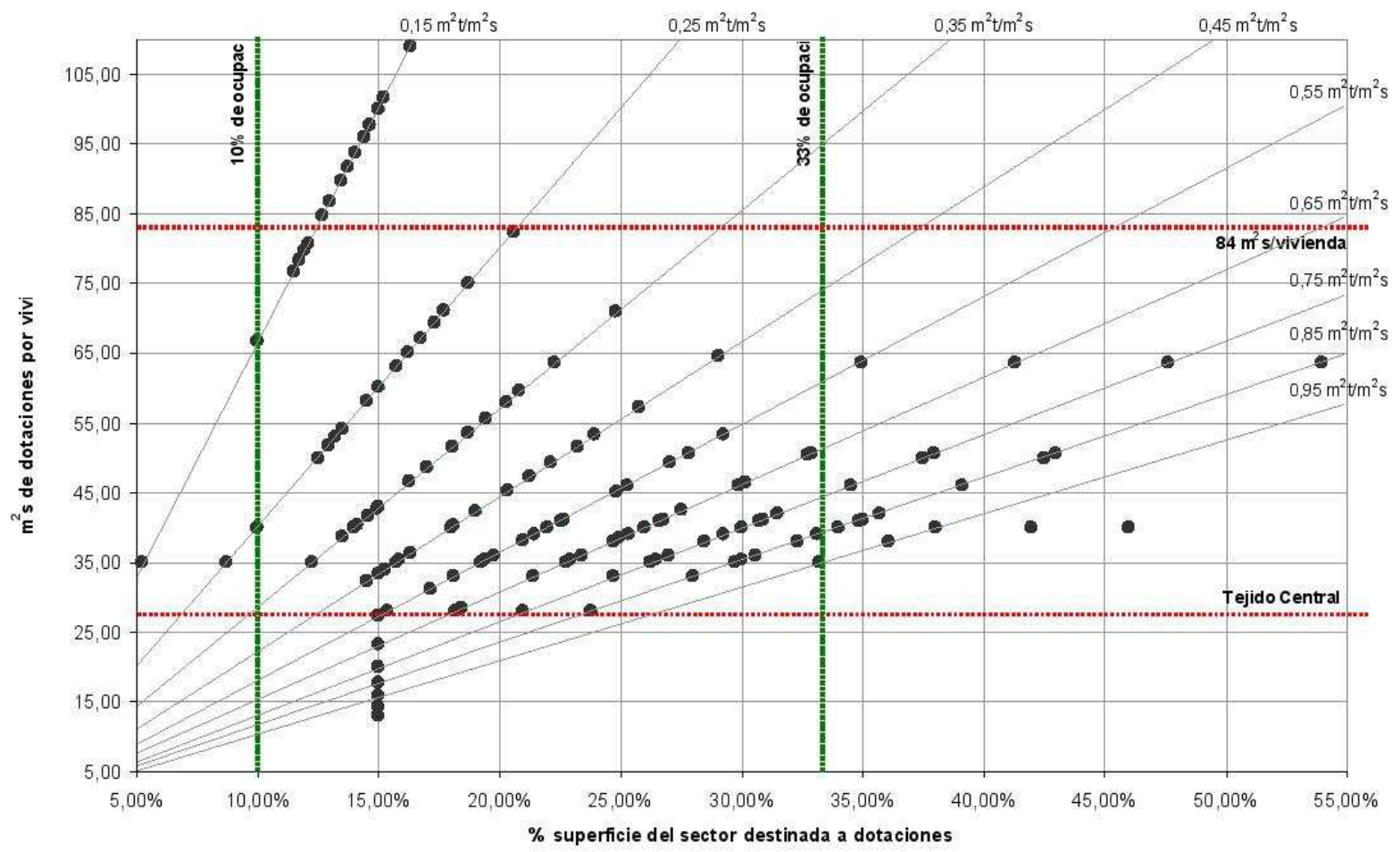

FIGURA 32: Límites a la superficie ocupada y a las dotaciones por vivienda en sectores tipo de uso residencial de todas las normativas estudiadas

Elaboración propia 
umbrales están relacionados con densidades muy bajas (inferiores a 15 viviendas por hectárea) o altas (75 viviendas por hectárea).

Las edificabilidades para las que existe mayor equilibrio entre el porcentaje de la superficie del sector ocupado y las cesiones por vivienda son las que oscilan entre 0,35 y $0,65 \mathrm{~m}^{2} \mathrm{t} / \mathrm{m}^{2} \mathrm{~s}$. Todos los sectores tipo se encuentran dentro de los umbrales límite, salvo el caso de sectores aragoneses de más de 2.000 viviendas a partir de $0,55 \mathrm{~m}^{2} \mathrm{t} / \mathrm{m}^{2}$ s de edificabilidad.

Las normativas autonómicas de Castilla-La Mancha, Castilla y León y Cataluña proponen estándares dotacionales que, en todos los casos, se mantienen dentro de los umbrales señalados. En el caso castellanoleonés, de hecho, las posibilidades están muy limitadas por la fijación de densidades mínimas y máximas muy estrictas, lo que en la práctica reducirá sensiblemente la variedad de los nuevos modelos urbanos.

En cambio, las normativas de Aragón y Navarra y el Reglamento de Planeamiento de 1978 exceden los umbrales máximos, tanto en cesión por vivienda como en ocupación de superficie de los sectores, pero sólo para grandes conjuntos de vivienda. Ya hemos comentado la escasa lógica de esta modulación por número de viviendas del sector que, además, da lugar a resultados exagerados incluso para propuestas con carácter de mínimos. Antes que garantizar unos niveles de dotación determinados, se puede afirmar que reducen la posibilidad de establecer sectores grandes con edificabilidades altas y bajas.

Valencia ha optado por determinar únicamente las dotaciones mínimas necesarias por vivienda (estimadas en $35 \mathrm{~m}^{2}$ ), sin porcentajes mínimos, por lo que en los casos de sectores de baja densidad, el porcentaje de ocupación del mismo por parte de las dotaciones no supera el $10 \%$. No obstante, como hemos comentado en el apartado 4.3, la fijación de porcentajes mínimos sólo aporta grandes superficies de espacios públicos en los sectores donde menos se necesitan. Parece razonable la decisión de los legisladores valencianos de no fijar porcentajes mínimos, pues no es necesaria mayor proporción de espacios públicos en sectores de viviendas unifamiliares que en sectores de viviendas colectivas.

El caso del País Vasco es especial, puesto que regula una dotación mínima de $40 \mathrm{~m}^{2}$ por vivienda pero incluye el viario dentro de esta dotación. También establece un mínimo de zonas verdes del $10 \%$ de la superficie del sector. De esta forma puede ocurrir que, para densidades altas, las cesiones dotacionales por vivienda se reduzcan hasta $13,4 \mathrm{~m}^{2}$ por vivienda si el resto de la cesión se destina a viario, muy por debajo de los $27 \mathrm{~m}^{2}$ por vivienda que se proponen como umbral mínimo. Lo cierto es que las altas edificabilidades permitidas por la nueva Ley vasca conllevan una lógica reducción del suelo destinado a dotaciones, mostrando una apuesta por la compacidad del espacio edificado en detrimento de la disponibilidad, sobre todo, de equipamientos públicos.

\section{Conclusiones}

Como hemos visto a lo largo del estudio, los estándares urbanísticos recogidos de las normativas estudiadas establecen limitaciones para los nuevos barrios residenciales mediante la fijación de densidades máximas (y, a veces, también mínimas) y cesiones obligatorias de espacios libres y equipamientos. Sin embargo, estos estándares no están regulados de igual forma en todas las normativas y, además, no siempre producen resultados coherentes. A continuación, se desarrollan las conclusiones fundamentales de este trabajo:

\section{Disparidad de criterios entre las normativas estudiadas sobre la regulación de los es- tándares urbanísticos.}

No existe un criterio uniforme entre las normativas estudiadas respecto a los estándares de densidad y dotaciones. Tan sólo al regular la cantidad de espacios libres como dotación propia del sector (dotación local), las normativas estudiadas establecen estándares sensiblemente parecidos.

Sobre los equipamientos se establecen estándares muy variados; incluso dentro de la misma Comunidad Autónoma, se producen diferencias sobre la cantidad de equipamientos necesaria en función del número total de viviendas que se incluyen en el sector (así ocurre en Aragón y Navarra, y ocurría en el Reglamento de Planeamiento de 1978).

Pero es en la regulación de la densidad donde se produce la mayor disparidad de criterios; tanto en el aspecto concreto que se limita, pues en unos casos se limita la edificabilidad residencial y en otros la edificabilidad en general sin importar el uso ${ }^{12}$; como en la cuantificación del límite en sí, que varía considerablemente de una normativa a otra, hasta el punto de que la densidad máxima en algunas comunidades autónomas (Navarra) coincide con la densidad mínima permitida en otras (País Vasco).

\footnotetext{
${ }^{12}$ Esta disparidad en el concepto limitado por el estándar de densidad nos ha obligado a restringir el trabajo a sectores únicamente residenciales; sólo así hemos podido comparar unas normativas con otras.
} 


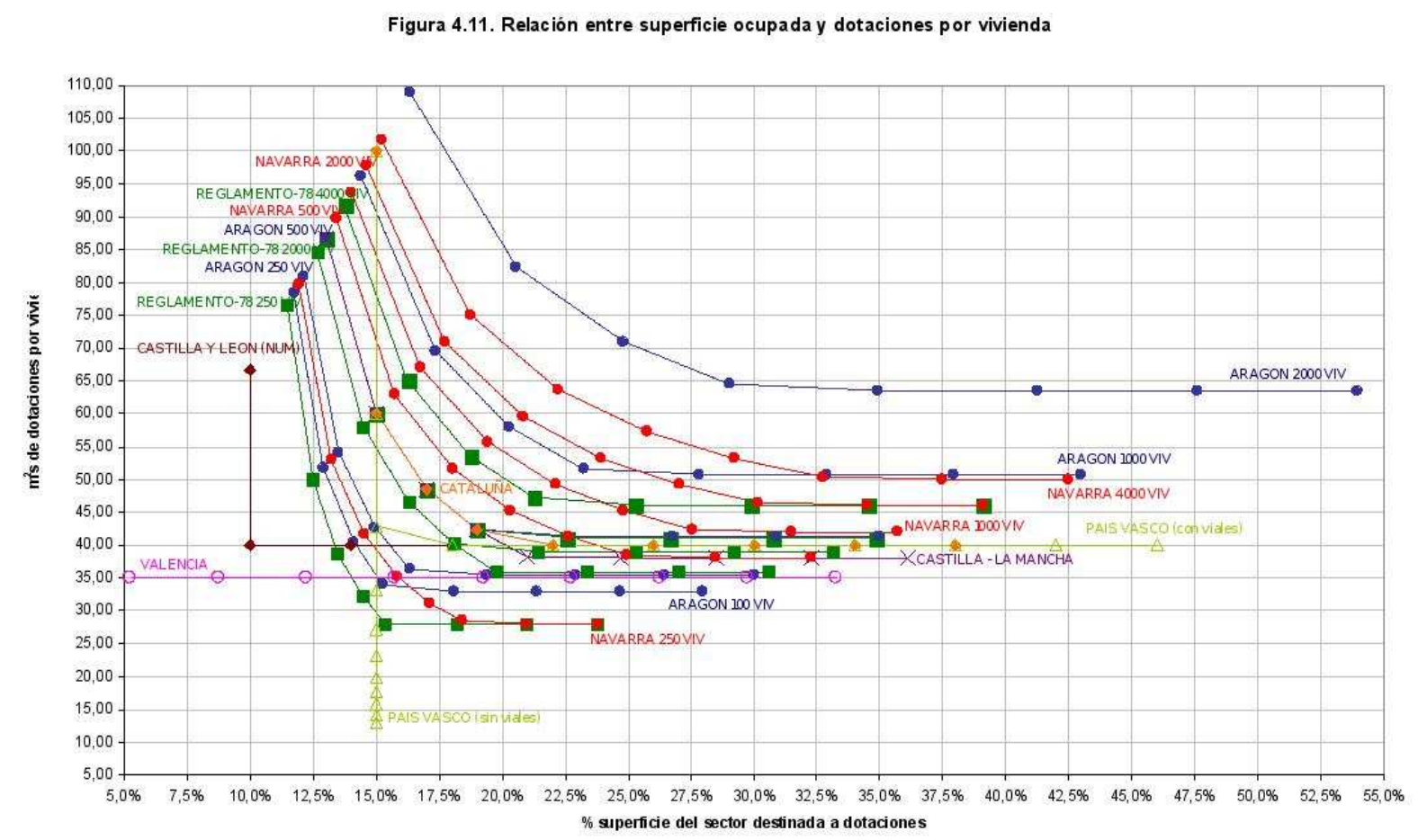

FIGURA 33: Relación entre superficie ocupada y dotaciones por vivienda Elaboración propia

Podemos concluir que los estándares considerados mínimos para garantizar una cierta calidad de vida en los nuevos barrios residenciales difieren considerablemente de unas comunidades autónomas a otras.

Esta disparidad de criterios ha de tenerse en cuenta para las siguientes conclusiones, en el sentido de que no pueden generalizarse los resultados obtenidos y deben matizarse dependiendo de la normativa.

\section{Exceso de espacios libres públicos en sectores con baja densidad de viviendas.}

En los sectores con baja densidad de viviendas (menos de 20-25 viviendas por hectárea) se da un exceso en la cantidad por vivienda de espacios libres públicos. Esto se debe a que la mayoría de las normativas impone que un porcentaje mínimo de la superficie del sector (habitualmente un 10\%) debe destinarse a espacios libres públicos, independientemente de la cantidad de viviendas que se vayan a construir.

Con esta regulación se da la paradoja de que los sectores de baja densidad, en los cuales es habitual la tipología de viviendas unifamiliares con jardines privados, además, cuentan con mayores ratios de espacios libres públicos por vivienda que sectores más densos. Se da una mayor dotación de espacios libres públicos donde es menos necesario, lo cual no puede considerarse eficiente.

Podría pensarse que se da la situación inversa en los sectores de alta densidad, es decir, una escasez de espacios libres públicos por vivienda; pero no es así, puesto que todas las normativas estudiadas aseguran una cantidad mínima a través de los módulos por vivienda.

Solamente tres de las normativas estudiadas han regulado los estándares evitando que pueda darse este exceso de espacios libres: la normativa valenciana lo logra eliminando el porcentaje mínimo de espacios libres y aplicando únicamente el módulo por vivienda, por lo que este ratio siempre es constante, independientemente de la densidad del sector; mientras que las normativas de Castilla y León y del País Vasco eluden el problema impidiendo que pueda darse el caso de sectores de baja densidad mediante la fijación de límites mínimos de densidad. 
3. Las dotaciones requieren gran cantidad de superficie en sectores con alta densidad de viviendas.

En los sectores con elevada densidad de viviendas (a partir de 75 viviendas por hectárea, hasta el límite máximo de cada normativa) se destina a dotaciones un porcentaje importante de la superficie de suelo, lo cual limita el espacio disponible para el resto de usos. Esto provoca un desequilibrio en la ordenación del sector, debido a un exceso de espacio público, que recuerda los inhóspitos modelos del urbanismo funcionalista de los Congresos Internacionales de Arquitectura Moderna (CIAM); y debido a que la considerable edificabilidad del sector (recordemos que es de alta densidad) debe materializarse en el reducido espacio disponible para las parcelas privadas.

Esta situación no se produce de igual forma en todas las normativas. Es en la normativa aragonesa y en el Reglamento de Planeamiento de 1978, donde se producen los mayores desequilibrios, pero únicamente en aquellos sectores que contienen un elevado número de viviendas ${ }^{13}$. En otras normativas (Castilla-La Mancha, Cataluña, Navarra y Valencia) se produce un consumo importante de suelo por parte de las dotaciones, pero nunca es mayor de un tercio de la superficie total del sector. Caso aparte es el de la normativa vasca, que incluye el viario dentro del estándar dotacional, por lo que no es posible conocer el porcentaje de superficie que pueden ocupar las dotaciones de espacios libres y equipamientos.

En cualquier caso, esta conclusión es menos generalizable que la anterior, pero conviene destacarla por la importancia que tiene que los legisladores comprueben que no se producen contradicciones entre los estándares de densidad y los estándares de dotaciones, puesto que un exceso en la superficie ocupada por las dotaciones puede impedir el desarrollo de modelos urbanos de alta densidad.

4. La aplicación de los estándares dotacionales produce resultados equilibrados en sectores con densidad media de viviendas.

A partir de los datos anteriores, podemos concluir que los estándares regulados por las normativas estudiadas producen unos resultados equilibrados en sectores con densidades medias de viviendas (entre 25 y 70 viviendas por hectárea), tanto desde el punto de vista del ratio de dotaciones por vivienda, como desde el punto de vista del reparto de los usos del suelo en la ordenación.

Esta situación puede deberse a una consecuencia no prevista de una regulación de estándares realizada de forma independiente; o bien, puede tratarse de una intención premeditada de los legisladores para favorecer los modelos urbanos residenciales de media densidad.

En todo caso, como ya hemos dicho, la dispersión normativa ha generado una falta de homogeneidad en los estándares urbanísticos que hace difícil establecer conclusiones generales. No obstante, el presente trabajo puede resultar útil al resaltar determinadas relaciones entre los estándares de densidad y los estándares dotacionales que los legisladores deben tener en cuenta a la hora de establecer nuevas normativas o de reformar las existentes.

También pone de relieve la importancia de la fijación de estándares en las normativas pues, de forma indirecta, acaban condicionando los modelos urbanos que pueden establecer los planes urbanísticos. Por ello, es necesario que estos estándares mínimos, en caso de que sigan estableciéndose en normativas de carácter general, estén basados en estudios rigurosos sobre las necesidades de los ciudadanos y también sobre los modelos de crecimiento urbano más convenientes.

\section{Fuentes y referencias bibliográficas}

\section{Fuentes normativas}

\section{España}

- Real Decreto 2159/1978, de 23 de junio, por el que se aprueba el Reglamento de Planeamiento para el Desarrollo y Aplicación de la Ley sobre Régimen del Suelo y Ordenación Urbana.

- Real Decreto 1346/1976, de 9 de abril, por el que se aprueba el Texto Refundido de la Ley sobre Régimen del Suelo y Ordenación Urbana.

\section{Aragón}

\footnotetext{
${ }^{13}$ Hay que recordar que estas normativas diferencian la cantidad de dotaciones que debe tener un sector en función del número de viviendas que acoge.
} 
- Decreto 52/2002, de 19 de febrero, por el que se aprueba el Reglamento de Desarrollo Parcial de la Ley 5/1999, de 25 de marzo, Urbanística, en materia de Organización, Planeamiento Urbanístico y Régimen Especial de Pequeños Municipios.

- Ley 5/1999, de 25 de marzo, Urbanística.

\section{Castilla-La Mancha}

- Decreto 248/2004, de 14 de septiembre, por el que se aprueba el Reglamento de Planeamiento de la Ley 2/1998, de 4 de junio, de Ordenación del Territorio y de la Actividad Urbanística.

- Decreto Legislativo 1/2004, de 28 de diciembre, por el que se aprueba el Texto Refundido de la Ley de Ordenación del Territorio y de la Actividad Urbanística.

\section{Castilla y León}

- Decreto 22/2004, de 29 de enero, por el que se aprueba el Reglamento de Urbanismo de Castilla y León.

- Ley 5/1999, de 8 de abril, de Urbanismo de Castilla y León.

\section{Cataluña}

- Decreto 305/2006, de 18 de julio, por el que se aprueba el Reglamento de la Ley de Urbanismo.

- Decreto Legislativo 1/2005, de 26 de julio, por el que se aprueba el Texto Refundido de la Ley de Urbanismo.

\section{Navarra}

- Decreto foral 85/1995, de 3 de abril, por el que se aprueba el Reglamento de Desarrollo de la Ley Foral 10/1994, de 4 de julio, de Ordenación del Territorio y Urbanismo.

- Ley foral 10/1994, de 4 de julio, de Ordenación del Territorio y Urbanismo.

- Ley foral 35/2002, de 20 de diciembre, de Ordenación del Territorio y Urbanismo.

\section{País Vasco}

- Ley 2/2006, de 30 de junio, de Suelo y Urbanismo.

\section{Comunidad Valenciana}

- Decreto 67/2006, de 19 de mayo, por el que se aprueba el Reglamento de Ordenación y Gestión Territorial y Urbanistica.

- Ley 4/2004, de 30 de junio, de Ordenación del Territorio y Protección del Paisaje.

- Ley 10/2004, de 9 de diciembre, del Suelo No Urbanizable.

- Ley 16/2005, de 30 de diciembre, Urbanística Valenciana.

\section{Bibliografía}

AA.VV.

1996 Ciudades europeas sostenibles.

Comisión Europea. Dirección General XI, Medio Ambiente, Seguridad Nuclear y Protección Civil. Bruselas, Bélgica.

Alguacil Gómez, Julio

2000 Calidad de vida y praxis urbana. Centro de Investigaciones Sociológicas. Madrid, España.

de la Cal, Pablo y Pemán, Ignacio

1998 «Estándares dotacionales. Una reflexión en torno al planeamiento de desarrollo en Aragón» Ciudad y Territorio: Estudios Territoriales, no 117-118. Ministerio de Fomento. Madrid, España. 
Campos Venuti, Giuseppe

1971 La Administración del Urbanismo.

Gustavo Gili. Barcelona, España.

CAz, Rosario et ál.

2004 Planes parciales residenciales.

Junta de Castilla y León. Valladolid, España.

De Esteban Alonso, Alfonso

1976 «Los estándares urbanísticos»

Ciudad y Territorio, $\mathrm{n}^{\mathrm{O}}$ 2. Ministerio de Fomento. Madrid, España.

Esteban Noguera, Juli

2003 La ordenación urbanística: conceptos, herramientas y prácticas.

Electa. Barcelona, España.

García de Enterría, Eduardo y Parejo Alfonso, Luciano

1981 Lecciones de derecho urbanístico.

Editorial Civitas. Madrid, España.

Hernández Aja, Agustín (Director)

1997 La ciudad de los ciudadanos.

Centro de Publicaciones. Ministerio de Fomento. Madrid, España.

Hernández Aja, Agustín y Leiva Rodríguez, Amaya

2006 Parámetros dotacionales para la ciudad de los ciudadanos.

Cuadernos del Instituto Juan de Herrera. Madrid, España.

Martínez Sarandeses, José

1999 Guía de diseño urbano.

Centro de publicaciones. Ministerio de Fomento. Madrid, España.

Salvador Palomo, Pedro J.

2003 La planificación verde en las ciudades.

Gustavo Gili. Barcelona, España.

Sámano Bueno, Pablo

2006 «Algunas precisiones en torno al estándar de densidad máxima. En particular, su relación con los sistemas generales»

Revista de Derecho Urbanístico, no 224. Madrid, España.

Saravia Madrigal, Manuel

200245 años de estándares urbanísticos en España (1956-2001).

Informe para el seminario internacional Welfare urbano e standard urbanisciti. Roma, Italia. 